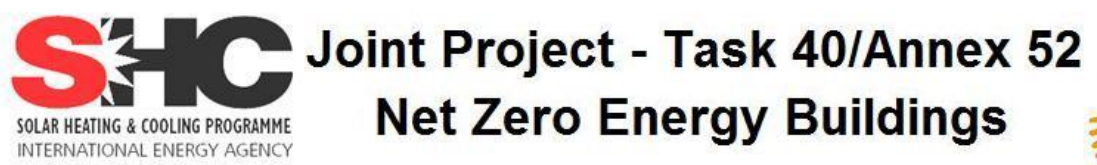

\title{
Measurement and Verification protocol for Net Zero Energy Buildings
}

A report of Subtask A

IEA Task 40/Annex 52 Towards Net Zero Energy Solar Buildings

2013, September 


\title{
Measurement and Verification protocol for Net Zero Energy Buildings
}

\author{
A report of Subtask A - A2 \\ Date: 2013 September
}

Authors: Federico Noris, Assunta Napolitano and Roberto Lollini
$\begin{array}{ll}\text { Institution } & \text { EURAC research } \\ \text { Address } & \text { Viale Druso 1, } 39100 \text { Bolzano, Italy } \\ \text { Phone } & 00390471055651 \\ \text { Fax } & 00390471055699 \\ \text { e-mail } & \text { roberto.lollini@eurac.edu }\end{array}$

Thanks to contributions from:

Søren Østergard Jensen, DTI - Denmark

Jose Candanedo, Concordia University - Canada

Sonja Geier, AEE INTEC - Austria

Michel Tardif, CanmetENERGY - Canada

Daniel Aelenei, Universidade Nova de Lisboa - Portugal

Francois Garde, University of Reunion Island - France

Eike Musall, University of Wuppertal - Germany

Igor Sartori, SINTEF - Norway

Aurelie Lenoir, University of Reunion Island- France

Jaume Salom, Catalonia Institute for Energy Research, IREC - Spain 
Contents

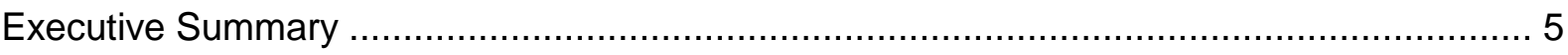

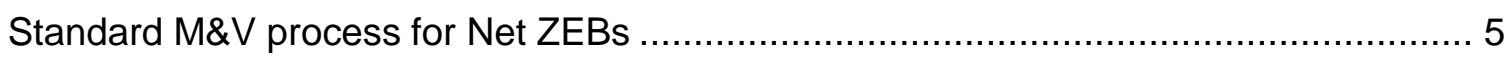

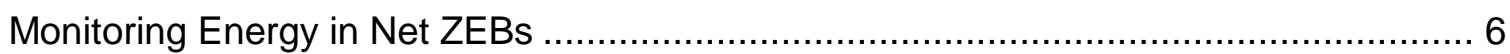

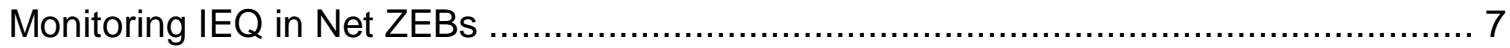

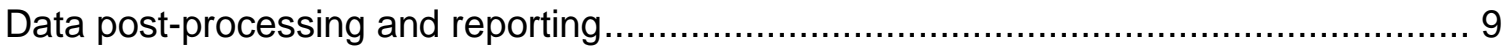

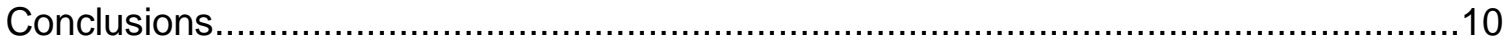

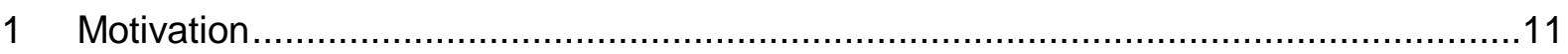

2 Literature review on existing standard monitoring protocols ......................................12

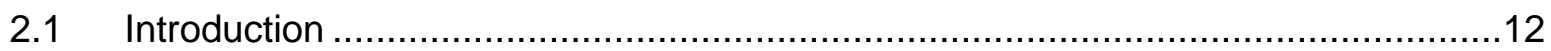

2.2 Towards the standardization of monitoring procedures for buildings ....................12

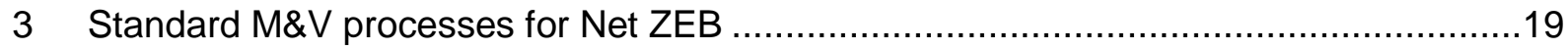

3.1 Standard monitoring protocol for Net ZEBs ...................................................

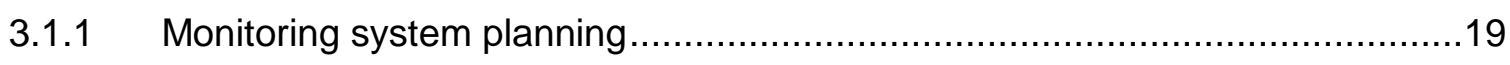

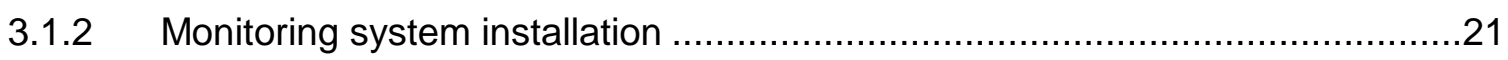

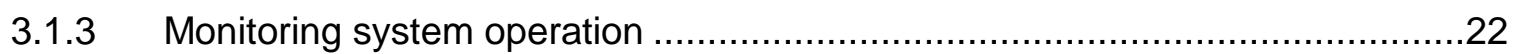

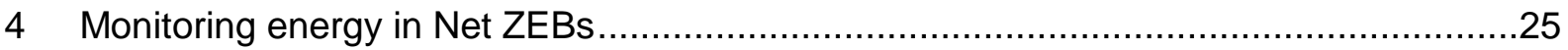

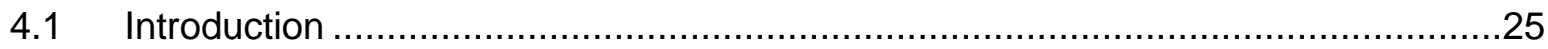

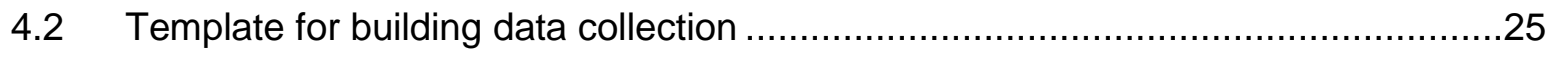

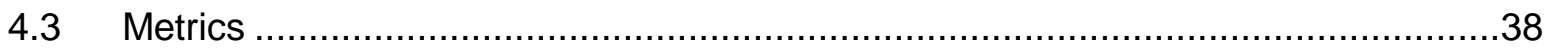

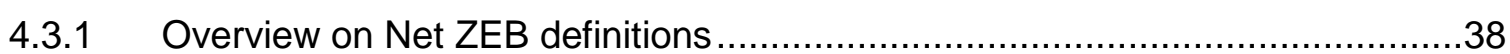

4.3.2 Metrics selection for Net ZEB definitions based on "load/generation" balance.38

4.3.3 Selection of metrics for Net ZEB definitions based on "delivered/exported

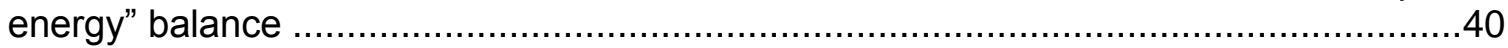

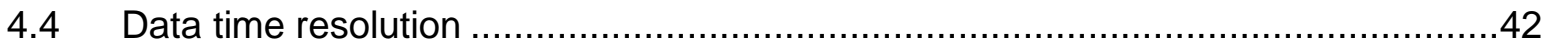

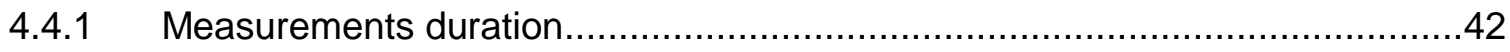

4.4.2 Sampling and recording time ...................................................................... 44

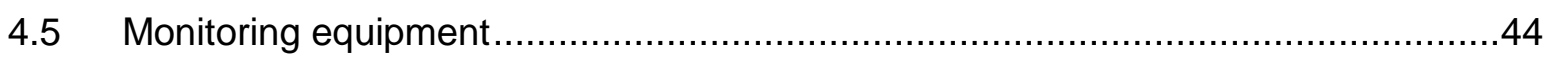

5 Monitoring Indoor Environmental Criteria (IEQ) .................................................46

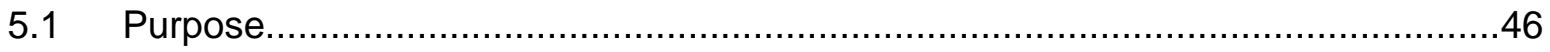

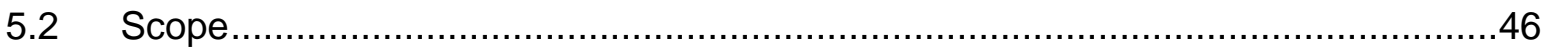

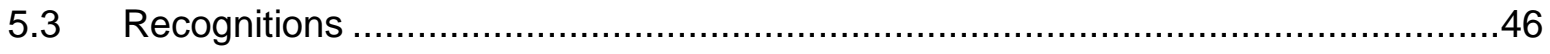

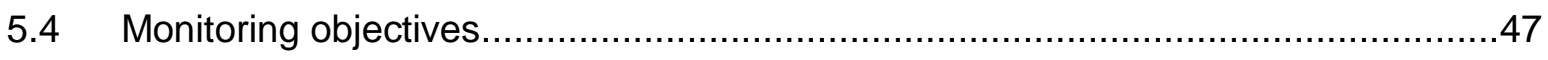

5.5 Experiences on impact of effective climate conditions .....................................48

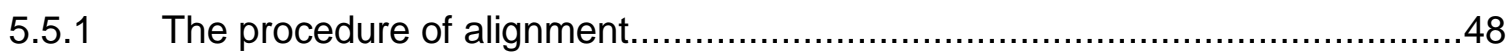

5.5.2 Example multi-family house "Dreherstrasse", Vienna ...................................49 


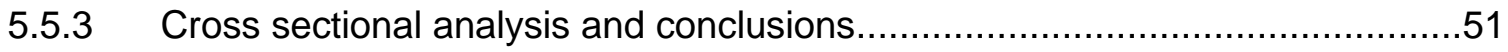

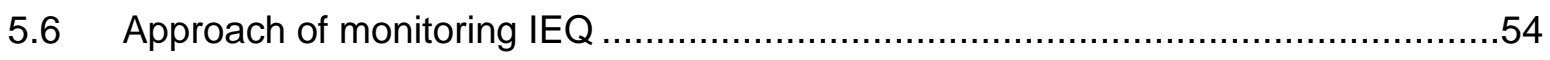

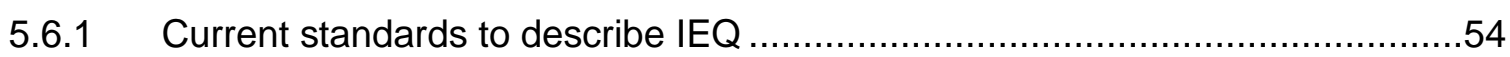

5.6.2 Introduction of appropriate levels of monitoring for IEQ ..............................54

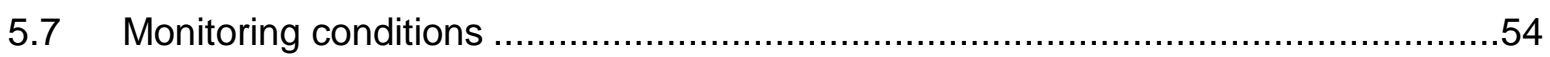

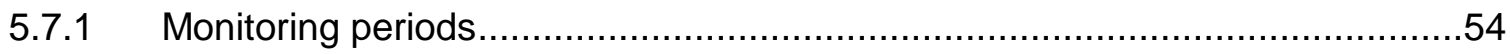

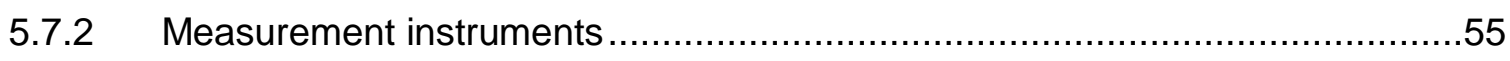

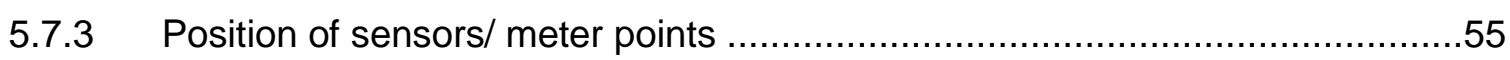

Range and distribution of measurement installation .............................................62

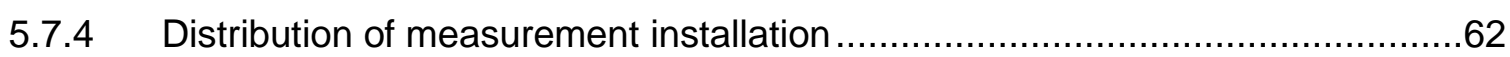

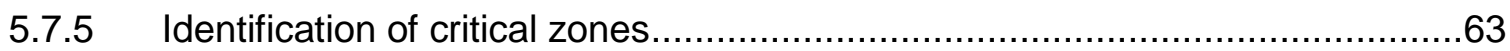

5.7.6 Identification of homogeneous and representative areas, clusters or units ......65

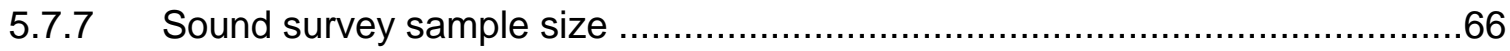

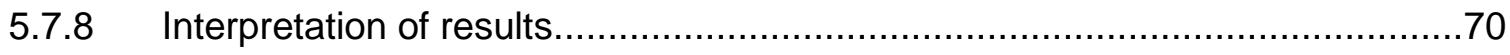

5.7.9 Post Occupancy Evaluation (POE) questionnaires ...................................70

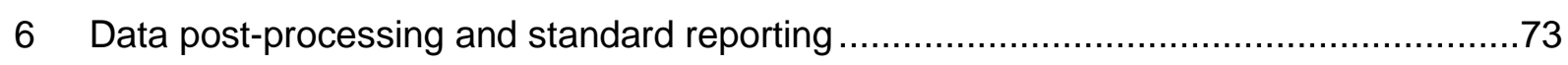

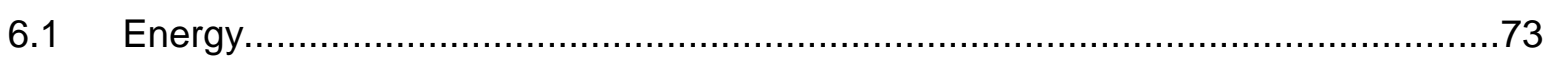

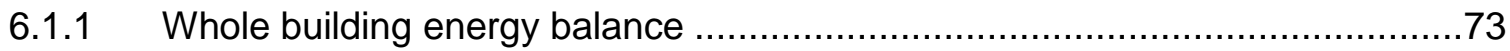

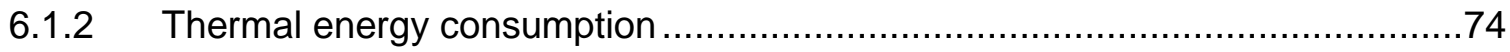

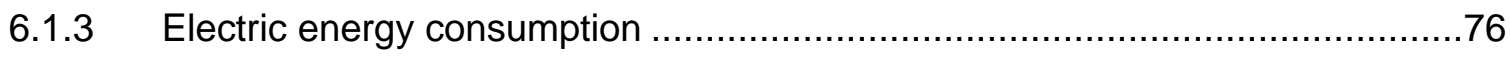

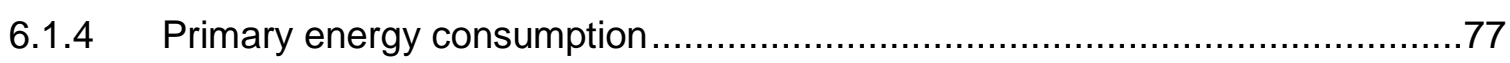

6.1.5 Sub-metered energy measurements .....................................................

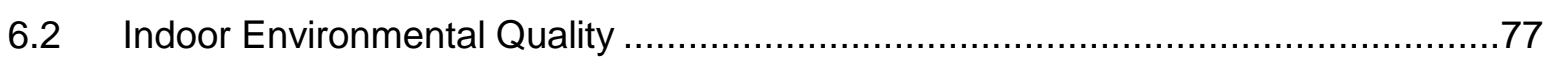

6.2.1 Analysis of ambient temperature and relative humidity ..............................77

6.2.2 Thermal comfort analysis during winter with Fanger model, EN ISO 7730 ......78

6.2.3 Thermal comfort analysis with psychometric chart and ASHRAE comfort zones 79

6.2.4 Thermal comfort analysis in hot climate/summer or tropical regions with the

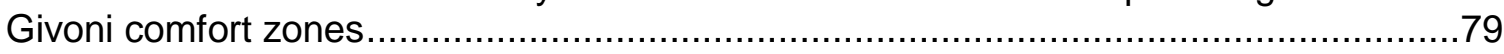

6.2.5 Comfort evaluation in compliance with standard EN 15251:2008 ...................80

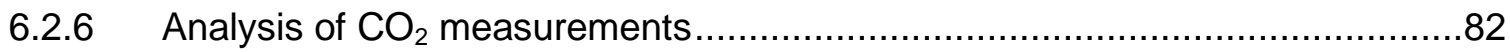

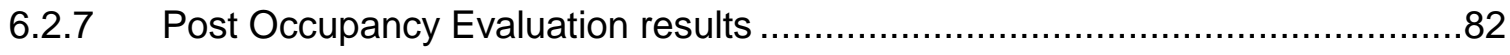

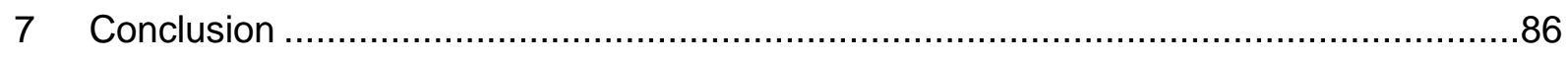

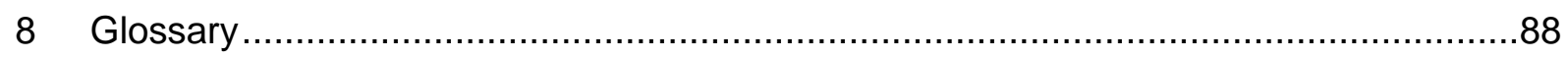

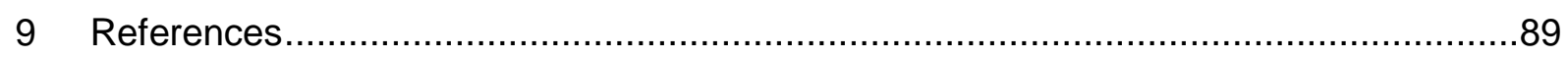

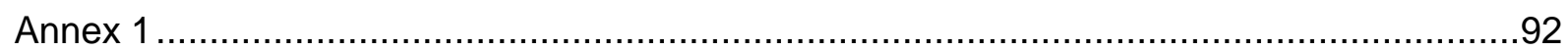




\section{Executive Summary}

In recent years the movement towards more efficient and sustainable buildings has driven the building sector towards the adoption of Net Zero Energy Buildings (Net ZEB) concepts based on the basically zero external energy balance resulting from the renewable energy sources covering a great extent of the building loads. In this framework, the International Energy Agency (IEA) Task 40 / Annex 52 focuses on harmonizing definitions, developing tools, innovative solutions and guidelines related to Net ZEB. Most building energy performance certifications are currently issued on the basis of design input data and several important assumptions (e.g., weather conditions, user behaviors, management of the building) are made and often do not reflect the actual boundary conditions during operation. For this reason, it is necessary to carry out performance assessments during the operation phase on the basis of monitoring data. The current document summarizes the Measurement and Verification (M\&V) protocol for Net ZEB developed within IEA Task 40/Annex 52 Subtask A. This report assists with the planning, implementation and data evaluation for Net ZEB monitoring. The document is divided in two main parts focusing on energy balance and indoor environmental quality (IEQ) assessment. The monitoring can be used to compare design versus real performance for building energy label verification or as a tool to further improve building performance. However, although the recognition of the cost-effectiveness (Mills and Matthew, 2009) of monitoring for many applications, measurement campaigns are not yet common because of the investment cost and the effort required during the different phases. A standardization of monitoring procedures will reduce the effort required in monitoring activities and therefore facilitate the diffusion. The purpose of defining a monitoring procedure to check the Net ZEB definition has one of the main goal to calculate the balance associated with the Net ZEB definition.

\section{Standard M\&V process for Net ZEBs}

This section presents a series of steps/aspects that must be considered during planning, installation and operation of a monitoring system for evaluating Net ZEBs. These steps are summarized in Table 1. Several common monitoring strategies exist:

1. Whole-building approach, based on measurement of the energy flow to the whole building carried out at the building boundary manually or via utility meters (gas and electric).

2. Sub-metering approach, where measurements of isolated energy uses of components/systems are gathered through a more expensive and dedicated equipment.

3. The indoor comfort where comfort parameters (temperature, relative humidity, luminosity, etc.) are measured to additionally assess occupant comfort level and identify malfunctioning. 
Table 1. Steps to be considered during the different phases of Net ZEB monitoring

\begin{tabular}{|c|c|c|}
\hline \# & Step & Description applicable for Net ZEB \\
\hline \multicolumn{3}{|r|}{ Planning } \\
\hline 1 & $\begin{array}{l}\text { Set monitoring } \\
\text { objectives/goals }\end{array}$ & $\begin{array}{l}\text { Check balance according to the selected definition, additional } \\
\text { indexes (e.g., load match, heating demand) and IEQ. }\end{array}$ \\
\hline 2 & Collect Building data & $\begin{array}{l}\text { Standard format to illustrate the building: focus on the energy } \\
\text { flows considered in the balance and load match. }\end{array}$ \\
\hline 3 & $\begin{array}{l}\text { Identify } \\
\text { boundaries }\end{array}$ & $\begin{array}{l}\text { Whole building approach for the balance verification and sub- } \\
\text { metering for the assessment of specific loads. }\end{array}$ \\
\hline 4 & Select metrics & $\begin{array}{l}\text { Depending on definition, different metrics must be measured, at } \\
\text { least to verify balance. Ideally, also check subsystem } \\
\text { performance and IEQ. }\end{array}$ \\
\hline 5 & Perform data reduction & $\begin{array}{l}\text { Derivation of required metrics by indirect measurements or } \\
\text { through estimation from literature. }\end{array}$ \\
\hline 6 & $\begin{array}{l}\text { Define data collection } \\
\text { frequency and duration }\end{array}$ & $\begin{array}{l}\text { Long-term measurements for the assessment of yearly balance } \\
\text { and monthly load match. Shorter data frequency for test of } \\
\text { subsystems. }\end{array}$ \\
\hline 7 & $\begin{array}{l}\text { Identify suitable sensors } \\
\text { and data acquisition } \\
\text { system }\end{array}$ & $\begin{array}{l}\text { The selection of instruments depends on the metric, duration and } \\
\text { data collection frequency. }\end{array}$ \\
\hline
\end{tabular}

\section{Installation}

8 Assess technical feasibility

Verify if the plan can actually be implemented with the real layout.

9 Recognize and solve metering gaps

10 Final plan and installation Identify and act to overcome challenges and limitations.

11 Sensor calibrations Executive planning and implementation.

12 Monitoring system Check accuracy and calibrate sensor periodically. commissioning

Test of correct hardware installation and operation as well data transmission to the Data Acquisition System.

\section{Operation}

13 Define data quality check procedures

Defining approaches to solve missing or inaccurate data. This includes estimation procedures for missing and erroneous recorded data.

14 Data post-processing

Define post-processing procedures to calculate balance (e.g., Net ZEB evaluator tool), other indexes, subsystem performance and IEQ.

15 Standard reporting

Standard report on at least annual frequency. It includes a) building and monitoring system description; b) current year results; c) results for the overall duration of the monitoring.

16 Planning and implementing Listing maintenance actions and time schedule to guarantee the operation maintenance correct operation of the monitoring equipment

\section{Monitoring Energy in Net ZEBs}

This section describes in further details some of the steps summarized in Table 1. A standard reference diagram is proposed for Net ZEB monitoring. Since the Net ZEB definition can differ, the standard reference diagram should assist identifying which energy flows are needed for different buildings. The comprehensive scheme can then be reduced to 
have a monitoring system accomplishing the objectives. Typically, two types of balance calculations are common (Sartori et al., 2012), which influence the energy flows to measure:

- Load/generation, typically performed during the design phase, more complex for monitoring.

- Imported/exported, more common during field monitoring, depends if all energy uses are included in definition.

Based on the applicable Net ZEB definition, the balance must be calculated on primary energy or carbon emission equivalents (therefore, the multiplication by the conversion factors is needed). The frequency at which the data is recorded depends on the definitions and which indexes are being evaluated. Different measurement duration are applicable to monitoring depending on the objective and the definition:

- Spot measurements: very short duration. Useful for constant metrics or to detect instantaneous conditions. Can be repeated to gather information of trend over time.

- Short-time measurements: short duration (e.g., weeks). For both sub-metering and whole building approach to provide information about time-dependent behaviors.

- Long-time measurements: spanning for more than a year. Useful to assess metrics influenced by weather variations, user behaviors or operating conditions.

\section{Monitoring IEQ in Net ZEBs}

One of the risks is that Net ZEBs sacrifice IEQ requirements in order to reduce energy consumption. Therefore, IEQ must also be monitored to verify acceptable level of comfort. Additionally, these measurements are needed for adjustment purposes to be able to compare consumption with the design values and detect malfunctioning. This section specifies different standard level of monitoring strategies applicable to the Net ZEB verification procedure including the range of IEQ indicators needed for the alignment process and to check comfort.

Often the planned and measured consumptions vary and the reasons can be multiple, including indoor and outdoor conditions different than the input values assumed. Therefore, an adjustment is needed to be able to compare design and measured data and identify possible reasons for deviation. Basically, the measured heat consumption $\left[\mathrm{HC}_{\text {measured }}\right]$ is adjusted with the standard indoor temperature to obtain the standard heat consumption $\left[\mathrm{HC}_{20^{\circ} \mathrm{C}}\right]$. Subsequently, the alignment due to weather conditions is conducted by multiplying the $\left[\mathrm{HC}_{20}{ }^{\circ} \mathrm{C}\right]$ by the ratio between the standard climate heat demand $\left[\mathrm{HC}_{20^{\circ} \mathrm{C} \_ \text {climatestandard }}\right]$ and the one with measured climate $\left[\mathrm{HD}_{\text {calc_20 }}{ }^{\circ} \mathrm{C}_{\text {climate_measured }}\right]$. Figure show the results from the alignment process. In this example, the measured energy use for heating exceeds in every case the designed values but became closer after adjustment, highlighting the impact of indoor conditions on the balance verification. Often overheating in summer and winter is observed as common problem of wasted energy and lack of occupant comfort. 


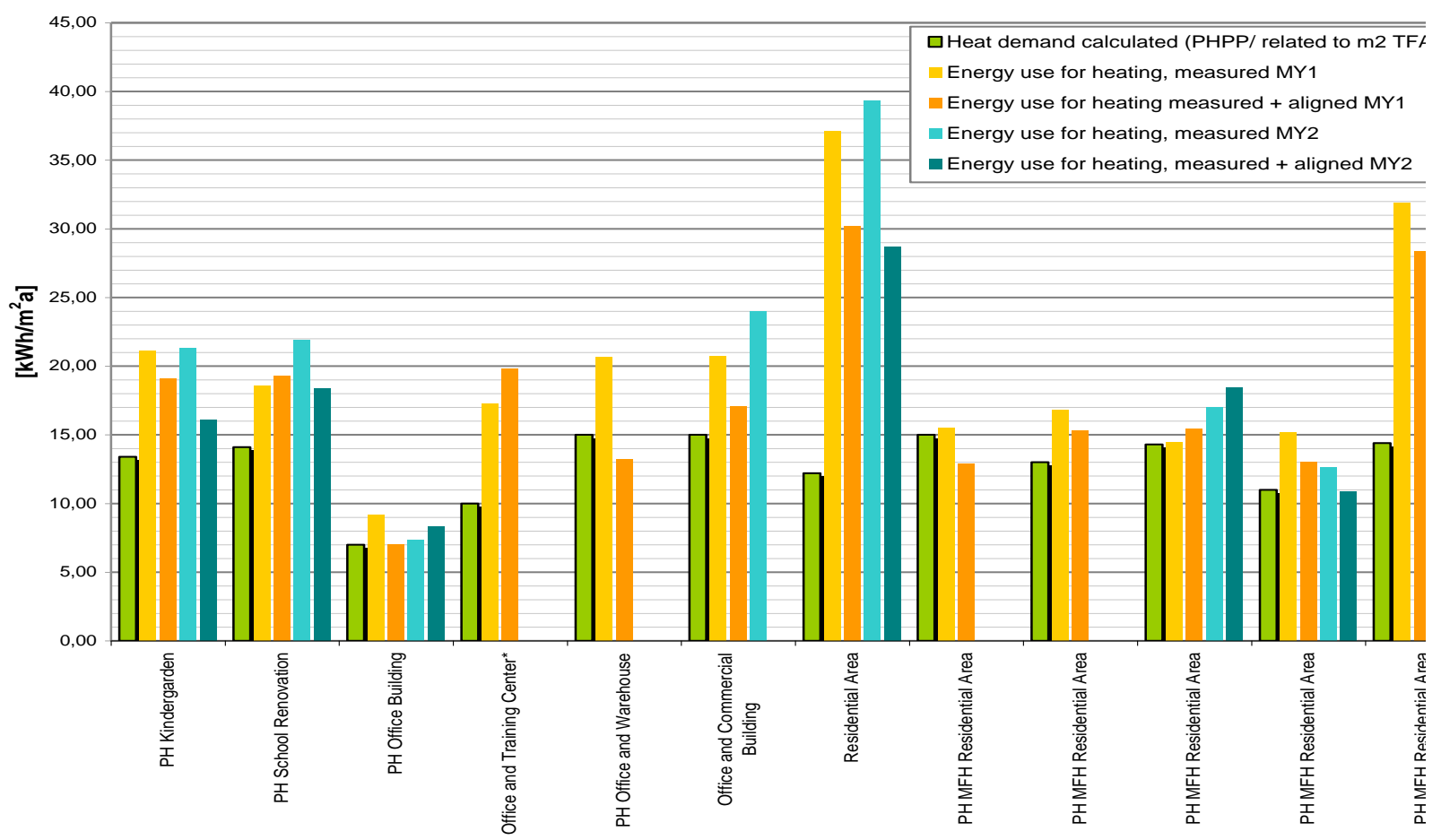

Figure 1. Comparison of design, measured and aligned heat consumptions for high efficiency buildings in Austria, included in the 'IBK' monitoring project. Source: AEE INTEC 2011

IEQ measurements are also conducted to assess occupant comfort via direct or indirect (questionnaires or measurement) assessment. Additionally, if comfort conditions are not present, the occupant will react to find solutions that may also have impacts on the energy performance. Therefore, building commissioning to continuously verify performance is crucial. The level of IEQ monitoring will depend on the specific goals (e.g., alignment process and/or assessment of comfort) and the effort/budget available. Selecting few relevant parameters will allow to equip a greater number of points, while more parameters will provide a detailed picture. Table 2 presents an overview of different monitoring levels.

Table 2. IEQ parameters associated with different levels of monitoring.

\begin{tabular}{|c|c|c|c|}
\hline $\begin{array}{l}\text { Level 1 - Basic } \\
\text { Monitoring }\end{array}$ & $\begin{array}{l}\text { Level } 2 \text { - Advanced } \\
\text { Basic Monitoring }\end{array}$ & $\begin{array}{l}\text { Level } 3 \text { - Detailed } \\
\text { Monitoring }\end{array}$ & $\begin{array}{l}\text { Level } 4 \quad-\quad \text { Advanced } \\
\text { Detailed Monitoring }\end{array}$ \\
\hline $\begin{array}{ll}\text { - } & \text { Indoor air } \\
& \text { temperature } \\
\text { - Outdoor air } \\
\text { temperature } \\
\text { Global } \\
\text { irradiation }\end{array}$ & $\begin{array}{l}\text { Level } 1 \text { plus: } \\
-\quad \text { Indoor humidity } \\
-\quad \text { Operative } \\
\quad \text { temperature }\end{array}$ & $\begin{array}{l}\text { Level } 2 \text { plus: } \\
-\quad \text { Indoor air } \\
\text { velocity } \\
-\quad \mathrm{CO}_{2} \\
\text { concentration } \\
\text { - } \\
\text { Outdoor } \\
\text { humidity }\end{array}$ & 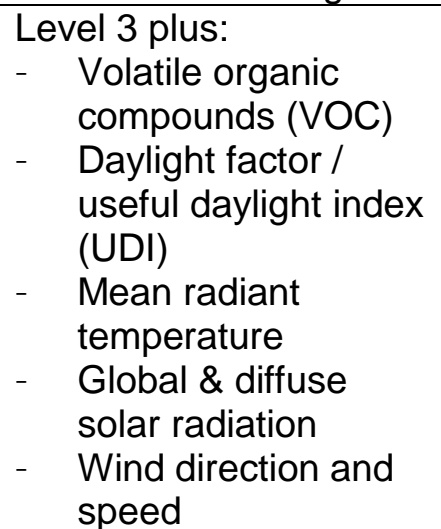 \\
\hline
\end{tabular}

The duration of the measurements is important due to its association with weather conditions and seasonality. For specific inquires spot and short term monitoring is appropriate, but for the energy balance check and to assess comfort, long term monitoring is needed (possible with smart meters and more common ICT devices or integrated in BMS). Typically, the first 
year a building is occupied is used to correct anomalies and for the occupants to adjust.

The position of the sensors vary with the building type and distribution of occupants, typically in the centre of the rooms away from windows, doors and other sources. One of the key element of a monitoring is the selection of the position and number of measurement point to get representative and scientific based values for IEQ. Strategies to reduce the number of sensors are described in the document, mainly based on the identification of 'homogeneous areas' and 'critical zones'. Therefore, there could be a step-wise approach where some areas will have a more detailed monitoring than others. In order to contain costs, careful selection of relevant information must be conducted. The use of statistics to identify the survey sample size and select the appropriate points can assist with this.

Post occupancy evaluation (POE) questionnaires are a powerful tool to assess IEQ when properly administered. They can be used as separate tool but often are coupled with measurements and/or site visit. We can distinguish between spot surveys (feedback regarding the moment when the survey is answered) and general satisfaction surveys (general evaluation of the indoor environment).

\section{Data post-processing and reporting}

After the energy and IEQ data are collected, they need to be processed to include them in a standard report. This section describes possible post-processing and data visualization.

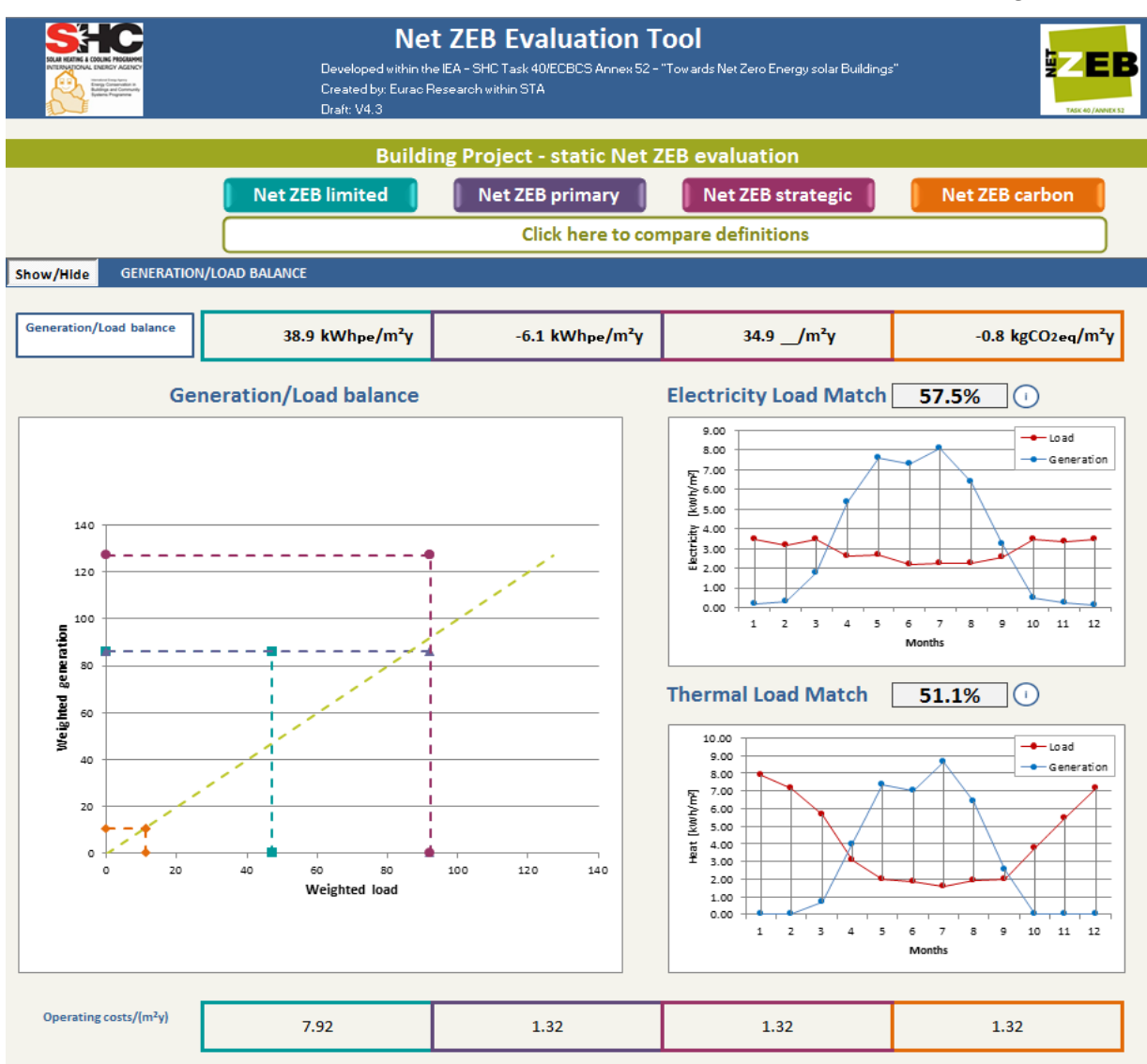

Figure 2. Net ZEB evaluation tool outputs presentation
The analysis of energy performance is important for energy balance verification and identify possible influencing malfunctioning After selecting the applicable definition, the balance can be checked. The Net ZEB evaluation tool, available for free download at http://task40.ieashc.org/net-zeb, can assist with the calculation of the energy balance, load match index and operation cost (see Figure ).

Additionally, detailed analysis for thermal energy, electricity and specific subsystems should be performed to characterize performance and possibly implement corrective measures. Different post-processing and figures can be used for this. For thermal energy is common to present the dependency with external variable (e.g., Heating Degree Days (HDD) and solar radiation), while for electricity the breakdown for different areas of the building and/or the 
consumption distribution between lighting, technical equipment and plug loads (see Error! Reference source not found.). If on-site RES are present, production data should also be analyzed and included in the report. Finally, if detailed monitoring is present for certain subsystems, in depth analysis can be performed depending on the objectives.

For IEQ, depending on the monitoring objectives, different analyses can be performed. For comfort assessment, depending on whether the building is mechanically cooled or not different comfort assessment methods must be used. The most common figures/methods are the ASHRAE comfort zones based on the psychrometric chart, the adaptive comfort and the Givoni comfort zones. The adaptive comfort model is common in naturally cooled buildings during summer conditions; it provides four categories that should be considered for different applications. The Givoni comfort zones are often used for summer conditions in tropical regions and it includes different zones depending on the air velocity.

In addition to comfort parameters, carbon dioxide $\left(\mathrm{CO}_{2}\right)$ is often monitored because it is a good indicator of inadequate ventilation and/or elevated occupancy. Assessing the answers to POE is often a quite challenging task requiring statistical assistance. The M\&V protocol available on the IEA Task40 website provides more information.

\section{Conclusions}

The adoption of ambitious energy performance targets in buildings and the need of substantiate claims of energy efficiency through measured data, requires the development of standard measurement and verification procedures. For the measurement and verification $(M \& V)$ of Net ZEBs performance we identified the activities that must be conducted for the assessment of the balance associated with the applicable Net ZEB definition and the IEQ conditions. Three phases have been identified: planning, installation and operation of a monitoring system, including sixteen different steps to be conducted. Within this context, a standard diagram was developed to illustrate the building and facilitate the identification of the energy flows to monitor, influenced by the type of balance calculation performed (imported/exported or generation/load). The accuracy, frequency and the duration of the measurements also depend on the additional analysis desired. Subsequently, based also on acceptable budget, sensors and data acquisition system can be identified. After the planning phase, the actual monitoring can occur via spot, short or long measurements. After the data is acquired, post processing is used to investigate the fulfillment of the balance as well as additional aspects (e.g., comfort). The Net ZEB evaluation tool can be used to assist when checking the balance. To compare the measured consumption with the design values the alignment procedure is suggested to take into consideration indoor and outdoor conditions different than assumed. Particular emphasis should be paid to the IEQ assessment to ensure the energy performance are not achieved at the expense of a reduction of indoor comfort conditions; different monitoring levels and strategies to identify the relevant areas to be monitored are suggested, including POE surveys. Finally, a standard report, including data analysis and data visualization, must be prepared and disseminated. 


\section{Motivation}

In recent years the movement towards more efficient and sustainable buildings has driven the construction sector towards buildings that require small amount of energy and, therefore, contribute minimally to the emission of greenhouse gases. These ambitious performance targets have led to the adoption of Net Zero Energy Buildings (Net ZEB) concepts based on the basically zero external energy need resulting from the renewable energy sources covering to a great extent the building loads. In this framework, the International Energy Agency (IEA) Task 40 / Annex 52 has the objective to study Net ZEB and specifically to harmonize definitions, develop tools, innovative solutions and guidelines. This document focuses on Measurement and Verification (M\&V) processes to check that a building is Net Zero Energy in practice and the building conditions. Most certifications of energy performance in buildings are, in fact, currently issued on the basis of design input data and several important assumptions such as weather conditions, user behaviors, managing of the building (e.g., HVAC plant settings, shading system use) are made. Even if such assumptions can be highly accurate, they do not reflect the actual boundary conditions since the real building operation can differ significantly from the planned one. For this reason it is necessary to carry out performance assessments in the operation phase on the basis of monitoring data. This document reports the current state of art on standardization of M\&V processes, through an overview of existing procedures. Findings are then adapted to the goal of assessing claimed Net ZEB. Since an harmonized Net ZEB definition has not been established yet and, in general, M\&V protocols vary with the target of the verification and monitoring procedures, the balance assessment (that depends on the definition) can vary as well. The report points out the major issues of monitoring Net ZEBs and defines activities from the concept and design to the installation and exploitation of a monitoring system. The goal of this protocol is to assist with the monitoring planning and implementation. The document is divided in two main parts focusing on energy balance assessment (chapter 4) and indoor environmental quality (IEQ) assessment (chapter 5). 


\section{Literature review on existing standard monitoring protocols}

\subsection{Introduction}

With the increase of regulatory requirements on building energy performance and the development of innovative financing mechanisms, the need to substantiate claims of energy efficiency, via measured data, takes on added importance. Performance measurements carried out on individual components in controlled laboratory boundary conditions are idealized and do not capture the dynamic interactions of multiple subsystems (National Institute of Standards and Technology - NIST). Even more complex testing facilities, suited to investigate such interactions, seldom reproduce all the complexities of actual building installations and do not encompass all the possible operation conditions, especially the actual user behavior. Thereby, field monitoring, meant as observation of building real operation parameters for the evaluation of its system energy performance, through measurements sampled and recorded at regular intervals, becomes a necessary part of energy-efficiency programs. From this perspective, "monitoring" is not only aimed at controlling building facilities to ensure suitable comfort conditions (as usually perceived as Building Energy Management Systems - BEMS), but it favors energy efficiency by increasing the awareness of building owner/manager with respect to energy uses, suggesting energy saving measures to be adopted and evaluating them afterwards (audit, diagnosis and continuous commissioning). It permits to verify that a building performs within design expectations and thus can be used as the basis to retain or revoke building energy performance labels. In a broader perspective, monitoring can also support the recognition of claimed energy efficient design solutions so they can faster penetrate the market. Finally, at national level, monitoring can demonstrate the effectiveness of energy policies and be the basis for decisions on financial subsidies and incentive pay to foster particular technologies (e.g. PV, solar thermal, insulation).

Although the recognition of the effectiveness of a monitoring system, measurement campaigns for energy performance assessments are not yet a common practice in buildings and they are often limited to research or demonstration projects. Major barriers are the equipment cost and the effort required in monitoring activities, spanning from the system planning to the elaboration of the collected data (post-processing). However, with regards to the financial aspect, monitoring has demonstrated to be a highly cost-effective means of obtaining significant energy savings across a variety of building types (Mills and Matthew, 2009). The larger and more complex the building is, the more profitable the monitoring is likely to be. A standardization of monitoring procedures, in particular for new buildings or important refurbishments, will reduce the effort required in monitoring activities and consequently the relevant costs and needed skills, allowing to extend monitoring practices to a larger number of non-residential and residential buildings. The harmonization of building performance standards on an international scale, like it is happening for the Net ZEB concept, allows comparison of building performances and supports the development and dissemination of standard assessment procedures that are effective, handy and affordable.

\subsection{Towards the standardization of monitoring procedures for buildings}

The first step in developing a standard monitoring procedure is the definition of its goals. MacDonald and Wasserman stated that "Gathering information and measuring data about energy use and conditions in buildings depend to a large extent on the purpose and objective for performing the work" (MacDonald, 1989). Purposes for measurements can be several. The "Building Energy Monitoring Workbook" published in 1992" (ENERGY SYSTEMS LABORATORY, 1992), within the LoanSTAR Monitoring and Analysis Program, as a "standalone survival guide to acquiring energy use and environmental data in buildings" has 
identified seven categories representing most building monitoring programs, covering diverse issues including analysis of the human factor in a building, issues about environmental quality, diagnosis of operation and maintenance problems (O\&M), measurements of system efficiency, savings from energy retrofits, studies of end-uses, conservation planning (Figure ). Different monitoring approaches are required since different information needs to be gathered at varying frequencies to cover all the mentioned programs. Nine monitoring methods have been identified, differing for the measurement method (on-off, before-after, simulated occupancy), the reference buildings to be compared with the measured building (Test-Ref. Similar Building, Normalized Data Base, Calibrated Models) and data needed (Whole Building Energy \& Conditions, Hardwire Sub-metered and Non-Intrusive Sub metered).

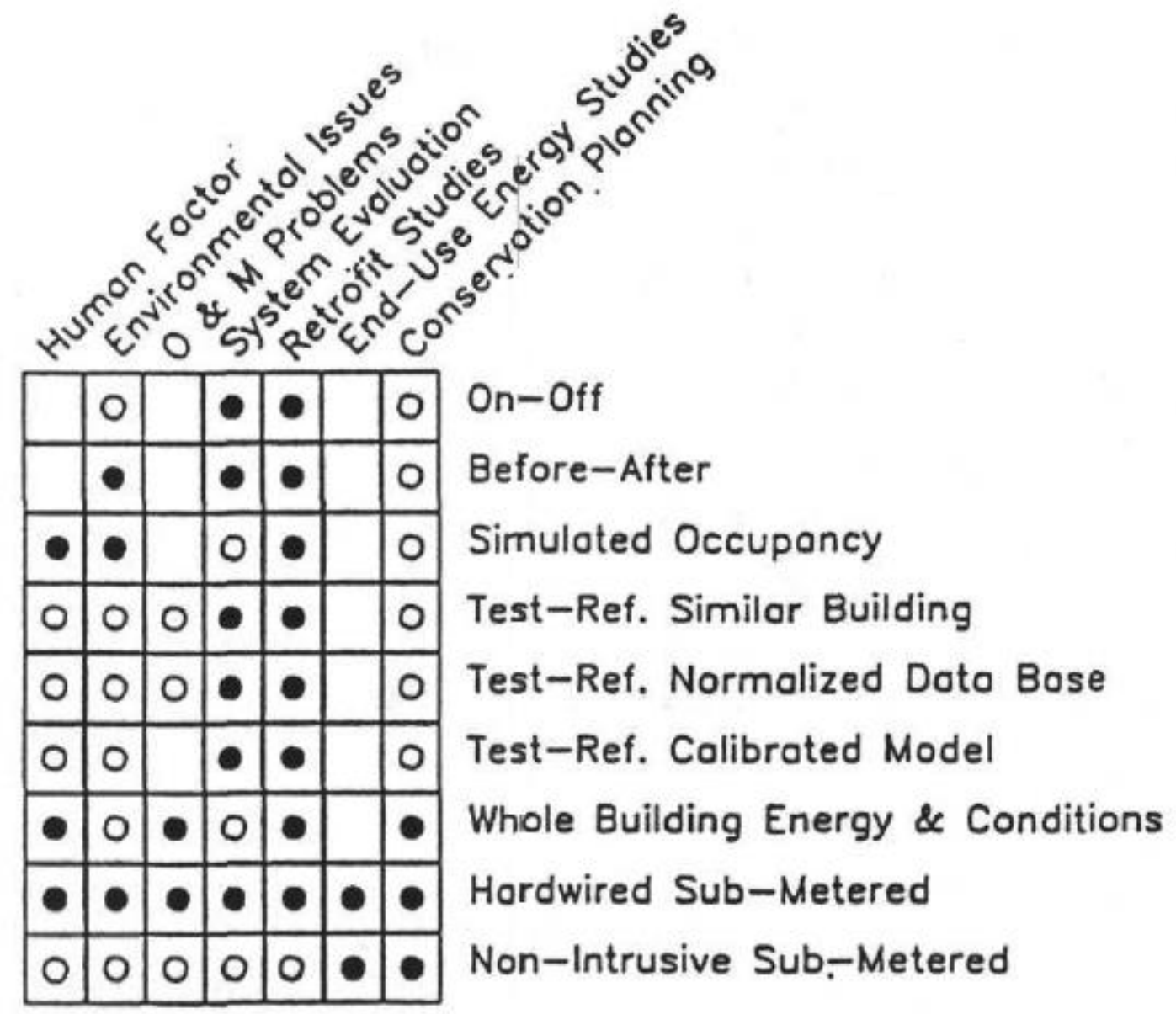

Figure 2-1. Type of program versus the design of the experiment. This matrix shows the relationship between the type of monitoring program and the design of the experiment (Haberl, 1990). Solid circle means strong correlation, whilst blank circle means weak relationship.

Most of the monitoring approaches cited in the workbook have been adopted in subsequent guidelines with a terminology that has been improved over time. Among others, the following approaches are highlighted since they introduce main features (and relative levels of detail) of a monitoring approach:

4. Whole building measurement approach, where periodic readings at the building boundary are carried out taken manually or via utility meters (gas and electric). 
5. Sub-metering measurement approach, where measurements on particular components or systems are gathered through a more complex, expensive and dedicated equipment.

6. The indoor comfort where comfort parameters (temperature, relative humidity, luminosity, noise, etc.) are measured to assess occupant comfort level.

With reference to monitoring programs, the attempts of standardizing monitoring procedures have been mainly focusing on the quantification of energy, water or demand savings, resulting from the implementation of an Energy Conservation Measure (ECM). First attempt towards the standardization of monitoring procedures has been pursued by the Efficiency Valuation Organization (EVO). Since 1996, EVO has been publishing the so called "International Performance Measurement and Verification Protocol" (IPMVP). (first edition entitled the "North American Energy Measurement and Verification"), with the aim of providing $M \& V$ tools to quantify the results of energy efficiency projects and programs (EVO, 2012). In the Fall of 2002, ASHRAE, having many of the same original authors as IPMVP, published Guideline 14-2002 "Measurement of Energy and Demand Savings" to fill a need for a standard set of procedures addressing the determination of energy savings in residential, commercial and industrial buildings by comparing before and after energy use measurements, which are adjusted for non-ECM changes affecting energy use (ASHRAE, 2002). In line with the mentioned documents, in 2008, the Department of Resources, Energy and Tourism of the Australian Government published the Energy Savings Measurement Guide (ESMG) as "a best practice guide to assist companies estimate, measure, evaluate and track energy savings, quantifiable costs and benefits created as a result of implementing energy efficiency opportunities". In the same year, the "M\&V Guidelines: Measurement and Verification for Federal Energy Projects" within the Federal Energy Management Program (FEMP) was published by Nexant, Inc (2008), also following the method developed in the IPMVP.

The cited documents mostly outline the stages of project planning, management and full execution of a monitoring, without going in detail with technical specifications of the M\&V process. They basically define key terms and highlight aspects that must be considered in developing a $M \& V$ plan, but do not provide details for specific measures or technologies. This means that when an M\&V approach is implemented, it has to be suited to the individual projects and addressed to the specific objectives of energy savings measurements. Given that measuring energy savings means comparing measured use (or demand) before and after implementation of an ECM (EVO, 2012), monitoring specifications not only depend on the building features and operation before the implementation of the ECM, but on the implemented ECM as well. For example, given two identical buildings with identical boundary conditions, the monitoring procedure can differ in terms of metrics, sampling and recording time steps, equipment, data quality requirements, data elaboration and reporting, depending on the applied ECM. As already discussed in 1987 by Misuriello (1987), "The diverse nature of monitoring projects realistically precludes a universal protocol applicable to all monitoring efforts." In this sense the limitation of the objective of the monitoring project, can help to the standardization of $\mathrm{M} \& \mathrm{~V}$ processes. Although the cited documents pursued such objective, the energy savings evaluation is still too wide to standardize specific measurements for buildings. Nevertheless, the LoanStar workbook, IPMVP and the Australian guide provide a conceptual framework for measuring, computing, and reporting energy impacts that can be itemized and addressed to more limited and specific objectives, like the verification of the balance in Net ZEB, fostering the accomplishment of standard procedures. Thereby, such documents can be used as state of the art for the development of a monitoring protocol for Net ZEB. In fact, as the Net ZEB concept has been recently introduced, no relevant standard monitoring program has been established yet. To the knowledge of the authors, ongoing activities to this end are being carried out by the NIST that has set, as strategic goal, the 
development of a Measurement Science for Net Zero Energy and High Performance Buildings. Such Measurement Science apparently addresses the development of a concrete monitoring system (more than a standard protocol) to assess energy consumption, $\mathrm{CO}_{2}$ emissions, indoor air quality, and cost effectiveness of buildings, in a holistic, integrated manner, that considers system interactions involving weather conditions (external loads), building envelope (liaise between outdoor and indoor environments), internal loads, control systems, and space conditioning equipment.

The purpose of defining a monitoring procedure to check the Net ZEB definition is limited to the calculation of the balance relevant to the adopted Net ZEB definition and its assessment with respect to the benchmark value " 0 ". The presence of such a benchmark will reduce the effort required in monitoring campaigns, in comparison with any guideline focusing on the evaluation of energy savings achieved with the implementation of an ECM. The major simplification is that no "baseline" scenario (EVO, 2012), the energy use status before the implementation of any ECM has to be defined, eliminating the effort (extended monitoring campaigns, databases work of reference, modeling and simulations) for collecting data during the baseline time. The development of a monitoring procedure focusing on the assessment of energy balance in Net ZEB, mostly focuses at the current operation of a building and not to its comparison with past operations (unless it is applied to renovated buildings converted into Net ZEB). The focus is mainly on the calculation of a balance and its evaluation with respect to the "zero" benchmark. Once the objective has been set, the first decision to be made according to EVO (2012) for designing a monitoring system refers to the detail level of measurements as illustrated in Figure 2-2:

1. the whole-facility approach, based on the measurement of the energy flow to the whole building or a section of it, named whole building approach in ENERGY SYSTEMS LABORATORY (1992)

2. the retrofit-isolation approach, based on the measurements of isolated energy uses, requiring the sub-metering, named sub-metering approach in ENERGY SYSTEMS LABORATORY (1992).
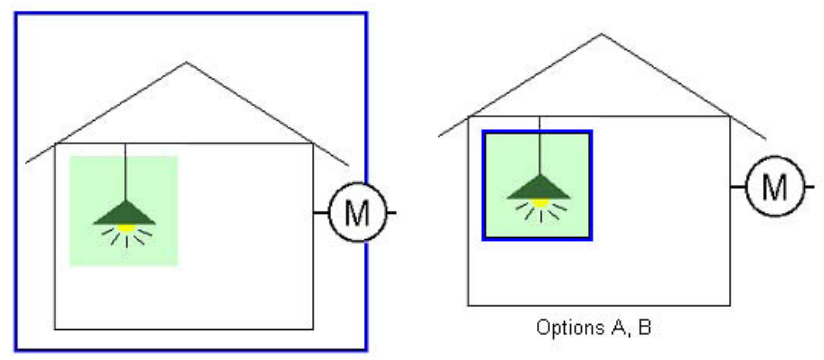

Figure 2-2. Whole facility approach and retrofit-isolation approach as represented in M\&V for Federal (Nexant, Inc., 2008)

The goal of this step is to set the physical boundary of the building where measurements have to be gathered. Practically, this step can only be carried out once the features of the building are known. Concrete templates and tools for describing monitored buildings features and measurement approaches are provided in the "Procedure for Measuring and Reporting Commercial Building Energy Performance", developed by the National Renewable Energy Laboratory (NREL), within the Performance Metrics project and published in 2005. This procedure is intended to provide a standard method for measuring and characterizing the energy performance of commercial buildings and it goes more in detail with technical specifications compared with the other cited guides (Australian Government, Energy 
Efficiency Opportunities Section, Energy and Environment Division, 2008; EVO, 2012; Nexant, Inc., 2008). The NREL document adopts the definition of two levels of monitoring detail as well, named tier 1 and tier 2, that correspond to the whole building or retrofit isolation approach respectively. Tier 1 provides results for the whole facility, based primarily on utility meter readings, hence on a monthly or yearly time step. Tier 2 yields time-series results (typically collected every 15- or 60-min data), itemized by type of end use based on sub-metering and a data acquisition system (DAS). In comparison with other cited guides (Australian Government, Energy Efficiency Opportunities Section, Energy and Environment Division, 2008, EVO, 2012; Nexant, Inc., 2008; ASHRAE, 2002), the document identifies the two boundaries in details (Figure 2-3). The first boundary is represented by the interface between the building and the local energy infrastructure which exchanges energy with the building. The secondary boundary encompasses the inside of the building; note the difference with Figure 2-2, as it focuses on evaluating all single systems energy performance. It aims at determining the energy consumption, electrical energy demand, and on-site energy production in existing commercial buildings of all types (commercial buildings are the focus of the NREL procedure, but it can also be taken as starting point for other building typologies). To this end, it identifies all forms of purchased energy (e.g., electricity, oil, gas, coal, liquefied propane gas, district heat), all forms of on-site energy conversion (e.g., fuel cells, fueled generators, and cogeneration units) and on-site energy production (e.g., photovoltaic, wind, geothermal and solar thermal). All these items are referred to as "metrics", i.e. a standard definition of any measurable quantity according to (U.S. Department of Energy, Office of Energy Efficiency and Renewable Energy, 2003). Once the building is given and the monitoring objectives set, it is possible to identify the necessary metrics among the ones listed. Barley et al. (2005) also propose a diagram to represent the metrics in buildings like in Figure 2-4, but no standardization has been achieved in this sense, so no standard tool to represent monitored projects has been defined in the guideline.

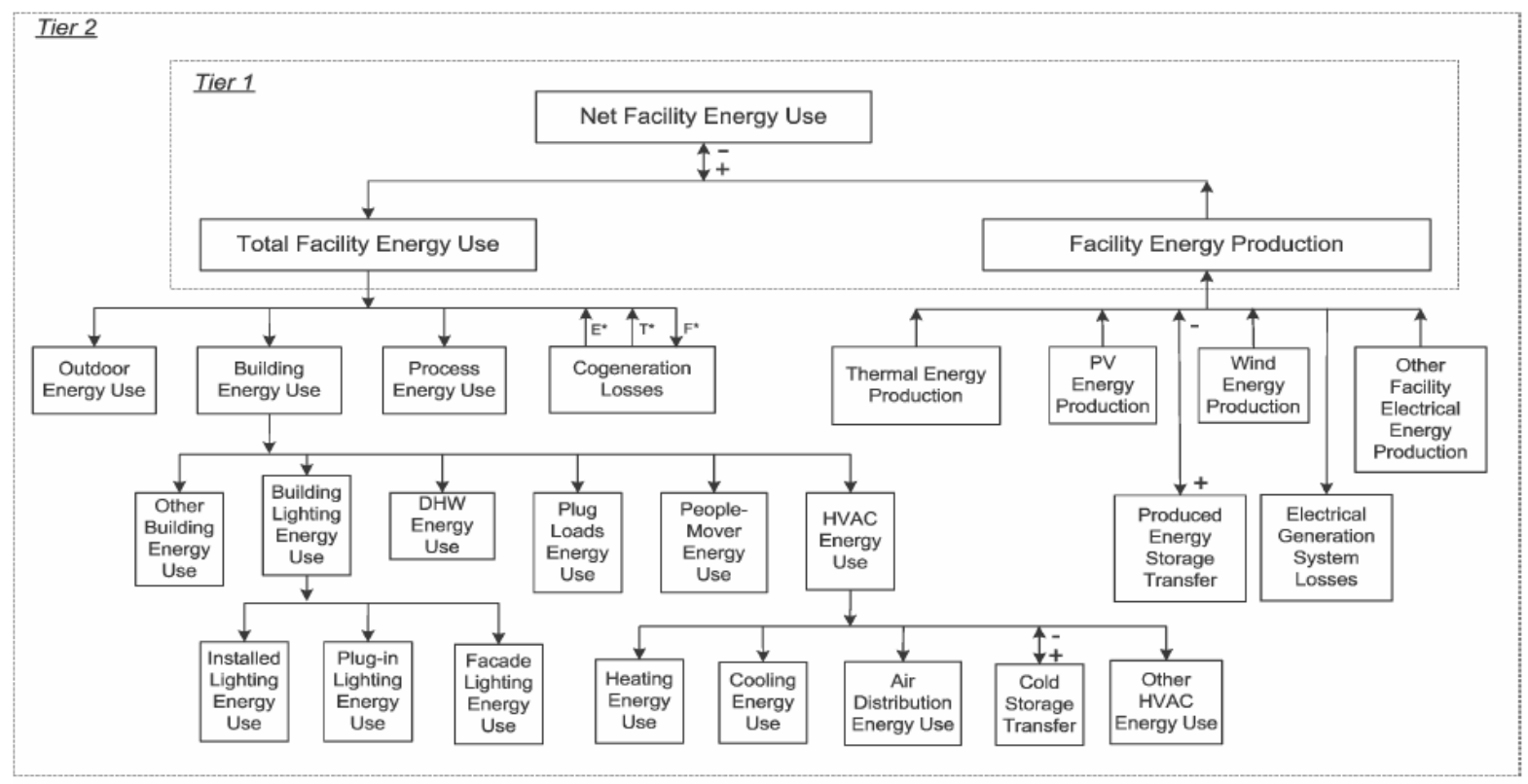

Figure 2-3. Diagram of related energy performance metric (Barley et al., 2005) 


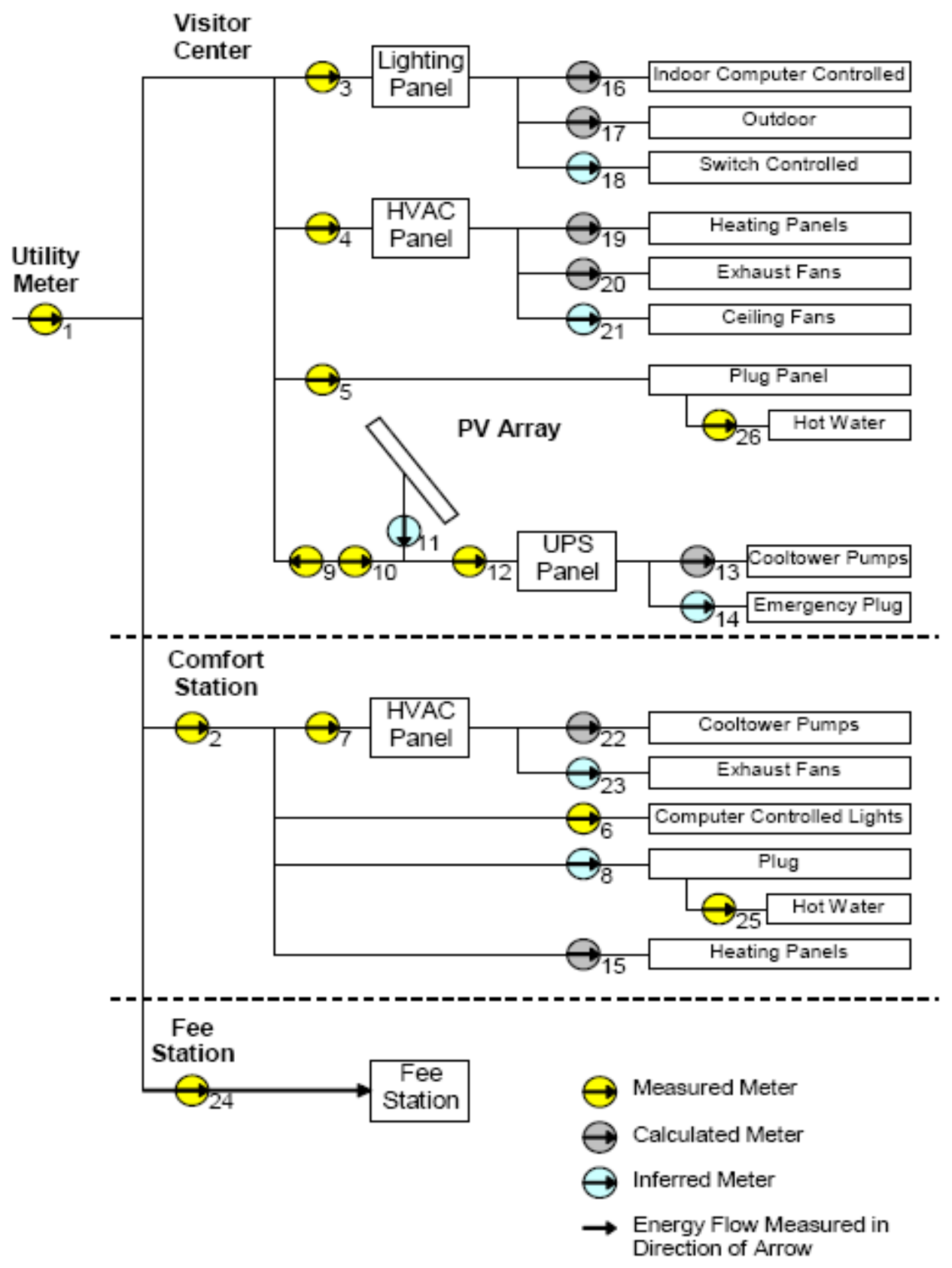

Figure 2-4. Example diagram of Tier 2 measurement scheme (Barley et al., 2005)

The design of a measurement system consists of determining how to measure the selected metrics in practice. Before selecting any equipment to measure a metric, monitoring planners should attempt to obtain the metric indirectly from other metrics or from available relevant data elaboration (Australian Government, Energy Efficiency Opportunities Section, Energy and Environment Division, 2008). For instance, if the consumption of a constant speed pump is evaluated, it could be enough to collect data on its operation time and its nominal power, avoiding any direct measurement. Possibly the nominal power draw could be verified with a spot measurement, without permanently metering it. This will lower the cost of the measurement system, but the data quality could be reduced as well. Thereby the selection of an indirect measurement depends on the desired trade-off between measurements cost and data quality. Once the metrics to be directly measured are identified, it is 
necessary to specify the recording frequency (i.e. the time step at which data have to be collected). Such parameter depends again on the objective of monitoring, but it also depends on the required data accuracy. High frequency data samples can be useful to increase understanding of operation details but lead to the generation of a greater amount of data that needs to be stored and elaborated. (Australian Government, Energy Efficiency Opportunities Section, Energy and Environment Division, 2008) provides time resolution suggestions on the basis of metrics and operational parameters of single energy systems.

The duration of the monitoring campaign also needs to be selected. This refers to the so called measurement techniques in (ASHRAE, 2002) and classified into spot, short and long term measurements. The duration selection mainly depends on the monitoring objectives but also on the specific metrics and influences the equipment selection. The selection of the proper Data Acquisition System mainly includes the choice of sensors fitting the selected metrics, possible signal conditioners, signals converters, data-loggers, central computer and a data acquisition software. An extensive literature exists on the components to support the selection. A short summary and some references are already provided in ASHRAE (2002) and Barley et al. (2005). Once the required sensors are identified for each metric, it is necessary to check the technical feasibility of their installation. In case the installation of some sensors is not feasible, alternative ways to collect data on the relevant metric needs to be found. (Australian Government, Energy Efficiency Opportunities Section, Energy and Environment Division, 2008) gives some suggestions about how to overcome the so called "metering gaps", but they are strictly dependent on the monitored building. If the installation is not completed in compliance with the sensor requirements, estimation of data accuracy and possible adjustments, must be consider. Data quality also needs to be considered after system installation and commissioning. Indeed, data acquisition systems can fail during data collection, transfer and storage. Sensor failure can occur because of power failure or communication issues as well as the sensor drifts over time. Thus, a systematic calibration of sensors must be planned to ensure the accuracy of the data collection. Finally, alarms should alert every time data are not transferred to the central computer or recorded, so that an immediate recovery can be accomplished. If it is not possible, procedures to substitute missing data should be identified and implemented. In any case, any measurement should be accompanied by a estimation of its uncertainties according to existing standards.

The final step of the monitoring protocols considered in existing literature refers to the "reporting". EVO (2012) provides an example format about how to present measurement results. The format depends on the selected performance metrics and on the overall monitoring objectives. In general, it should include:

1. Description of the building and its operation mode;

2. Description of the measurement system: metrics, collection resolution time, duration of the monitoring campaign, equipment and its accuracy;

3. Measured data with elaboration for the calculation of the desired performance metrics: description and justification of any data correction or missing data management should be reported as well;

7. Result and visual representation of the selected performance metrics with associated discussion. 


\section{Standard M\&V processes for Net ZEB}

\subsection{Standard monitoring protocol for Net ZEBs}

Following the existing standard monitoring protocols summarized above, a procedure to check that Net ZEBs achieve the target is presented in this section. The procedure includes sixteen steps grouped into three different phases (planning, installation and operation) of the implementation of a monitoring campaign with specific focus on the aspects relevant to Net ZEB. Some topics, like monitoring equipment or installation guidance, will not be covered because they are not specific to Net ZEB but refers to general building monitoring procedures. Table 3-3,

Table 3-4, and

Table 5-3 summarize the overall process towards the implementation of an M\&V protocol for Net ZEBs.

\subsubsection{Monitoring system planning}

\section{Set Monitoring Objectives/Goals}

A M\&V protocol for Net ZEBs aims at verifying that claimed Net ZEBs achieve the target in practice. The challenge is that different Net ZEB definitions exist, which require different metrics and monitoring parameters. Actually, each definition can be translated into a balance. Hence, checking that a building is in compliance with the Net ZEB definition requires to measure the energy flows crossing the physical and balance boundaries selected in the definition (Sartori et al., 2012). Further requirements could be set in a Net ZEB definition, including for instance the upper limits of the heating demand, the primary energy to name a few. These requirements are typically set in energy ratings systems, like the Passivhaus certification, or national building codes. They can vary by countries, but also in the same country when referring to private or local rating certifications agencies. As their assessment can be rather difficult and expensive, this topic will not be discussed in this report. Finally, a Net ZEB definition can include additional indicators that provide information regarding for instance the load match or the grid interaction indices (Salom et al., 2011; Sartori et al., 2012).

The achievement of the zero balance should also guarantee that Indoor Environmental Quality (IEQ) is provided. Generally speaking, IEQ includes hygrothermal comfort, indoor air quality (IAQ), acoustic comfort and visual comfort. Actually, comfort is the first objective to be pursued in building design and guaranteed during the operation, regardless of the building energy performance targets. Nevertheless, comfort measurements become more important for ambitious energy targets. The risk is that Net ZEB sacrifice IEQ requirements in order to reduce energy consumption. Nevertheless, the verification of IEQ requires a special itemization of the standard monitoring protocol, as described in chapter 5 . The completeness and complexity of a Net ZEB definition is reflected in the M\&V process in terms of feasibility and affordability. The minimum requirement is to use IEQ measurement for the Net ZEB balance verification (for adjustment purposes). However, the document illustrate the IEQ assessment to verify that the acceptable building user environmental conditions are present.

This report also aims at defining a procedure for the assessment of the load match index (discussed in 6.1.1), although this is considered a second level of Net ZEB monitoring.

\section{Collection of building data}


In subchapter "4.2 Template for building data collection" a standard diagram for the illustration of the energy flows within building and between the building and the surrounding is proposed. Such diagram is helpful not only to describe the building but also to easily identify the measurements required to check different Net ZEB definitions.

\section{Definition of monitoring boundaries}

Monitoring boundaries are strictly dependent on the Net ZEB definition applied to the building, in particular on physical and balance boundary settings and on the possible additional indicators to estimate, such as the load match (Sartori et al., 2012). Subchapter 4.3 shows different monitoring boundaries depending on different Net ZEB definitions.

\section{Selection of metrics and relevant data required}

Based on the specific monitoring goals, different levels of energy monitoring could be considered. The minimum requirement (level I) are the data needed for the balance verification, including those needed for the climate adjustment (see subchapter 5.5.1); depending whether the 'load/generation' or the 'delivered/exported' balance approach is selected different metrics need to be measured (see subchapter 4.3). For the balance check, the metric selection must consider the building physical boundaries and both what is included or excluded from the balance boundary. If there is the desire to estimate a specific load (e.g., the appliance electricity use), this would require the installation of a relevant meters, in addition to the ones located on the physical boundaries. This means moving from the interface between the building and the surrounding grids (whole building approach) to the inside of the building (sub-metering approach). Subchapter 4.3 lists the metrics needed to check different Net ZEB definitions and show them in the reference diagram for monitoring buildings. In some instances, the collection of utility meter data could be sufficient to check the delivered/exported balance and gather information about general performance.

In addition to the monitoring of IEQ parameters (see chapter 5), the energy monitoring system could also include additional sensors to expand the scope and, for instance, compare the design and the real performance, assess the correct operation of specific systems or the interaction between these energy flows and the IEQ / user behavior aspects. In this level II energy monitoring system, the resolution, sampling time and recording time does not necessarily coincide with those needed in level I, since higher frequency may be needed. However, sometimes shorter measurement duration may be enough for the purpose. An overview of the appropriate available sensors is presented in subchapter 4.5. The diagram in subchapter 4.2 presents a comprehensive illustration of the energy flow of interest (e.g., heating, cooling, DHW, ventilation, lighting, appliances, RES) that could be measured depending on the objectives. Other important parameters influencing the performance of buildings include ventilation rate, air exchange rate, free gains from plug loads/lighting/appliances, the use of wood stoves among others. The assessment of the correct operation of systems and equipment it is out of the scope of this document and will not be discussed here.

\section{Data reduction}

If any relationship exists between the selected metrics, the dependent metrics can be evaluated indirectly through this relationship. This way, the number of measurement points and thereby the effort and the monitoring cost are reduced. Such method can diminish data reliability as well as reduce possibly quality check: the trade-off between data quality and costs has to be evaluated. This step is not discussed in this M\&V protocol because the data reduction approach is strictly dependent on the actual building. 


\section{Selection of data collection frequency and duration of measurements}

The measurement duration depends on the balancing period and on the overall duration used as reference for verifying that a building is really Net Zero Energy (subchapter 4.4). Data collection frequency is given by the sampling and recording intervals. Nevertheless, for the load match assessment, data must be stored at least on monthly level, depending on the applied meter configuration. The sampling time can then be shorter or equal to the monthly resolution, depending on the desired data accuracy (subchapter 4.4).

7. Identification of suitable sensors and data acquisition system

On the basis of the metrics, measurement duration and desired accuracy, the proper equipment will be identified in all of its components. The desired data accuracy depends on the monitoring system manager/owner. Subchapter "4.5 Monitoring equipment" shows these aspects and lists sensor technologies available on the market for different metrics.

\subsubsection{Monitoring system installation}

8. Check of the technical feasibility for the installation

The check of the technical feasibility of the installation is needed to verify if the equipment selected can actually be installed in the building. Such technical feasibility is dependent on the energy system layout compared to the project drafts. Often the actual layout is different from the project drafts. It is necessary to check the space availability for the sensor installation (e.g. flow meters), their connection with the electric panel, and distances to be covered among others. As this step is strictly dependent on the building project and not related to only Net ZEB, it will not be covered in this document.

\section{Recognition of possible metering gaps and how to solve them}

This step aims at identifying proper measures to overcome possible technical unfeasibility resulted from the previous step. Clearly, such step must also assess the impact on data accuracy due to the implemented measures. This aspect of the monitoring is strictly dependent on the specific building of interest.

\section{Final planning of the monitoring equipment and installation}

It concerns the executive design and the implementation of the monitoring system, that depend on the building of interest.

\section{Sensor calibrations}

Meters and sensors should be calibrated as indicated by the manufacturer. Primary standards should be utilized whenever possible. Before and after the installation each sensor used should be checked and calibrated to correct for possible drift. A plan for periodic calibration and correction should be developed and implemented.

12. Commissioning 
The monitoring system commissioning starts with the planning phase and continue with the set-up and tests of the hardware and software components of the system. Test of the operation includes check of the information gathered and transferred by the data acquisition system: availability of the data, values collected, metrics, time frequency, data storage. Such phase must be seriously taken into consideration as it can be long. Despite the importance of listing actions to be undertaken for commissioning, the commissioning will not be investigated within this document because is not strictly related to Net ZEB.

\subsubsection{Monitoring system operation}

13. Definition data quality check procedures (e.g., solving instrument spikes, missing data) Although the previous step aims at checking that the system works properly, some failures can occur during its operation. In these cases, it is necessary to identify estimation/calculation approaches to overcome possible lacks of the monitoring system (e.g. missing data substitution, adjustments of values). Every time any data correction measure is implemented, the resulting data quality has to be assessed and clearly stated in a log so readers understand the assumptions and the approximation undertaken.

\section{Definition and implementation of data post-processing (e.g., performance indicators)}

Once all the necessary measurements are collected and stored, data can be processed. Towards the standardization of monitoring procedures for Net ZEB, a predefined post processing can be identified. It includes the calculation of the balance, according to the applied Net ZEB definition as well as additional indicators related to the grid-building interaction. Within IEA Task 40/Annex 52 activities, a MS Excel based 'Net ZEB evaluator tool' (available for free download at http://task40.iea-shc.org/net-zeb) was developed for the evaluation of different Net ZEB definitions with monitoring data (or design data) as input. Such tool calculates the balance according to the different Net ZEB definitions and the load match index, requiring yearly and/or monthly data as input.

\section{Definition of a standard reporting}

As the balancing period is annual, a report should be delivered at the end of every year of operation. Nevertheless, as yearly results can vary with time, it is necessary to evaluate the compliance of the building with the Net ZEB definition on a longer time span, preferably the overall duration of measurements. A standard report should include three sections:

1) the first section should present the building and its monitoring system (constant section of the report),

2) the second section should display the results of the current year

3) the third section should show the data elaboration for the overall duration of the monitoring campaign.

Specifically, the first section should include:

- The description of the building, according to the design data (indoor and outdoor loads for sizing) and monitoring system (highlight of the metrics) as introduction.

- The description of the monitoring system should list possible data reduction (step 5) and quality improvements (step 13), accompanied by the sensor accuracy. 
- The metrics considered as well as the post-processing data approach displayed, namely the balance and additional indicators.

The second section should include:

- The results of balance related to the current year. The diagrams should enable an easy understanding of the results, accompanied with numerical information. Some examples are already included in the IEA Task 40/Annex 52 Net ZEB evaluator tool.

- Comfort assessments related to the current year (see chapter 5).

- Explanation of the results with discussion of possible influencing factors, such as building use, number of occupants, climate conditions to explain possible deviations from expected results.

The third section of the standard report should include:

- Overall results for each year with the associated comparison and evaluation of the variation of the influencing factors to draw more general conclusions

- Evaluation of the balance results and load match based with statistical analysis.

\section{Operation maintenance}

To guarantee that the monitoring system works properly during the monitoring campaign, it is necessary to plan maintenance activities (monitoring system continuous commissioning). Special attention must be given to sensor calibration and malfunctioning but also to data storage and sensor power supply (e.g., external power or battery power). Despite general guidelines about maintenance actions and schedule, the topic will not be addressed in this document because not strictly relevant to Net ZEBs.

Table 3-3. List of the steps for the implementation of a M\&V protocol for Net ZEBs in the planning phase.

\begin{tabular}{|c|c|c|c|}
\hline & Standard M\&V & M\&V for Net ZEBs & $\begin{array}{l}\text { Relevance to Net } \\
\text { ZEB }\end{array}$ \\
\hline 1 & $\begin{array}{l}\text { Set monitoring } \\
\text { objectives/goals }\end{array}$ & $\begin{array}{l}\text { Check balance according to the definition and } \\
\text { additional indexes (e.g., load match, comfort) }\end{array}$ & $\begin{array}{l}\text { Specific for } \\
\text { ZEB }\end{array}$ \\
\hline 2 & Building data collection & $\begin{array}{l}\text { Standard format to illustrate the building: focus } \\
\text { on the energy flows considered in the balance } \\
\text { and load match }\end{array}$ & $\begin{array}{l}\text { Specific for } \\
\text { ZEB }\end{array}$ \\
\hline 3 & $\begin{array}{l}\text { Identification of } \\
\text { monitoring boundaries }\end{array}$ & $\begin{array}{l}\text { Whole building approach for the balance } \\
\text { verification and sub-metering for the } \\
\text { assessment of specific loads }\end{array}$ & $\begin{array}{l}\text { Specific for } \\
\text { ZEB }\end{array}$ \\
\hline 4 & Metrics selection & $\begin{array}{l}\text { Depending on the balance selected and on the } \\
\text { additional indexes and analyses of interest, a } \\
\text { variety of metrics must be measured }\end{array}$ & $\begin{array}{l}\text { Specific for Net } \\
\text { ZEB }\end{array}$ \\
\hline 5 & Data reduction & $\begin{array}{l}\text { Derivation of required metrics by indirect } \\
\text { measurements or through estimation (e.g., from } \\
\text { literature data) }\end{array}$ & $\begin{array}{l}\text { Specific for Net } \\
\text { ZEB but dependent } \\
\text { on the building }\end{array}$ \\
\hline
\end{tabular}


6 Data collection frequency and measurement duration

7 Identification of suitable sensors and data acquisition system
Long time measurements for the assessment of Specific for Net the yearly balance and e.g. monthly load match. ZEB Data recording intervals shorter as they influence the load match

The selection of instruments depends on the metric and data collection frequency.
Specific for Net ZEB but dependent on the building.

Table 3-4 List of the steps for the implementation of a M\&V protocol for Net ZEBs in the installation phase.

\begin{tabular}{|c|c|c|c|}
\hline & Standard M\&V & M\&V for Net ZEBs & Relevance to Net ZEB \\
\hline 8 & Technical feasibility & $\begin{array}{l}\text { Check if the plan can actually be } \\
\text { implemented }\end{array}$ & $\begin{array}{l}\text { Not specific to Net } \\
\text { ZEBs and dependent } \\
\text { on the building }\end{array}$ \\
\hline 9 & $\begin{array}{l}\text { Recognition and } \\
\text { resolution of metering } \\
\text { gaps }\end{array}$ & Compensating for the unfeasibility & $\begin{array}{l}\text { Not specific to Net } \\
\text { ZEBs and dependent } \\
\text { on the building }\end{array}$ \\
\hline 10 & $\begin{array}{l}\text { Final plan and } \\
\text { installation }\end{array}$ & Planning and installing & $\begin{array}{l}\text { Not specific to Net } \\
\text { ZEBs and dependent } \\
\text { on the building }\end{array}$ \\
\hline 11 & Sensor calibrations & Check sensor accuracy & $\begin{array}{l}\text { Not specific to Net } \\
\text { ZEBs and dependent } \\
\text { on the building }\end{array}$ \\
\hline 12 & Commissioning & $\begin{array}{l}\text { Testing the hardware correct installation } \\
\text { and operation as well data transmission to } \\
\text { the Data Acquisition System }\end{array}$ & $\begin{array}{l}\text { Not specific to Net } \\
\text { ZEBs and dependent } \\
\text { on the building }\end{array}$ \\
\hline
\end{tabular}

Table 5-3 List of the steps for the implementation of a M\&V protocol for Net ZEBs in the operation phase.

\begin{tabular}{|c|c|c|c|}
\hline & Standard M\&V & \multicolumn{1}{|c|}{ M\&V for Net ZEBs } & Relevance to Net ZEB \\
\hline 13 & $\begin{array}{l}\text { Defining data quality } \\
\text { check procedures }\end{array}$ & $\begin{array}{l}\text { Defining approaches to solve missing or } \\
\text { inaccurate data. }\end{array}$ & Not specific to Net ZEBs \\
\hline 14 & Data post-processing & $\begin{array}{l}\text { Net ZEB definition evaluator plus one file } \\
\text { to elaborate data on monthly basis. }\end{array}$ & Specific for Net ZEBs \\
\hline 15 & Standard reporting & $\begin{array}{l}\text { Standard reporting balance and load Specific for Net ZEBs } \\
\text { match results, dependence on } \\
\text { influencing factors, statistics for the } \\
\text { duration of the monitoring campaign. }\end{array}$ \\
\hline 16 & $\begin{array}{l}\text { Planning and } \\
\text { implementing } \\
\text { operation } \\
\text { maintenance }\end{array}$ & $\begin{array}{l}\text { Listing maintenance actions and time } \\
\text { scheduling to guarantee the correct } \\
\text { operation of the monitoring equipment }\end{array}$ & Not specific to Net ZEBs \\
\hline
\end{tabular}




\section{Monitoring energy in Net ZEBs}

\subsection{Introduction}

In this chapter, the M\&V protocol steps presented in chapter 3 specific for Net ZEBs are described in details. Specifically:

- A standard diagram for the representation of building systems and flows (see step 2 in subchapter 3.1.1) is described and some example application shown.

- Monitoring boundaries are set (step 3 in subchapter 3.1.1) on the basis of the objectives identified.

- Metrics are selected based on important criteria for the development of a Net ZEB definition (step 4 in subchapter 3.1.1).

- Time resolution is investigated from the point of view of measurement duration, sampling and recording time (step 6 in subchapter 3.1.1).

- An overview is given of available sensors for different metrics and data accuracy required by the monitoring system (step 7 in subchapter 3.1.1).

- A standard report for Net ZEB is described in chapter "6 Data post-processing and standard reporting" (step 15 in subchapter 3.1.3).

\subsection{Template for building data collection}

The description of a building for the verification of the Net Zero Energy target should point out the energy flows occurring from, to and within the building. As Net ZEB definitions can differ, thereby involving different energy flows, a comprehensive scheme was developed in MS Visio (Figure 4-1). The aim is to enable the illustration of different buildings from the point of view of energy production and subsystems, for the most current applied solutions. The comprehensive scheme can then be reduced to focus on specific energy flows depending on the objective to accomplish (e.g., balance check, load match evaluation and further energy performance figures). The building is delimited by a dash brown line. Within these borders, the light blue area indicates the physical technical rooms in a building where, usually, the following systems are located:

- Heating systems,

- Cooling systems,

- Domestic Hot Water (DHW) systems,

- Centralized air handling units,

- Cogeneration units,

- Storage systems,

- Renewable energy systems,

- Plumbing connecting different technical building subsystems 
IEA SHC/ECBCS Task 40/Annex 52 - Towards Net Zero Energy solar Buildings $M \& V$ protocol for Net ZEB. A technical report of STA

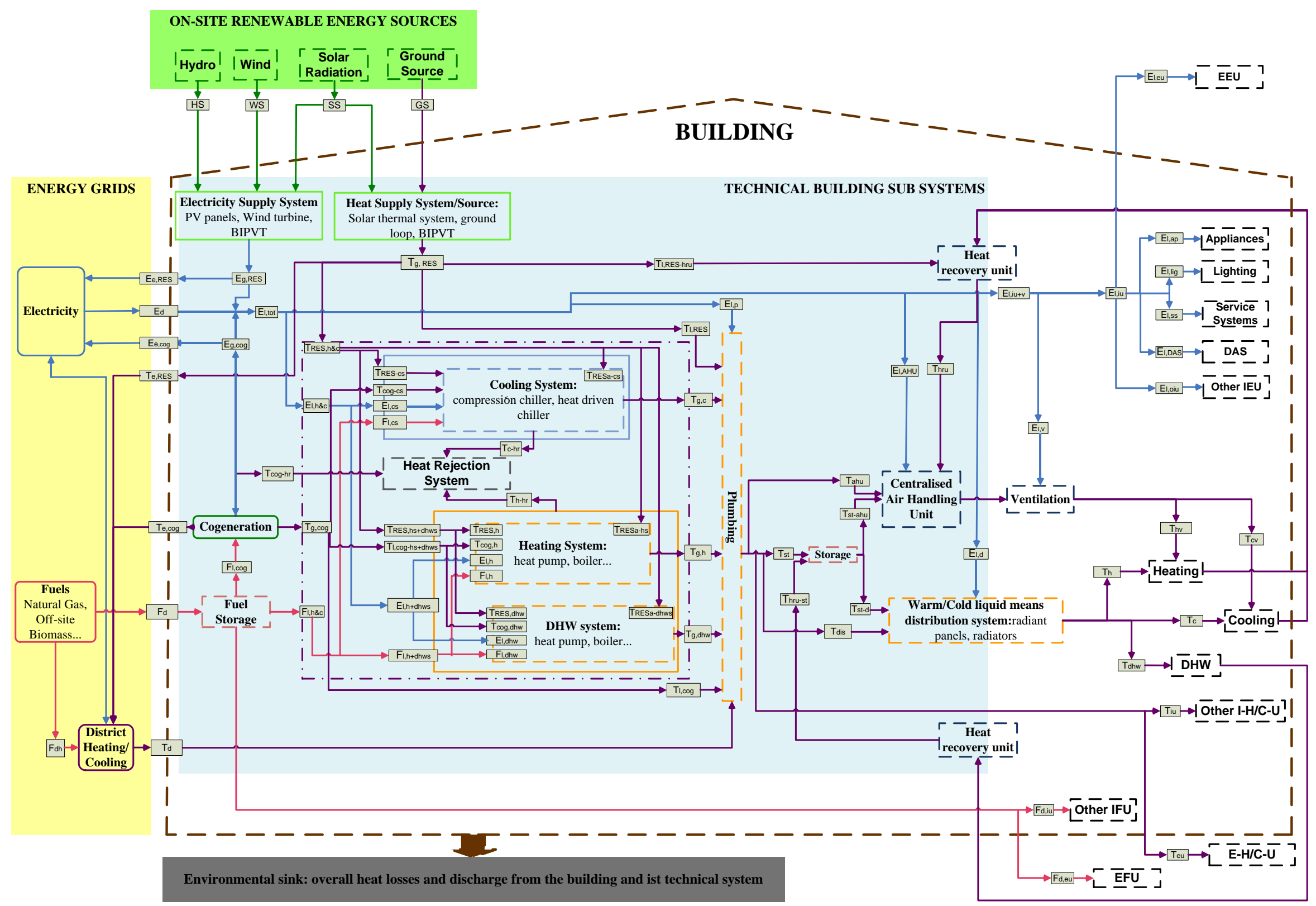

Figure 4-1. Standard reference diagram for monitoring 


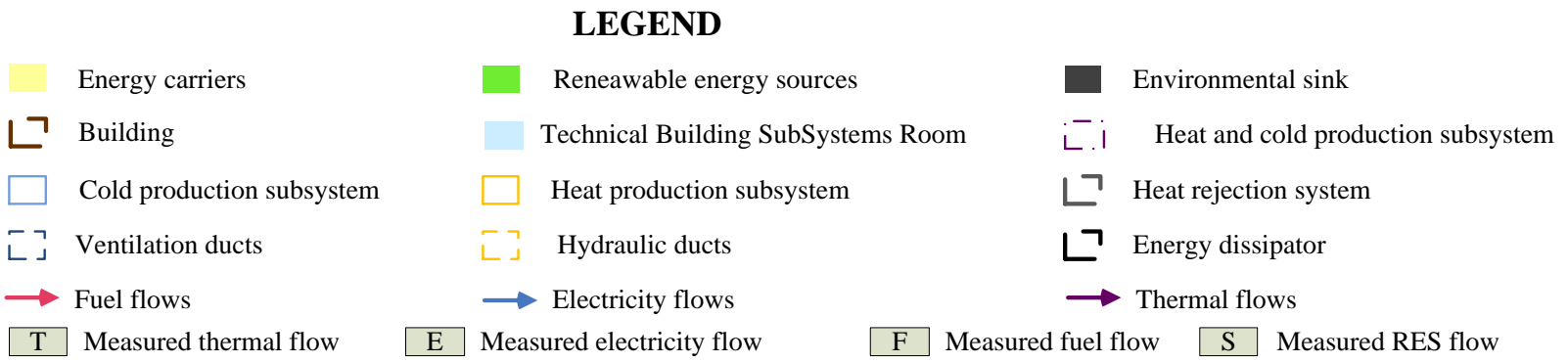

[Öther IEU | Other Internal Electricity Use (e.g. electrical cooking, lift...)

Ōther $\overline{\mathbf{I}-\mathrm{H}} / \overline{\mathbf{C}-\mathrm{U}} \mid$ Other Internal Heat/Cold Use (e.g. process heat...)

Other IFU| Other Internal Fuel Use (e.g. cooking)

ᄂEEE $\neg \quad$ External Electricity Use (e.g. vehicles, external lighting...)

LE- $\overline{\mathbf{H} / \mathbf{C}}-\overline{\mathrm{U}} \mathbf{I} \quad$ External Heat/Cold Use (e.g. snow melting)

EEFU I External Fuel Use (e.g. heating...)

$\begin{array}{ll}\text { E } & \text { Electricity } \\ \text { F } & \text { Fuel } \\ \text { HS } & \text { Hydro Source } \\ \text { RES } & \text { Renewable Energy System } \\ \text { SS } & \text { Solar Source } \\ \text { T } & \text { Thermal energy } \\ \text { WS } & \text { Wind Source } \\ \text { GS } & \text { Ground Source } \\ \text { ahu } & \text { air handling unit } \\ \text { ap } & \text { appliances } \\ \text { c } & \text { cooling }\end{array}$

$\begin{array}{ll}\text { cog } & \text { cogeneration } \\ \text { cs } & \text { cooling system } \\ \text { cv } & \text { cooling from ventilation } \\ \text { d } & \text { delivered } \\ \text { dhw } & \text { domestic hot water } \\ \text { dhws } & \text { domestic hot water system } \\ \text { dis } & \text { distribution } \\ \text { e } & \text { export } \\ \text { eu } & \text { external use } \\ \text { g } & \text { generation } \\ \text { h } & \text { heating }\end{array}$

$\begin{array}{ll}\text { hs } & \text { heating system } \\ \text { h\&c } & \text { heat\&cold } \\ \text { hru } & \text { heat recovery unit } \\ \text { hv } & \text { heat from ventilation } \\ \text { iu } & \text { internal use } \\ \mathbf{l} & \text { load } \\ \text { lig } & \text { lighting } \\ \text { oiu } & \text { other internal uses } \\ \text { ss } & \text { service systems } \\ \text { st } & \text { storage } \\ \mathbf{v} & \text { ventilation } \\ \text { ws } & \text { wind source }\end{array}$

Each system is a rectangle delimited by dash lines:

- The orange rectangle includes the "Heating system" and the "DHW system" where the equipment used to produce heat and DHW are listed for each project. If the same equipment is used for heating and DHW the two boxes can be joined and the necessary measurements reduced.

- The light blue rectangle includes the "Cooling system" where the equipment used to produce cooling have to be listed for each project.

The diagram is meant as a physical, not actual, illustration of the energy systems installed in the building and of the energy flows which are transferred from one system to another, and from the overall building to the external energy infrastructure. It is not aimed at representing the actual layout of the energy facility, but the physical input/output for each component, i.e. energy carrier for each component.

From this point of view the diagram enables the representation of different technologies for the various final uses. For technical subsystems, besides conventional technical subsystems 
(e.g., gas boiler, heat pumps, compression chillers), the following technologies can be represented:

- Thermally driven chillers and heat pumps,

- Ground and solar source heat pumps,

- Building integrated thermo-photovoltaic systems,

- Cogeneration units,

- Heat recovery from drain water and exhaust air.

Only the final uses relevant to the operation and the occupancy of the buildings are described (possible industrial uses are excluded). Final uses are represented by black dash line boxes and they are located in the white area on the right of the diagram. Final uses include:

- Heating and Cooling: terminals of distribution systems are shown at the border with the technical room (radiators, radiant panels),

- DHW,

- Ventilation (e.g., local fans),

- Lighting,

- Appliances,

- Service systems (e.g. electricity driven systems providing occupants with services: building control system),

- BEM (Building Energy Management for building controlling and data acquisition system to gather data) for continuous commissioning purposes,

- Other Internal Electricity Use (e.g., lift),

- Other Internal Heat/Cold use

- Other Internal Fuels Use (e.g., gas cooking)

The diagram also enables to illustrate flows produced or stored in the building (azure area) and then are used for external uses or for the neighborhood. For these reasons external loads have been added to the diagram, such as:

- External Electricity Use: e.g., vehicles, external lighting

- External Heat/Cold use: e.g., snow melting

- External Fuel Use: e.g., fuel stored in the building and given for external users.

The distinction between the light blue and white areas is not strict, as some technical building subsystems can be either located in the technical rooms or in the useful spaces as well (e.g. some mechanical ventilation components or flow distribution systems). For these reasons it has been decided to differentiate between:

- Centralized Air Handling Unit: it refers to the centralized Air Handling Units (AHU) that moves the air throughout the building;

- Ventilation: it refers to local mechanical return and supply ventilation which is carried out directly in the useful rooms of the building (e.g., it may include local fans). 
Another distinction is between:

- Plumbing: hydraulic pipes connecting the heating, cooling and DHW producing systems to the storage or to the distribution system. This box is also used to indicate the case where all the heat flows are mixed in some T-pipes, hydraulic junctions or collectors.

- Warm/cold liquid through distribution system: hydraulic pipes from the storage or plumbing to the heating/cooling final distribution points in the building (e.g. radiators, fan coils, radiant floors).

In case the heat and cold supply systems are directly connected to the heating/cooling terminals, bypassing also the storage, the two loops coincide. No measurements between the two boxes is needed. The yellow area on the left of the diagram represents the local energy suppliers which deliver/receive energy to/from the building. The green area shows the renewable energy sources available on the building site:

- Hydropower

- Wind

- Solar radiation

- Ground

The availability of renewable sources can be measured with special sensors like pyranometers for solar radiation or anemometers for wind availability. Usually such sensors are part of weather stations, which often includes further sensors (e.g., temperature, humidity). With respect to the ground heat source, standard available weather data are not useful and only estimates of the heat that can be extracted are usually possible. However, in some cases, it is also possible to locate a heat meter in the ground pipe loop for measuring the harvested energy and to install temperature sensors in the ground to estimate the energy content. For such occurrences a specific measurement point must be added. Biomass is considered a renewable source but it is usually a fuel purchased from an external supplier. For this reason it has been decided to list it in the fuel supplier box. The fact that it is renewable will be considered in the selection of a proper crediting factor which should also include the fact that the fuel is produced somewhere far from the building.

With respect to the arrows drawn in the diagram in Figure 4-1, the following labels are used:

- Purple lines indicate hot / cold flows,

- Blue lines indicate electricity flows,

- Pink lines indicates fuels flows.

The labeled small grey filled-in boxes identify energy or fuel flows that can be measured, they do not indicate sensor position. To complete the diagram from energy balance point of view, all losses (e.g., from energy conversion, distribution, regulation) should also be included. On the other hand, heat rejection to air from chimney or cooling tower should be represented but since these measurements are typically not carried out, they have not been shown to avoid unnecessary complexity or confusion. One grey area named "sink" has been drawn at the bottom of the diagram and has been connected to the overall building with a brown line to include all the heat losses and rejections.

Some applications of the diagram are shown in the following pages (Figures 4-2 to 4-8) and summarized in Table 6-1. They illustrate relevant buildings already monitored and connected within the authors of the present report. The sensor colors in the examples below indicate the following:

- Orange fill: sensors actually installed 
- Grey fill with black borders: sensors needed to assess system operation, but not installed

- Grey fill with red borders: additional sensors that would have been nice to install for additional evaluation, but were not installed (e.g., not physically installable)

Table 6-1. List of the surveyed buildings

\begin{tabular}{|l|l|l|}
\hline Name of the project & Location & Name of the institution for the analysis \\
\hline Plusenergy houses Weiz & Austria -City of Weiz & $\begin{array}{l}\text { AEE- Institute for Sustainable Technologies } \\
\text { (Austria) }\end{array}$ \\
\hline SNEH & Gleisdorf (Austria) & $\begin{array}{l}\text { AEE- Institute for Sustainable Technologies } \\
\text { (Austria) }\end{array}$ \\
\hline EcoTerra Alouette & $\begin{array}{l}\text { Eastman (Québec), } \\
\text { Canada }\end{array}$ & Concordia University, Hydro-Québec \\
\hline EnergyFlexHouse & Taastrup, Denmark & Danish Technological Institute \\
\hline EnerPos Building & $\begin{array}{l}\text { Saint-Pierre, Reunion } \\
\text { Island, France }\end{array}$ & $\begin{array}{l}\text { LPBS (Laboratory of Building Physics and } \\
\text { Systems) - University of Reunion Island }\end{array}$ \\
\hline $\begin{array}{l}\text { Plusenergy settlement } \\
\text { Freiburg }\end{array}$ & Freiburg, Germany & $\begin{array}{l}\text { University of Wuppertal, Department of } \\
\text { Architecture, Buildings physics and } \\
\text { Technical Services }\end{array}$ \\
\hline Naturalia Bau & Sinigo, Italy & EURAC \\
\hline
\end{tabular}


IEA SHC/ECBCS Task 40/Annex 52 - Towards Net Zero Energy solar Buildings M\&V protocol for Net ZEB. A technical report of STA

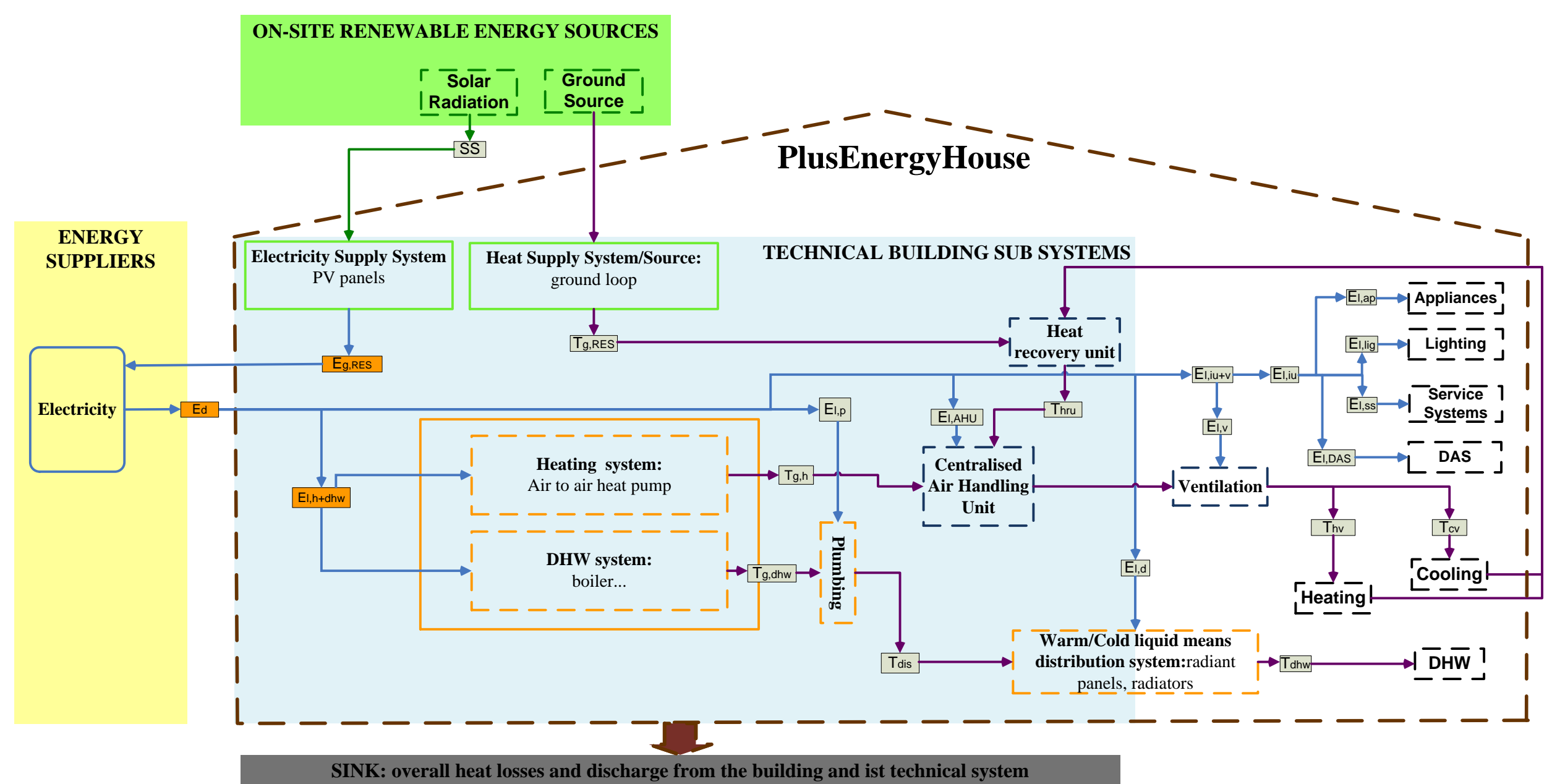

Figure 4-2. Monitoring diagram of the commercial building PlusEnergyHouse Weiz, Austria. Orange boxes indicate measured energy flows 
IEA SHC/ECBCS Task 40/Annex 52 - Towards Net Zero Energy solar Buildings $M \& V$ protocol for Net ZEB. A technical report of STA

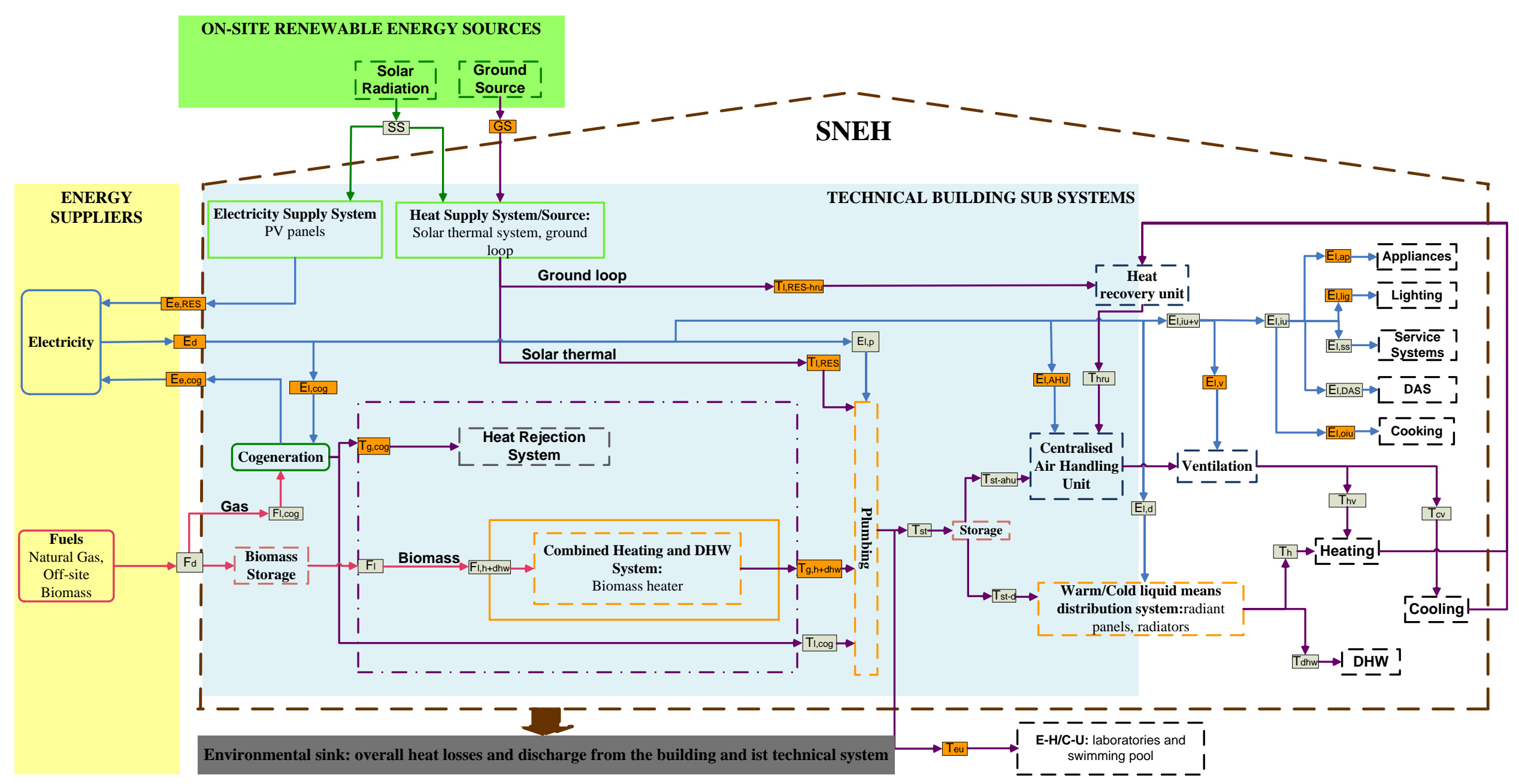

Figure 4-3. Monitoring diagram of the commercial building SNEH, office building in Gleisdorf, Austria. Orange boxes indicate measured energy flows. 
IEA SHC/ECBCS Task 40/Annex 52 - Towards Net Zero Energy solar Buildings $M \& V$ protocol for Net ZEB. A technical report of STA

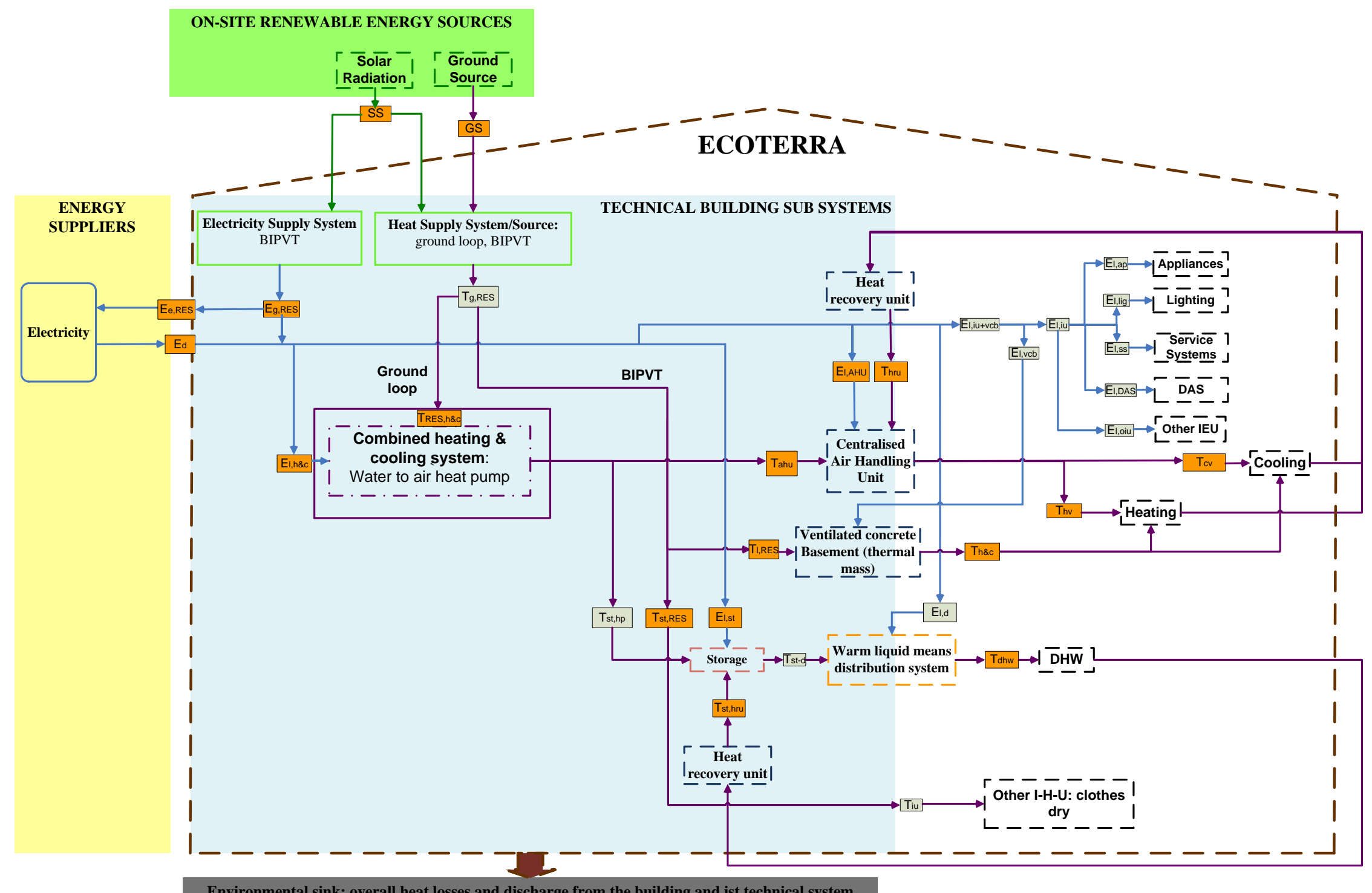

Figure 4-4. Monitoring diagram of the residential building ECOTERRA in Eastman, Canada. Orange boxes indicate measured energy flows. 
IEA SHC/ECBCS Task 40/Annex 52 - Towards Net Zero Energy solar Buildings $M \& V$ protocol for Net ZEB. A technical report of STA

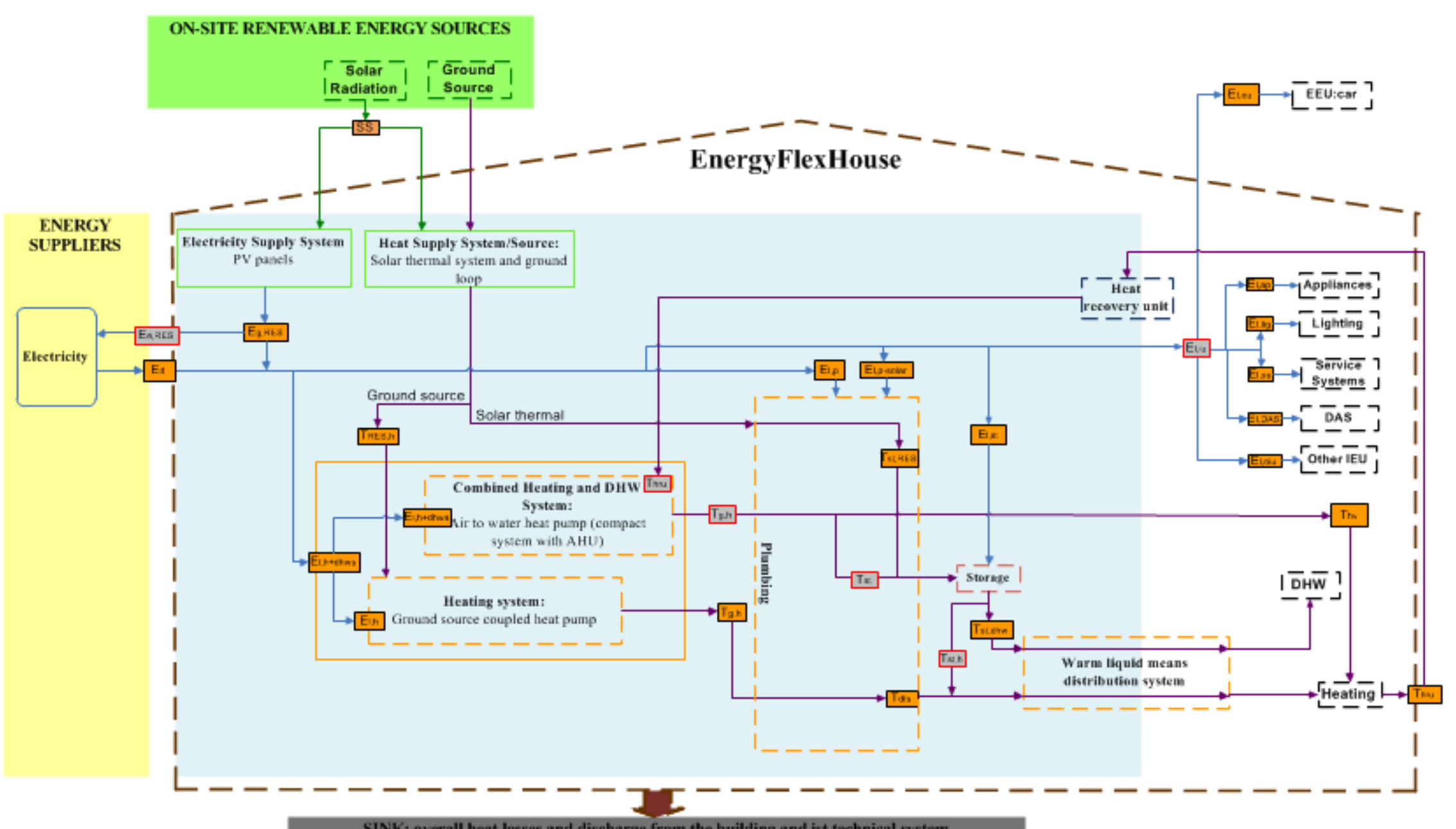

Figure 4-5. Monitoring diagram of the residential building EnergyFlexHouse, Taastrup, Denmark. Orange boxes indicate measured energy flows. 


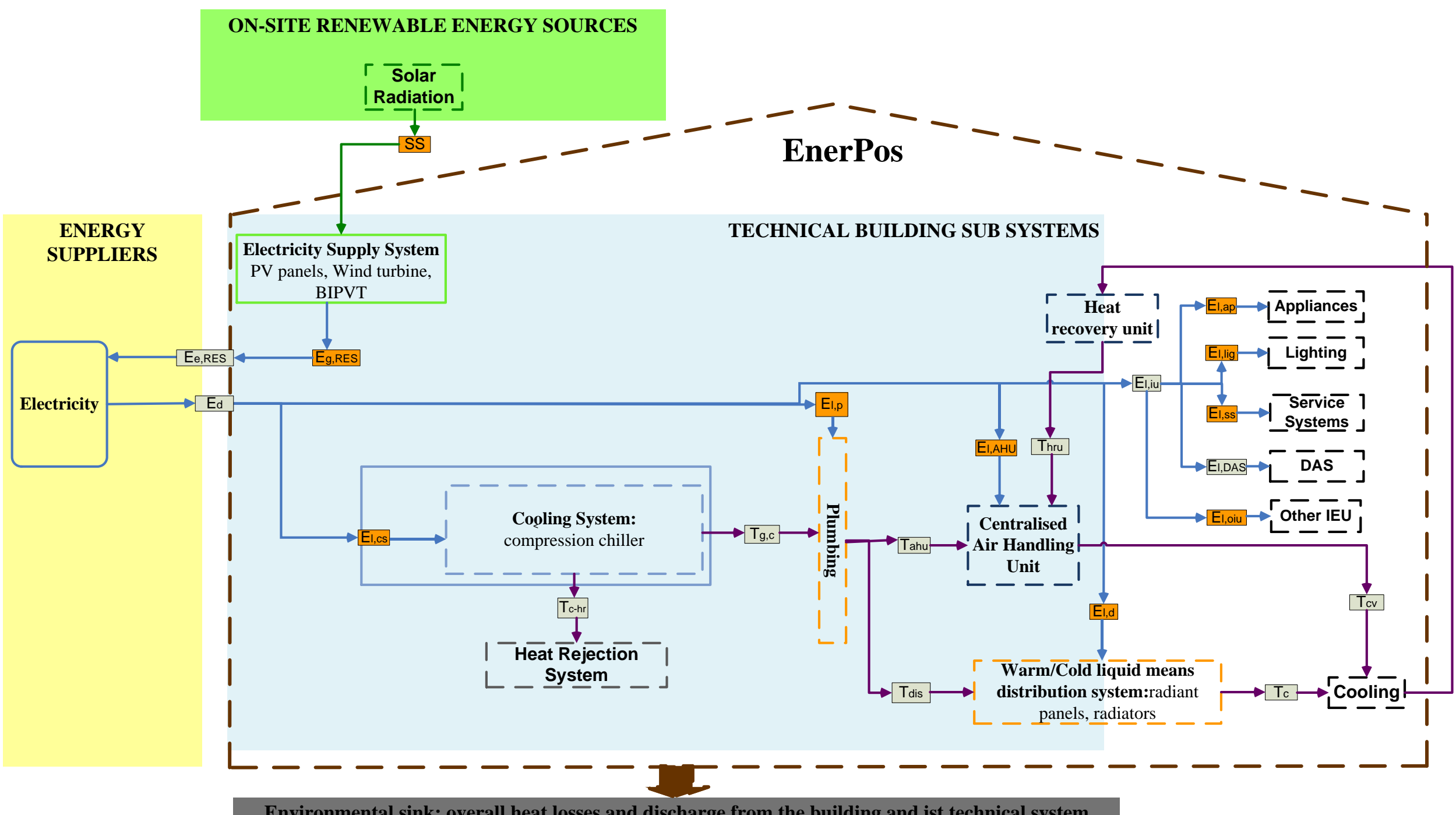

Environmental sink: overall heat losses and discharge from the building and ist technical system

Figure 4-6. Monitoring diagram of the commercial building la EnerPos, St. Pierre La Reunion, France. Orange boxes indicate measured energy flows. 
IEA SHC/ECBCS Task 40/Annex 52 - Towards Net Zero Energy solar Buildings $\mathrm{M} \& \mathrm{~V}$ protocol for Net ZEB. A technical report of STA

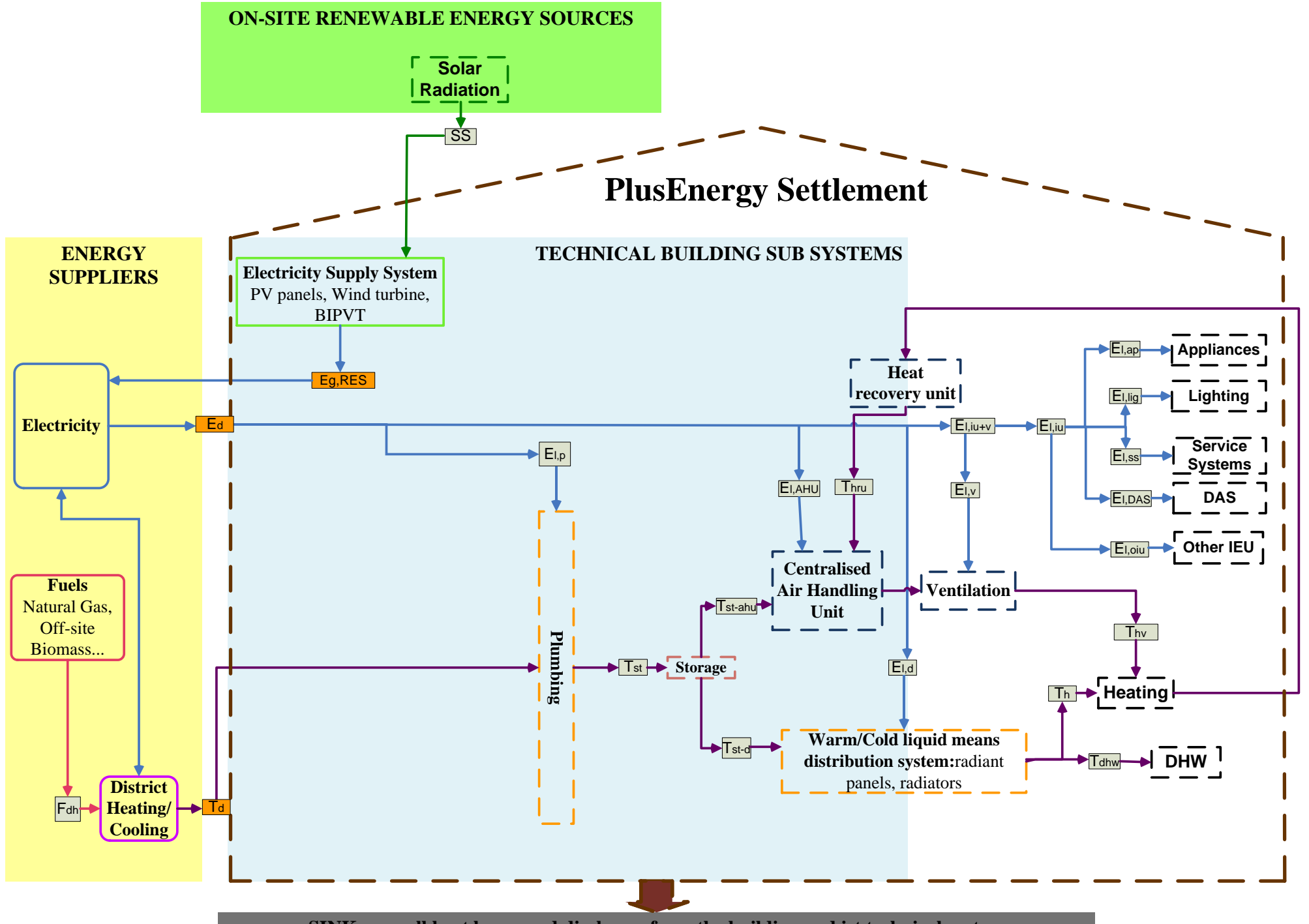

SINK: overall heat losses and discharge from the building and ist technical system

Figure 4-7. Monitoring diagram of the commercial building Plus Energy Settlement, Freiburg, Germany. Orange boxes indicate measured energy flows. 
IEA SHC/ECBCS Task 40/Annex 52 - Towards Net Zero Energy solar Buildings M\&V protocol for Net ZEB. A technical report of STA

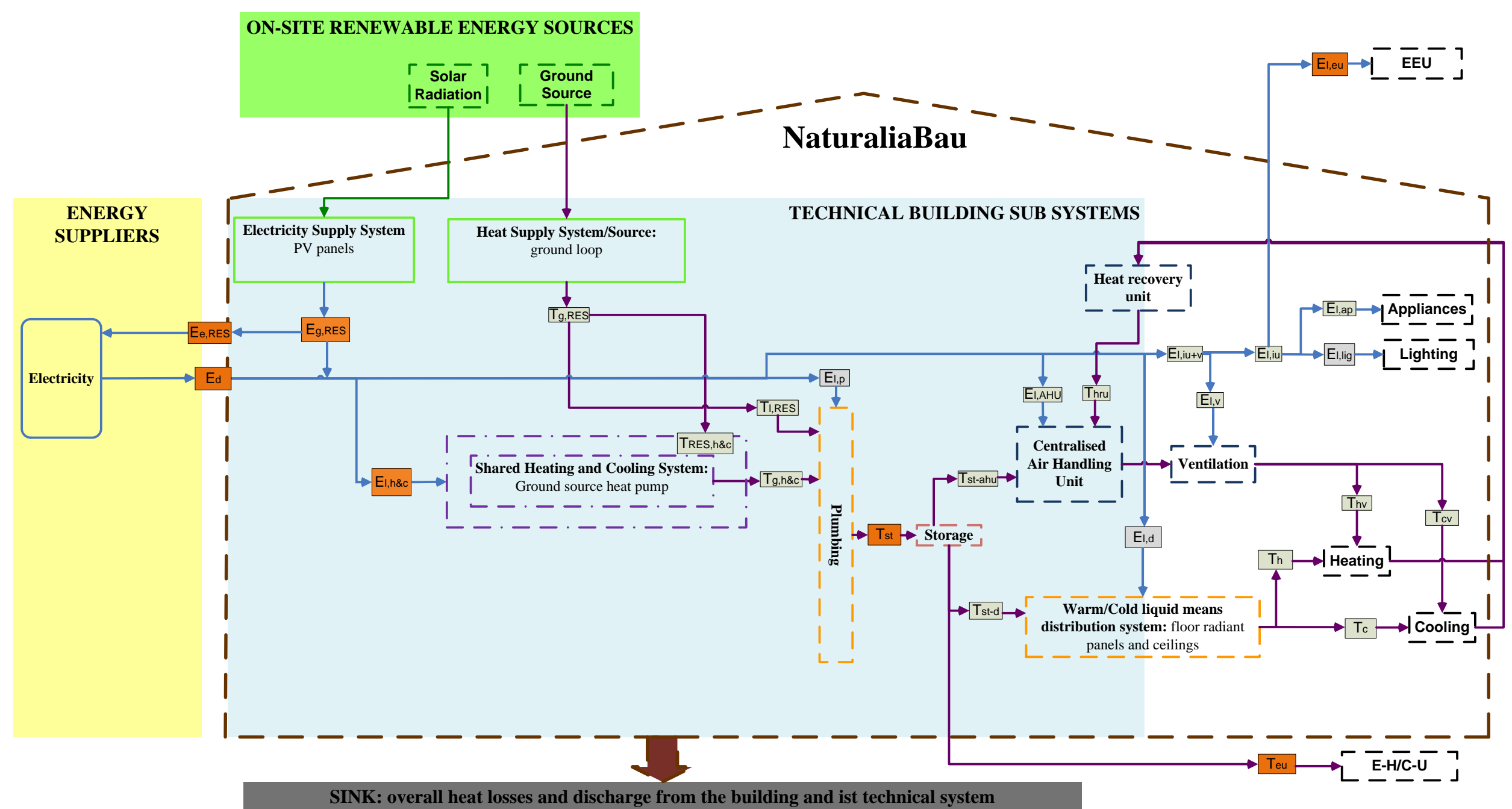

Figure 4-8. Monitoring diagram of the commercial building Naturalia Bau, Bolzano, Italy. Orange boxes indicate measured energy flows. 


\subsection{Metrics}

\subsubsection{Overview on Net ZEB definitions}

As already discussed in chapter 2, the implementation of a M\&V process to check Net ZEBs is strictly dependent on the applied Net ZEB definition. This chapter focuses on the relationship between monitoring settings (i.e., metrics, data collection frequency and measurement duration), and the criteria for Net ZEB definitions reported in Sartori et al. (2012). Most definitions applied in case studies refers to primary energy (Bourrelle et al., 2010), while rarely definitions on $\mathrm{CO}_{2}$ emissions and costs are also used. To verify the balance associated with the definitions, it is necessary to multiply selected energy flows for defined primary energy conversion factors or emission factors. Hence, the unit of the balance does not influence the monitoring procedure and the specific energy flows to be measured.

The selection of metrics mostly depends on the physical and balance boundaries (Sartori et al., 2012). Marszal et al. (2010) has shown that "the most accepted energy balance takes place between the energy use of a building and the renewable energy generation". This kind of balance can be easily applied in the design phase, where calculation of single building demand (e.g., heating, cooling, DHW, ventilation, lighting, appliances) and potential energy supply from renewable energy systems are already established in national building codes or international standards. From a monitoring perspective, the check of such balance requires a great effort as all items of the demand and the supply should be measured. According to Marszal et al. (2010) the German case (Figure 4-7) clearly addresses the balance between the delivered and exported energy. The delivered/exported balance is the easiest to check from a monitoring point of view, since the measurements should focus on the energy flows occurring between the building and the outside energy infrastructure. Subchapters 4.3.2 and 4.3.3 describe possible M\&V for Net ZEB with respect to the "load/generation balance" and the "import/export balance" and show the advantages to refer to the second balance for monitoring. An M\&V process for Net ZEB is also dependent on the balancing period and the time resolution required by additional descriptive figures, like the load match. According to Marszal et al. (2010) in many calculation methodologies the balance is yearly based. This means that the measurements lasting several years and data stored on yearly basis are sufficient to calculate the balance. If the Net ZEB definition includes the assessment of the load match index, monthly measurements will also be required. Nevertheless the sampling time can be shorter, as will be explained in subchapter 4.4.

\subsubsection{Metrics selection for Net ZEB definitions based on "load/generation" balance}

According to Sartori et al. (2012) the "generation/load" balance is

$$
\sum_{i} g_{i} \cdot w_{e, i}-\sum_{i} l_{i} \cdot w_{d, i}=G-L \geq 0
$$

where $g$ and / stands for generation and load, respectively; $w$ stands for weighting factor and $i$ for energy carrier. $G$ and $L$ stands for weighted generation and load, respectively. Additional discussion on the basis for selecting the weights can be found on Sartori et al. (2012).

Most methodologies consider in the balance all the energy loads including heating, cooling, DHW, ventilation, lighting, auxiliaries, cooking, appliances and other energy uses related to the building users. Hence, according to most calculation methodologies, renewable energy sources (RES) generation must be able to match the overall energy uses in the building on a yearly basis. Because all loads are considered in this approach, most technical building 
subsystems and the occupied building can be included in a grey area, as represented in Figure 4-9.

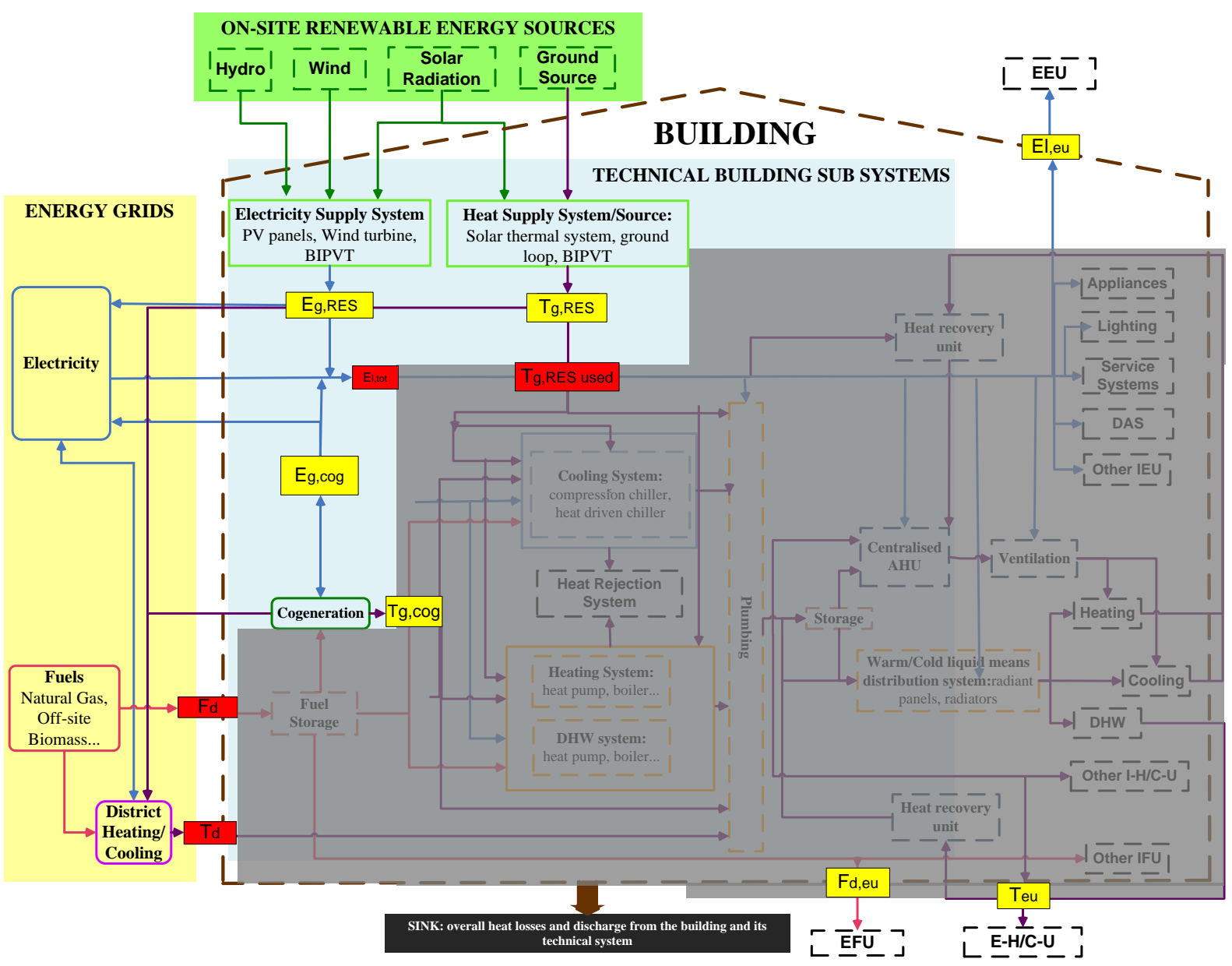

Figure 4-9. Boundary for Net ZEB definitions based on the balance between generation and load

To check the balance load/generation, the overall energy supplied by the technical building systems should be measured, i.e.:

- Electricity: $E_{g, R E S}$ and $E_{g, c o g}$

- Thermal energy flows: $T_{g, \text { RES }}$ and $T_{g, c o g}$

The load is given by the following flows:

- Electric: $E_{1, t o t}$

- Thermal: $T_{\text {gRES, used }}$ and $T_{d}$

- Fuels: $F_{d}$

Please note that in case the technical building subsystems supply energy to external services or to the local energy suppliers, the relevant energy uses should be measured as well. Such energy uses concern the flows entering the grey area (thereby metered as consumption) but are then delivered to external users, thus not serving the building. 
- External Electricity Use (EEU): $\mathrm{E}_{\mathrm{l}, \mathrm{eu}}$

- External Heat/Cold Use (E-H/C-U): $T_{\text {eu }}$

- External Fuel Use (EFU): $F_{\mathrm{d}, \mathrm{eu}}$

In case the entire production from solar thermal systems is completely exploited within the grey area (i.e. $T_{\text {g,RES }}=T_{\text {gRES, used, }}$ ), it is not necessary to measure it. Note that the two amounts are the same if they are measured at the same point, i.e. after the heat exchanger between the primary and solar loop or after the tank. Under these hypotheses, the $T_{g, R E S}$ measurement can be avoided, as it would appear twice in the same balance but with opposite sign. Furthermore, usually the heat coming from solar thermal collectors is directly used to match the heat/DHW load. Analogously, the electricity generated from RES is, instead, directly employed in technical building subsystems (e.g., lighting or heating system). Therefore, for example, since the solar contribution typically reduces the real external energy input to the heating and DHW systems, it is often considered as a heat efficiency measure. In case part of $T_{g, R E S}$ is exported to a district heating two sensors are needed: one to measure the real input to the grey area ( $\left.T_{\text {gRES,used, }}\right)$ and one to measure the overall production $\left(T_{g, R E S}\right)$. An example of such metrics selection is the EnerPos building in La Reunion (Figure 4-6). This building has the proper sensors to compare the building energy loads (for cooling, plumbing, appliances, lighting, service systems and other electricity uses) and the energy production (supplied by the PV system), without measuring the delivered and exported energy.

\subsubsection{Selection of metrics for Net ZEB definitions based on "delivered/exported energy" balance}

In this approach the balance is calculated based on the delivered and exported energy; the boundary is the overall building as shown in Figure 4-10. Similarly to Eq. 1, the balance can be calculated with the following equation:

$$
\sum_{i} e_{i} \cdot w_{e, i}-\sum_{i} d_{i} \cdot w_{d, i}=E-D \geq 0
$$

where $e$ and $d$ represents exported and delivered energy, while $w_{e}$ and $w_{d}$ are the applied weights to each energy carrier. $E$ and $D$ stands for weighted generation and load, respectively. From the point of view of energy flows, the following relationships are valid for each energy carrier:

$$
\begin{array}{cr}
l(i)=d(i)+x(i) & \underline{\text { Eq. } 3} \\
g(i)=e(i)+y(i) & \underline{\text { Eq. } 4} \\
g(i)-l(i)=e(i)+y(i)-(d(i)+x(i))=e(i)-d(i)+z(i)=e(i)-d(i) & \text { Eq. } 5
\end{array}
$$

In the equations above, where $\mathrm{I}$ is load, $\mathrm{g}$ is generated, $\mathrm{d}$ is delivered, $\mathrm{e}$ is exported and $\mathrm{x}$ (or $y$ ) is the self-consumption of the generated energy ${ }^{1}$. Thereby monitoring exported/delivered

\footnotetext{
${ }^{1}$ Here $g$ is meant as useful generation, net of possible storage and have $x=y$, and $z=y-x=0$. The equivalence is also true, obviously, for buildings without storage options; where the self-consumption is simply given by simultaneity between load and generation.
} 
energy or generation/load balance is equivalent. Please note that the single items (I and $\mathrm{d}$ or $g$ and e) are not equal as they differ for the self-consumption and that the balance does not output the same results if asymmetric weighting factors are used. Nevertheless, the monitoring approach aiming at checking the balance of delivered/exported energy is more feasible. The following measurements are necessary in this approach (Figure 4-10):

- Delivered energy (red highlighted sensors in Figure 4-10): $E_{d}, F_{d}$, and $T_{d}$;

- Exported energy (yellow highlighted sensors in Figure 4-10): $E_{e, R E S}, E_{e, c o g}, T_{e, R E S}$, $\mathrm{T}_{\mathrm{e}, \mathrm{cog} \text {. }}$

- External energy uses (also in yellow highlighted sensors in Figure 4-10): $E_{l, e u}, F_{d, e u}$, $\mathrm{T}_{\text {eu }}$

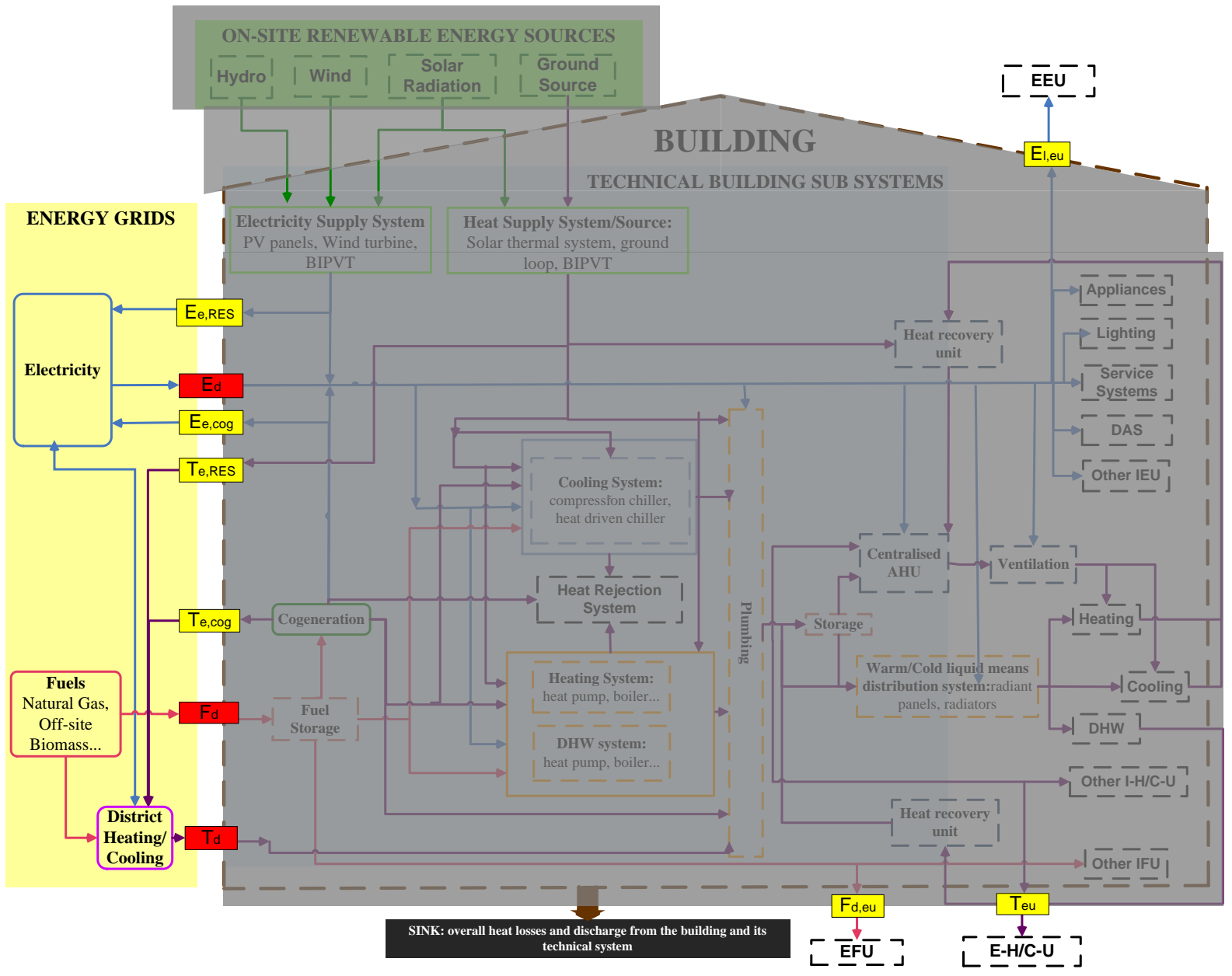

Figure 4-10 Boundary for Net ZEB definitions based on the balance "delivered/exported energy"

This balance verification approach is shown in Figure 4-7 where only delivered and exported energy measurements are performed to check the balance. Actually, the particular German regulation on the PV installations leads to the fact that the overall electricity use for different technical building subsystems is entirely accounted in the electricity delivered to the building from the grid. So the delivered electricity is actually the overall electricity use. This would not happen in a building where only part of the PV electricity feeds into the grid (Figure 4-5 and Figure 4-8). In these cases the overall electricity use is the sum of the electricity acquired from the grid and the electricity produced by on site RES and used directly in the building.

As already stated, the load/generation energy balance coincides with the delivered/exported balance only if all the energy uses are considered in the definitions. If selected energy uses 
are included, sub-metering is needed. An example is the current Italian regulation for the primary energy calculation. Such calculation is carried out considering the energy uses for heating, cooling, DHW, auxiliaries and lighting. Thereby, it would be needed to measure all the energy uses due to the listed services (but not others) to check a definition. So far only the metrics related to the balance have been discussed. Typically, since additional figures would be needed to verify conformity with a definition, more measurements could be needed. For instance to evaluate the load match index, measurements on generated energy carrier within the physical boundaries are needed even in the case of the balance delivered/exported energy.

\subsection{Data time resolution}

\subsubsection{Measurements duration}

Three categories of measurements exist depending on their duration (Figure 4-11).

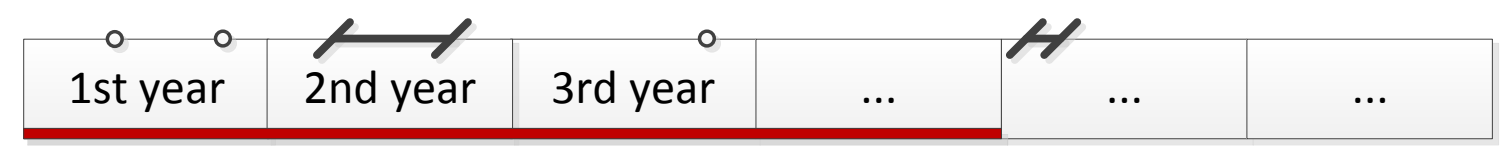

Spot measurements (up to one day)
Short time measurements (from days to months)
Long time measurements (min 1 year)
Building occupancy

Figure 4-11 Measurement duration possible

1. Spot and one time measurements

Spot measurements last short time, up to one day of operation. They are useful to instantaneously detect the value of a metric or to quickly check the functioning of a subsystem. On the other hand, they can be used to derive pieces of information on a longer time span when they are applied to measure time constant metrics. Such measurements can be repeated to obtain the trend over a longer time span of a metric/performance. Spot measurements are usually applied in a sub-metering approach. Some examples are:

- Metering of mass/volume flow through clamp-on ultrasonic flow meters: such a measurement can be useful in heat flows measurements, avoiding invasive metering in ducts, in combination with short or long temperature measurements;

- Metering the amperage of an electricity driven component, such as lighting system or constant speed pumps: the electricity consumption can be then derived by assuming the hours of operation;

- Assessing the PV system performances and failures by thermography under clear sky conditions (Botsaris and Tsanakas, 2010);

- Determining the daily operational characteristics of a device;

- Monitoring by portable unit the parameters influencing occupant thermal comfort;

- Check, adjust and improve the performance of the building and the systems. 


\section{Short term measurements}

Short-term monitoring is carried out to check the profile of metrics varying with time. They are usually on the order of weeks or months and can be applied in a sub-metering or whole building metering approach, for instance:

- To assess the energy savings resulting from the implementation of an efficiency measure with respect to a baseline;

- To evaluate the seasonal performance factor of HVAC equipment (heat pump, chillers, boilers, etc.);

- To assess the thermal comfort conditions;

- Check, adjust and improve the performance of the building and the systems.

\section{Long term measurements}

These type refers to measurements spanning for more than a year. Long term measurements are used to assess metrics influenced by variations in weather, occupant behavior or other operating conditions. Quite often the installation is permanent and are usually applied in a whole building metering approach, for instance:

- Metering energy uses on annual basis to compare several years of application (especially if energy measures are implemented to improve operation);

- Metering the RES energy supply to evaluate the production through the seasons;

- Check, adjust and improve the performance of the building and the systems.

In Net ZEB, the selection of the measurement duration depends on the objective and on the definition. To check the yearly balance, long term measurements are required (minimum one year of operation) to evaluate the performance with respect to different climate conditions across the seasons. The number of years the balance must be assessed could be part of a definition. In monitoring conducted to asses building performances, two years of measurements is typically considered the minimum requirement. The first year enables the evaluation of the balance and, in case the zero balance is not fulfilled, to detect possible malfunction as well as the identification of improvement strategies to reach the balance. Thereby, the second year enables the evaluation of the implemented efficiency measures.

Regardless of the measurement duration, it is recommended to start the monitoring campaign the second or third year of occupancy of the building. For instance the EN 15603 states: "It is recommended that the first one or two years after the erection of the building are discarded. The energy use during the first years is often larger than during the following years for several reasons...

- $\quad$ some additional energy is used to dry the building fabric;

- adjustment of control system may not be perfect from the first day of use

- there may be some faults that are corrected during the first year."

Additionally, there may be a period of adaptation of user behavior to the new building. For the assessment of the load match, at least one year of measurements is necessary. Nevertheless, the load match requires a sampling and recording interval times shorter than the year (at least monthly), as explained below. 


\subsubsection{Sampling and recording time}

The recording interval is meant as the time span at which the data is logged. The recording time can be longer or equal to the sampling interval. The sampling interval is defined as the time which elapses between measurements. It depends on the desired data accuracy, thereby on the monitoring equipment used. In case only the balance needs to be assessed, yearly recording time is sufficient. On the contrary, in order to evaluate the electricity and heat load match, at least monthly generation data, export and delivery are necessary.

\subsection{Monitoring equipment}

The core element of a Net ZEB definition is the energy balance and, one possible definition assess the balance between delivered and exported energy. These energy flows are usually monitored by the grid managers to regulate payments or by the energy service company (ESCO) to substantiate energy efficiency measures and get credits for the building. In some cases, the balance check is possible using the monitoring equipment installed by the grid management companies or external advisors. In this case the sampling interval will be set by the involved companies based on the required data accuracy. The recording time is selected by the monitoring company according to the definition requirements. Thereby, if only the balance needs to be assessed, yearly readings of the installed meters are sufficient. In case the assessment of the load match is needed, at least monthly readings should be carried out, but this depends on the applied meter configuration. Readings can be manual or via external data logger installed by the building owner, depending on the configuration, for instance in combination with electronic electricity meters.

Actually, data could also be acquired by the energy bills in case of electricity or gas grids. However, the recording time used by the energy suppliers and the kind of data (estimated or monitored) could not be adequate for the analysis and may not match the monthly or yearly time span. Thereby, some adjustments could be required influencing the reliability of the results. This usually happens with fossil fuels that are delivered to the building site often not at regular intervals but depending on the storage and consumption rate. This can make the evaluation of the used fuels on desired time spans difficult. In these cases, further measurements could be needed besides those provided by the fuel vendors (e.g., the volume/mass flow at the inlet of the relevant energy system). If sensors must be installed by the monitoring experts a wide variety of options is available. Table 4-2 lists the metering technologies usually utilized for the measurements of energy flows within a building.

Table 4-2: Common sensors for the measurements of energy flows within a building

\begin{tabular}{|l|l|}
\hline Type of meter & \multicolumn{1}{|c|}{ Technique } \\
\hline Electricity & $\begin{array}{l}\text { Electronic meters } \\
\text { Electromechanical induction meters }\end{array}$ \\
\hline Gas & $\begin{array}{l}\text { Positive displacement flowmeters: diaphragm or bellows meters } \\
\text { Coriolis flowmeters } \\
\text { Thermal mass flowmeters }\end{array}$ \\
\hline Solid flow & $\begin{array}{l}\text { Conveyor based methods } \\
\text { Free fall solid measurement } \\
\text { Detectors of the level of solids in tanks (radar, microwaves, acoustic sensors) }\end{array}$ \\
\hline Liquid flow & $\begin{array}{l}\text { Electromagnetic flowmeters } \\
\text { Ultrasonic flowmeters } \\
\text { Vortex-shedding flowmeters } \\
\text { Differential pressure (obstruction-type) meters: orifice plate, Venturi tube, flow } \\
\text { nozzle and Dall flow tube, Pitot static tube } \\
\text { Turbine meters }\end{array}$ \\
\hline
\end{tabular}


IEA SHC/ECBCS Task 40/Annex 52 - Towards Net Zero Energy solar Buildings

$M \& V$ protocol for Net ZEB. A technical report of STA

\begin{tabular}{l|l} 
Heating and & \multicolumn{2}{|l}{ Liquid flowmeters } \\
cooling & $\begin{aligned} \text { Temperature sensors: } \\
\bullet \quad \text { Thermoelectric effect sensors (thermocouple) } \\
\end{aligned}$ \\
& $-\quad$ Varying resistance devices: resistance thermometers, thermistors
\end{tabular}




\section{Monitoring Indoor Environmental Criteria (IEQ)}

The recast of the European Energy Performance of Buildings Directive (EPBD) was approved in May 2010. Article 2 states that all Member States must guarantee that by 2020 all new buildings have to be nearly zero energy buildings. Furthermore, Article 4 specifies that minimum energy performance requirements "shall take account of general indoor climate conditions, in order to avoid possible negative effects such as inadequate ventilation [..]".

Besides the requirements arising from the EPBD (that have to be implemented on national level) an increasing number of net zero energy or plus energy buildings is been already realized on "voluntary" basis. The core idea of all these building concepts is the balance between energy generation and consumption. The assessment of the performance seems to be straightforward: the generation must be equal to or exceed the required energy (demand). How this energy balance could be checked and verified is dealt with in the above chapters. However, recommendations for comfort criteria for Net ZEBs are also necessary as described in "Comfort and Energy Recommendations for Net Zero Energy Buildings - Internal Report A1-7" (Sartori, 2009). These comfort aspects are evaluated in the following sections.

\subsection{Purpose}

This chapter contributes to the verification procedures of nearly zero, zero energy or plus energy buildings and includes:

- Identification of indoor environmental quality (IEQ) indicators affecting comfort and the energy balance with associated alignment procedure

- Discussion of monitoring approaches and strategies for sensor position and level of monitoring effort that could be applied to Net ZEB verification procedure.

\subsection{Scope}

The scope of this chapter is to specify the range of IEQ indicators that must be measured in order to verify the net zero balance and to additionally assure that acceptable comfort conditions are present in the building.

\subsection{Recognitions}

Currently IEQ monitoring is not a naturally common procedure during commissioning phase of a building. It is mainly used for demonstration projects, to check performance indicators required by funding authorities or it is required by a few ambitious building operators. The IEQ monitoring implies a great level of performance measurements, causing a significant effort regarding instruments, procedures and subsequent evaluation. Existing standards for indoor thermal environmental like the ASHRAE Standard 55-2010, the EN ISO 7730, the EN 15251 or the ASHRAE Standard 189.1 should also be checked.

Increasingly popular building rating systems and integrated verification procedures include strict IEQ criteria like "LEED"2 with the action step "IEQc7.2"3 or "TQB" and promote the inclusion of IEQ in the verification process. However, as there is no public interest in monitoring indoor comfort and air quality of public buildings until now, this is not a mandatory

\footnotetext{
${ }^{2}$ www.buildinggreen.com/auth/article.cfm/2010/11/8/Your-guide-to-the-New-Draft-of-LEED-2012-public-comment-USGBC/

${ }^{3}$ www.leeduser.com

4 "TQB" is the abbreviation for "Total Quality Building" - Assessment that is promoted by the Austrian Association for Sustainable Building Construction. A lot of other building assessment methods in Austria base on that or are linked with it. www.oegnb.net
} 
procedure. The indoor environment is mentioned in the "EBPD" (Directive EU 31/2010) although currently the majority of countries has no firm legislative framework to check comfort criteria and energy balance.

Increasing application of emerging technologies like smart meters and building management systems should bring detailed observation of electric and thermal energy flows; however, the data recorded or IEQ indicators is uncertain and will keep mostly undocumented.

Besides user comfort, it is crucial to check IEQ since it represents an indication of system malfunctioning; recent demonstration projects show the impact of IEQ on building energy consumption highlighting the importance and the association of IEQ with energy balance to identify possible correlation (Lenoir et al., 2011; Lenoir et al., 2012a). Additionally, to correct evaluate the energy balance there is the need to also assess the indoor environment. Standard input variables for energy calculations during the design phase are related to the comfort of occupants (indoor temperature, air change rates, etc.) and an alignment procedure (see subchapter 5.5.1) must be performed.

\subsection{Monitoring objectives}

The monitoring of IEQ parameters can have different objective depending on the involved groups and their related interests. Besides the alignment procedure, the following main aspects may be classified as objective in an IEQ monitoring (Figure 5-1):

- System functionality to maintain IEQ (malfunction detection, improvement of operation).

- Compliance of IEQ indicators (e.g., comfort) with target values (e.g., design parameters).

- Information and documentation of building operation.

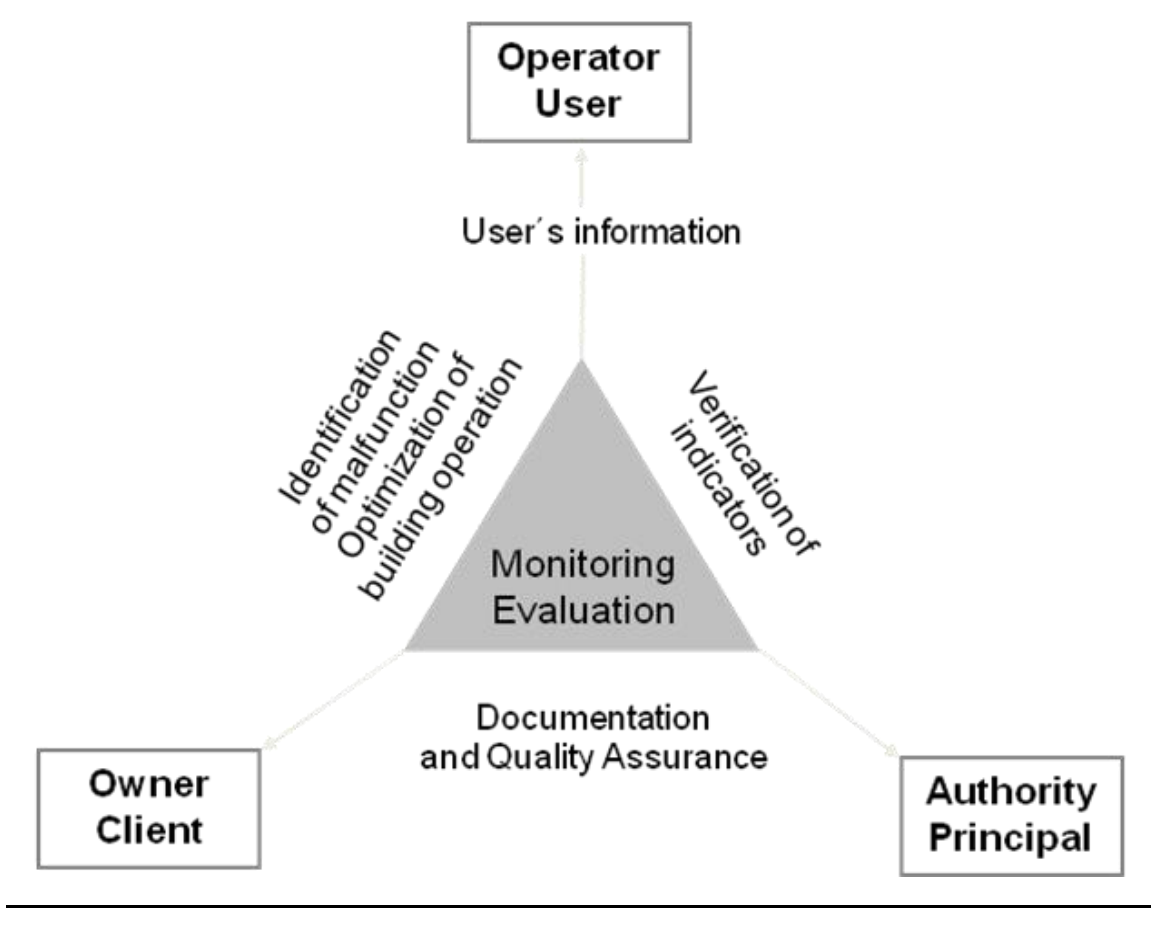

Figure 5-1. Objectives of different involved groups

\footnotetext{
${ }^{5}$ See EPBD introduction point (25): “....primarily those that improve indoor climatic conditions and the micro-climate around the buildings."
} 
A key objective while developing methods to check the balance of Net ZEB is the establishment of a standard monitoring approach to verify the compliance of the IEQ conditions and energy balance with given requirements, while keeping the effort reasonable.

\subsection{Experiences on impact of effective climate conditions}

Within the Austrian technology and research program "Building of Tomorrow" 14 futureoriented buildings were developed and realized by different consortia in Austria (the so-called "IBK I" and "IBK II" - projects ${ }^{6}$ ). These buildings were then monitored to verify the performance of the realized demonstration projects (energetical and ecological monitoring of the "Building of Tomorrow" IBK - demonstration projects, Wagner et al., 2009). The monitoring focused on the verification of energetic and comfort related indicators; most of the buildings were monitored for two years and a few are still being monitored. The measurement results of these high performance buildings show that the planned and calculated building performance after occupancy deviates from the expected results. Specifically, it was seen that the room temperatures were mostly higher than $20^{\circ} \mathrm{C}$. Most of the calculation tools like The Passive House Planning Package (PHPP) $)^{7,8}$ which calculate the heat demand [HD] in the design phase are based on standard indoor $\left(20^{\circ} \mathrm{C}\right)$ and outside (heating degree days - average of last 30 years) temperature conditions. However, detailed comparisons of measured data with calculated data need an alignment due to higher or lower indoor temperatures and the effective climate conditions. Thus, the measured effective energy flows of the demonstration buildings were aligned to the effective measured indoor temperatures and outdoor climate in order to compare their actual performance. The detailed procedure is described in the following example.

However, before performing the alignment between the model and the measurements with regard to indoor temperature and climate it is very important to make sure that the model (from the design phase) represents the actual building. It should be made sure that there is no input errors to the model, that changes during the erection of the building is included in the model, that the constructions and system components are modeled sufficiently correct and that the actual use of the building is correctly represented. For the latter that the correct air change rate, infiltration, free gain from plug loads, lightning, appliances and people are applied in the model. A procedure for alignment of models to the measurements is given in (Jensen, 2013).

\subsubsection{The procedure of alignment}

For each building an energy performance calculation is done, e.g. via PHPP, during the

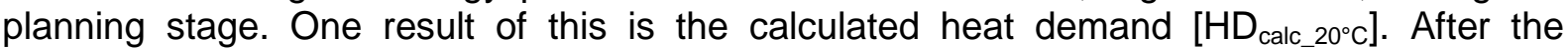
measurements during the operation phase, the measured indoor air temperature $\left[T_{r}\right]$ during the heating period $\left(\mathrm{T}_{\text {outdoor }}<15^{\circ} \mathrm{C}\right.$ ) is averaged and (instead of the $20^{\circ} \mathrm{C}$ ) fed into the original energy performance calculation to achieve a new calculated heat demand [ $\left.H D_{\text {calc_Tr_measured }}\right]$. The measured heat consumption $\left[\mathrm{HC}_{\text {measured }}\right]$ is now adjusted with the standard indoor temperature $\left[\mathrm{HC}_{20^{\circ} \mathrm{C}}\right]$ :

$H C_{20^{\circ} \mathrm{C}}=H C_{\text {measured }} \times \frac{H D_{\text {calc_20 } 20^{\circ} \mathrm{C}}}{H D_{\text {calc_Tr_measured }}}$

$\left[\mathrm{HC}_{20^{\circ} \mathrm{C}}\right]$ : measured heat consumption, aligned to $20^{\circ} \mathrm{C}$ indoor $\mathrm{T}$

$\left[\mathrm{HC}_{\text {measured }}\right]$ : measured heat consumption

\footnotetext{
6 "Innovative BauKonzepte I", "Innovative BauKonzepte II" http://www.nachhaltigwirtschaften.at/hdz pdf/brochuere ergebnisse hdz 07.pdf

${ }^{7} \mathrm{PHPP}$ or other tool for the calculation of building's energy performance

${ }^{8}$ Passive House Planning Package; http://www.passivhaustagung.de/Passive House E/PHPP.html
} 
$\left[\mathrm{HD}_{\text {calc } \_20^{\circ} \mathrm{C}}\right]$ : originally calculated heat demand, based on $20^{\circ} \mathrm{C}$ indoor $\mathrm{T}$

$\left[\mathrm{HD}_{\text {calc_Tr_measured }}\right]$ : new calculated heat demand, based on measured average indoor air $\mathrm{T}$

Second alignment is due to specific weather conditions in the year of the measurements. For that purpose the yearly measured weather data (outside temperatures and global radiation) for the location is inserted into PHPP or another calculation software to estimate the new heat demand $\left[\mathrm{HD}_{\text {calc_20 }} 0^{\circ} \mathrm{C}\right.$ _limate measured $]$. Afterwards this value is used to adjust the heat consumption $\left[\mathrm{HC}_{20^{\circ} \mathrm{C}}\right]$ calculated with (1) to the effective weather conditions during the period of measurements $\left[\mathrm{HC}_{20}{ }^{\circ} \mathrm{C}_{-}\right.$climatestandard]:

$H C_{20^{\circ} C_{-} \text {climate_standard }}=H C_{20^{\circ} \mathrm{C}} \times \frac{H D_{\text {calc_2 } 20^{\circ} C_{\text {cllimate_standard }}}}{H D_{\text {calc_ } 200^{\circ} C_{-} \text {climate_measured }}}$

$\left[\mathrm{HC}_{20^{\circ} \mathrm{C} \_ \text {climate_standard }}\right]$ : measured heat consumption, aligned to $20^{\circ} \mathrm{C}$ indoor $\mathrm{T}$ and standard climate

[HD $\mathrm{Halc}_{20} 0^{\circ} \mathrm{C} \_$climate_standard $]$: originally calculated heat demand, based on standard climate

$\left[\mathrm{HD}_{\text {calc_20 }} 0^{\circ} \mathrm{C} \_\right.$climate_measured $]$: new calculated heat demand, based on measured weather

\subsubsection{Example multi-family house "Dreherstrasse", Vienna}

This multifamily building has a longitudinal axis orientated north-south with a partial basement. The neighboring buildings partly shade this 27 -flat construction that has been occupied since December 2007. The multi-family house in Vienna was monitored within the "IBK" project for two years in order to check the compliance of the building performance (Wagner et al., 2010). Figure 5-3 shows an example of the comparison between measured and standard climate data sets. During the period of measurement the global irradiation and the outside temperatures were recorded. The calculation for the alignment with the climate data was done using the calculation tool "PHPP".
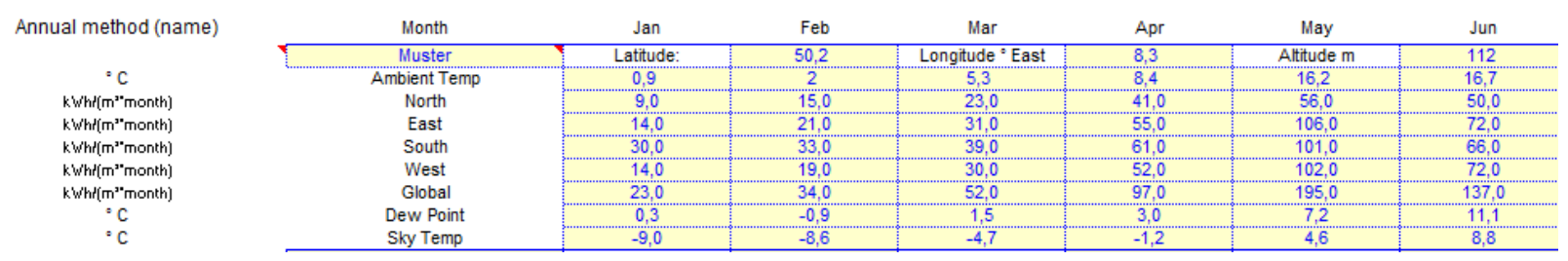
Figure 5-2. Cut-out of the calculation tool PHPP sheet "climate data" - cells with option to fill in own climate data sets.

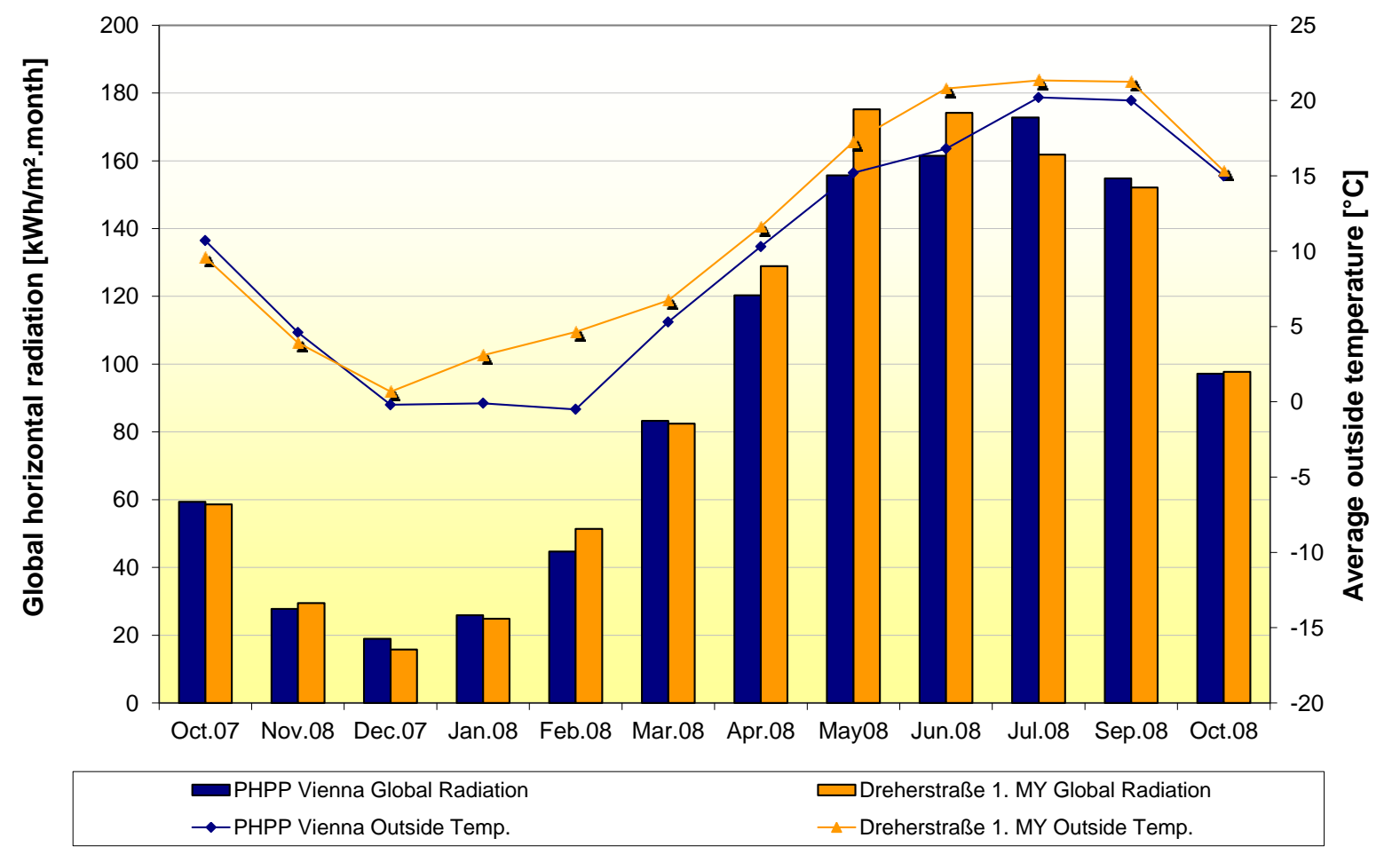

Figure 5-3: Passive house "Dreherstraße", Vienna. Comparison of standard climate data set (dark blue) and measured climate data (orange). The diagram depicts the monthly global radiation (bars) and the monthly average outside temperature (curved line) for the first year of measurements (1.MY). Source: (Wagner et al., 2010)

The following tables show information regarding the measured and standard (during design) data for the site for the two years considered. Table 5-1 shows the calculated and measured outdoor conditions, Table 5-2 the indoor temperatures, while Table 5-3 the calculated and measured energy for heating. Discrepancies between the calculated and measured values are visible for the external climate, the indoor conditions and finally for the heating consumption. Significant overheating is evident in both years. Through commissioning the building performance of the first year was improved in the second year (Table 5-3) to levels even better than the design value.

Table 5-1. Passive house "Dreherstraße", Vienna. Comparison of standard calculated and measured climate data. MY1 = Year of Measurement 1; MY2 = Year of Measurement 2. Source: $($ Wagner et al., $\underline{2010)}$

\begin{tabular}{|l|r|r|}
\hline & Global radiation $\left[\mathrm{kWh} / \mathrm{m}^{2} \mathrm{y}\right]$ & $\mathrm{T}_{\text {outdoor, average }}\left[{ }^{\circ} \mathrm{C}\right]$ \\
\hline Standard climate data set (Vienna, source) & 1,123 & 9.8 \\
\hline Measured climate data MY1 (Oct.07-Sept.08) & 1,153 & 11.3 \\
\hline Measured climate data MY2 (Oct.08-Sept.09) & 1,124 & 11.7 \\
\hline
\end{tabular}

Table 5-2. Passive house "Dreherstrasse", Vienna. Overview indoor temperatures. MY1= Year of Measurement 1; MY2 = Year of Measurement 2. Source: (Wagner et al., 2010)

\begin{tabular}{|l|l|r|}
\hline & MY1 & MY2 \\
\hline
\end{tabular}


Average indoor room temperature during heating period $\left(\mathrm{T}_{\text {outdoor }}<15^{\circ} \mathrm{C}\right)$ Average indoor room temperature during summer $\left(\mathrm{T}_{\text {outdoor }}>15^{\circ} \mathrm{C}\right)$

Percentage of hours of overheating $\left(T>26^{\circ} \mathrm{C}\right)$ out of the total yearly hours

$22.9^{\circ} \mathrm{C}$ $22.8^{\circ} \mathrm{C}$ $26.0^{\circ} \mathrm{C}$ $19 \%$ $17 \%$

Table 5-3: Passive house "Dreherstraße", Vienna. Comparison of standard climate and measured climate data. MY1= Year of Measurement 1; MY2 = Year of Measurement 2. Source: (Wagner et al., 2010)

\begin{tabular}{|l|r|r|}
\hline Heat demand calculated (PHPP), also design value & $11,0\left[\mathrm{kWh} / \mathrm{m}^{2} \mathrm{y}\right]$ \\
\hline & $\mathrm{MY} 1\left[\mathrm{kWh} / \mathrm{m}^{2} \mathrm{y}\right]$ & $\mathrm{MY} 2\left[\mathrm{kWh} / \mathrm{m}^{2} \mathrm{y}\right]$ \\
\hline Heat consumption (effective, measured) & 15.2 & 12.6 \\
\hline Heat consumption (aligned - indoor temperature \& climate) & 13.1 & 10.3 \\
\hline
\end{tabular}

The above example shows that after alignment the second year of measurements is more in agreement with the expected space heat demand than the first year of measurement. This supports the statement that the first year of measurements should be used for adjusting the running of the building and not for comparison with the design goals.

\subsubsection{Cross sectional analysis and conclusions}

The procedure to achieve the aligned heat demand is not a standard procedure. Nevertheless the proposed alignment does not take into consideration the full scope of the effective climate and user's behaviour but it contributes to an independent verification of the building performance. The results of the illustrated example regarding the passive house Dreherstraße" Vienna show that the effective climate and room temperature influence the energy consumption to a considerable extend. Subsequently, all measured "IBK"- buildings were analyzed regarding the interaction between effective climate, effective room temperatures, overheating and energy consumption for heating. Often the room temperatures during the heating season $\left(T_{\text {outdoor }}<15^{\circ} \mathrm{C}\right)$ were higher than what utilized in the design (Figure 5-4). A minimum of $22^{\circ} \mathrm{C}$ was identified as common. Additionally, many of the monitored buildings overheat in summer (Figure 5-5, Figure 5-6). With these data the measured energy consumption for heating of all relevant measured buildings were aligned due to effective climate and indoor temperature and the results can be seen in Figure 5-7. The energy use for heating exceeds in every case the designed values. However, through the alignment the measured data were adjusted and became closer to the design values, although the elevated room temperatures caused inefficiencies and worsened the performance. Therefore, the evaluation of effective indoor climate indicators plays an important role on the energy balance verification, besides the occupant's comfort verification. One important aspect to consider during analysis of energy and IEQ data is the control that occupants have on the indoor environment (e.g., temperature setting, window opening, ventilation rate). If the real conditions/settings differ from those assumed during the design phase, the results could vary as well. 
IEA SHC/ECBCS Task 40/Annex 52 - Towards Net Zero Energy solar Buildings

M\&V protocol for Net ZEB. A technical report of STA

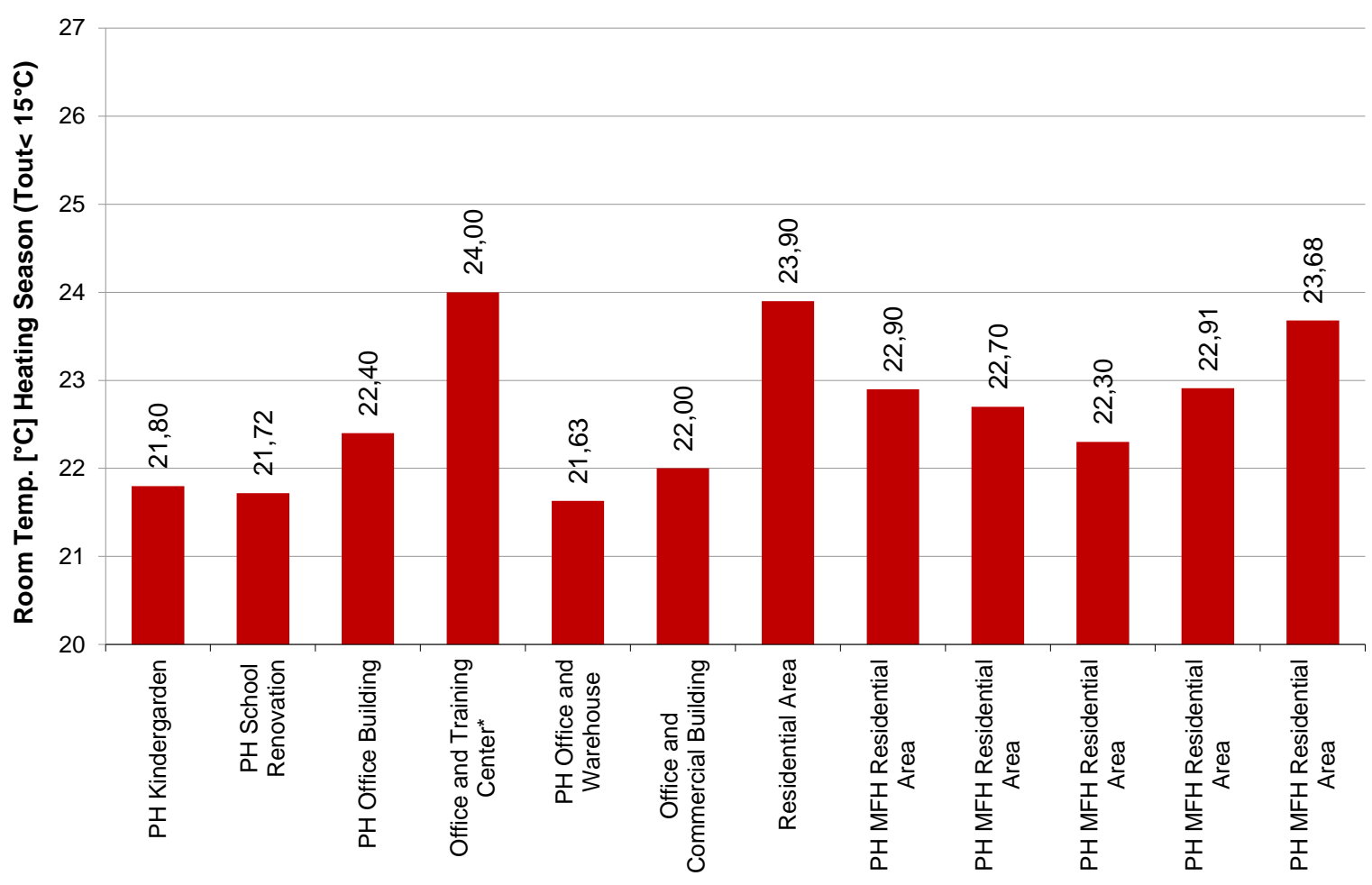

Figure 5-4: Measurement results of all relevant demonstration buildings within the "IBK" - monitoring project: Average effective room temperature $\left[{ }^{\circ} \mathrm{C}\right]$ for selected rooms during the entire heating season (Toutdoor $<15^{\circ} \mathrm{C}$ ). Source: AEE INTEC 2011

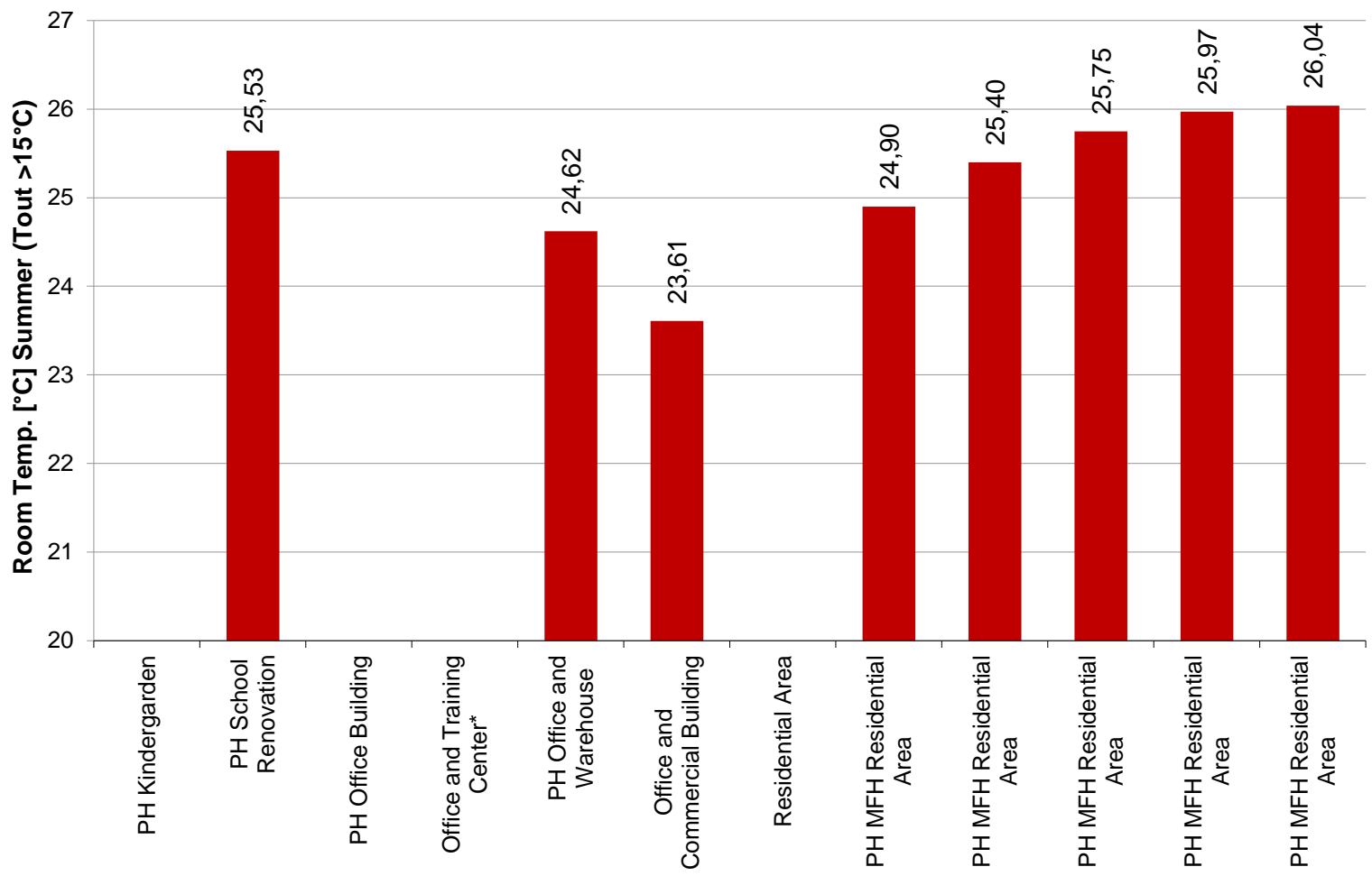

Figure 5-5: Measurement results of all relevant demonstration projects within the "IBK" - monitoring project: Average effective room temperature $\left[{ }^{\circ} \mathrm{C}\right]$ during the summer (Toutdoor $>15^{\circ} \mathrm{C}$ ). Source: $\mathrm{AEE}$ INTEC 2011 


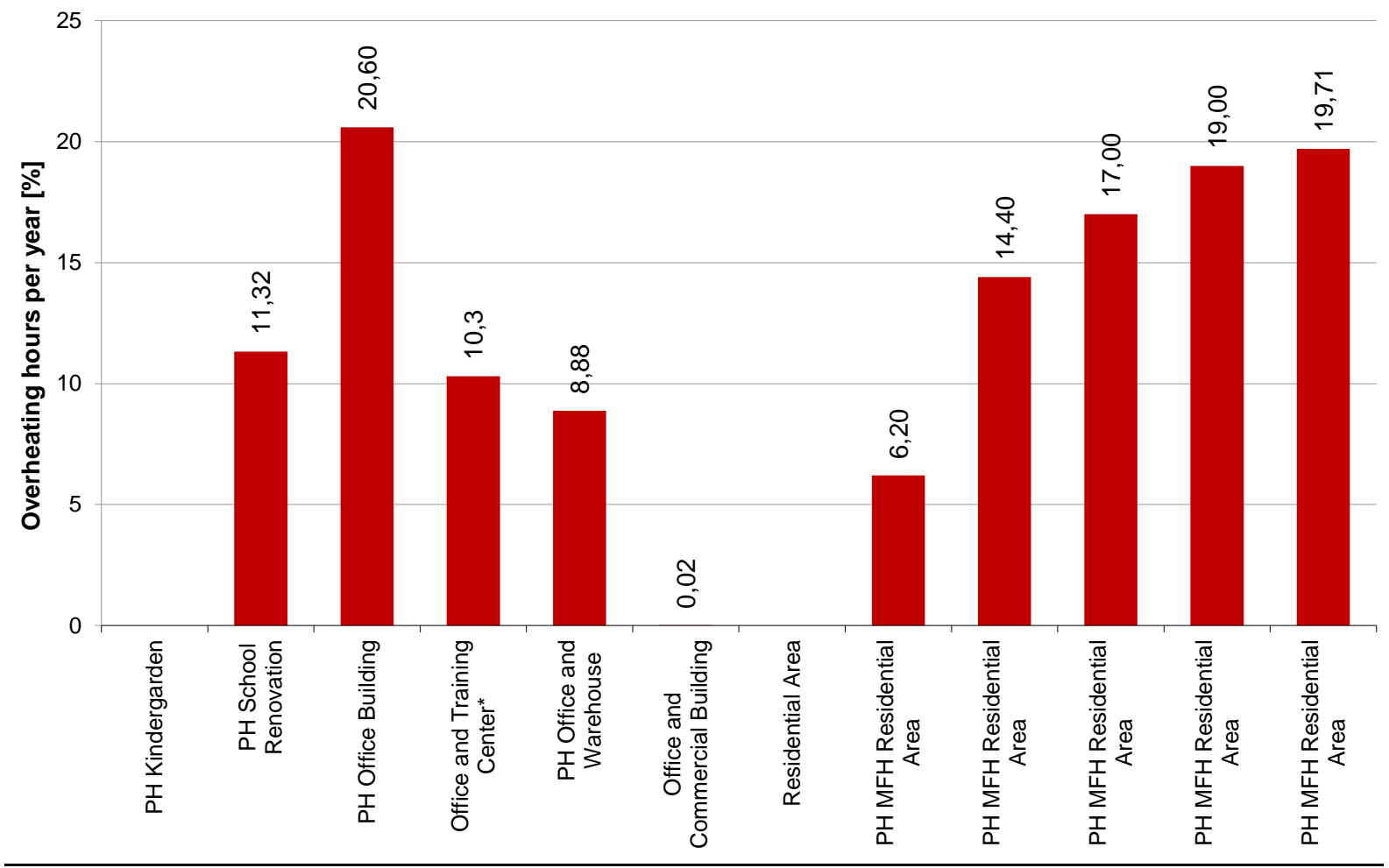

Figure 5-6: Measurement results of all relevant demonstration buildings within the "IBK" - monitoring project: Percentage of hours of overheating during the entire summer $\left(T_{\text {outdoor }}>15^{\circ} \mathrm{C}\right)$ related to the total annual amount of hours. Source: AEE INTEC 2011

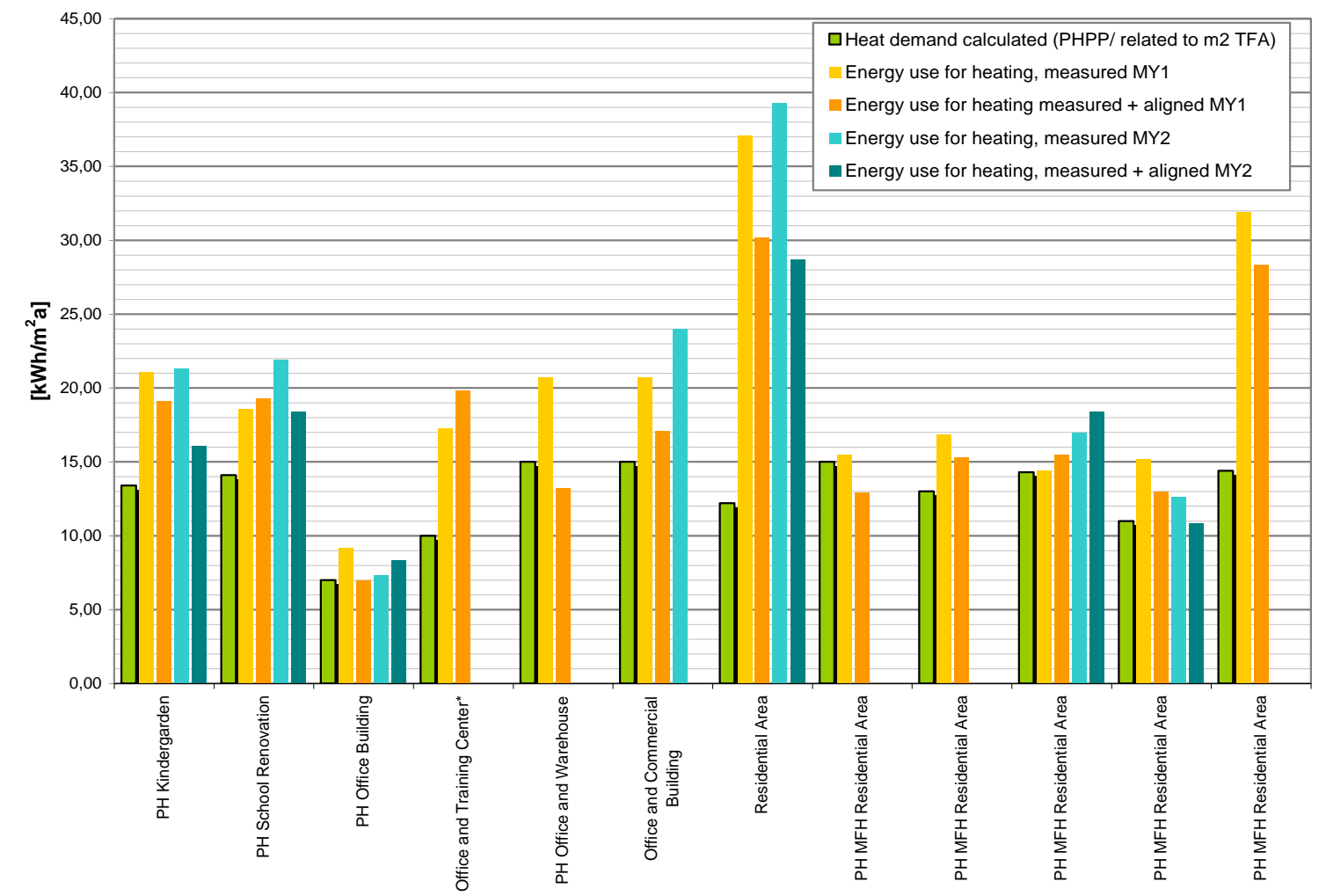

Figure 5-7: Cross analysis of all relevant demonstration buildings within the "IBK" - monitoring project. Source: AEE INTEC 2011 


\subsection{Approach of monitoring IEQ}

\subsubsection{Current standards to describe IEQ}

The standards of instrumentation and procedures used for indoor climatic measurements focus on the IEQ compliance verification with respect to given standards. The ASHRAE comfort standard $55-2010$ is often used to identify metrics of temperature, airspeed and humidity of mechanically or naturally ventilated building indoor environments. It also defines a precise methodology on measurement installation for monitoring comfort. The EN ISO 7730:2005 focuses on the analytical interpretation of thermal comfort using the Predicted Mean Vote (PMV) and Percentage People Dissatisfied (PPD) indices and also provides five procedure options for thermal comfort long-term evaluation. Standards like the EN ISO 7730 and guidelines released by the REHVA (Federation of European Heating, Ventilation and Airconditioning Associations) (Corgnati et al, 2011) describe different categories or classes of indoor climate quality defined by the percentage of unsatisfied persons in the specific room with respect to the occupant expectation level. The EN 15251 provides a firm framework of IEQ conditions influencing energy performance as well as principles for design and calculation. The assessment procedures to verify these standards show two basically different approaches:

- Direct assessment: the subjective vote of occupants in a building (influenced by their level of activity, clothing, etc) that lead to PMV-PPD indices

- Indirect assessment: the verification of measureable metrics of the indoor climate

\subsubsection{Introduction of appropriate levels of monitoring for IEQ}

Future building standards like Net ZEBs introduce the need for validation of the energy performance not only during design and permission phase, but also for commissioning and during operation phase. Commissioning is crucial to verify that a building performs continuously as designed and, if necessary, to implement corrective measures. Increased energy performance causes more sensitivity regarding parameters influencing the energy balance and could also potentially lead to highly efficient buildings that, however, lack acceptable comfort conditions. A single-sided verification of the energy balance, neglecting the impact on users, may cause a distorted picture of a building's performance.

However, it is not appropriate to plan a monitoring for indoor climate verification on the same high level of that for checking the balance building rating systems (as described above). The indoor climate monitoring will be affected by spatial and cost limitations; therefore, IEQ monitoring, complementary to the energy balance check, could be reduced to a few relevant metrics easy to measure that provide significant assessment indicators. Reduced monitoring performance does not provide detailed information on indoor climate but offers the possibility to equip a greater number of households with measurement points. On the other hand, an extensive measurement installation provides detailed feedback on IEQ, but is not viable for a large number of apartments. The selection between the different strategies depends on the monitoring objectives. A stepwise approach (with incremental levels of monitoring) is often employed since it addresses different purposes of IEQ monitoring (see Table 5-4).

\subsection{Monitoring conditions}

\subsubsection{Monitoring periods}

Current comfort monitoring procedures focus on verification of compliance with standards or IEQ specifications criteria. Since comfort conditions are influenced by outdoor climate conditions, measurement time-resolution and duration are important; typically short and spot 
periodic measurements are performed for specific inquiries. ASHRAE Standard 55-2010 provides a profound guideline in chapter 7. Whereas comfort monitoring is applied complementarily to the energy balance check, it should also provide a more longitudinal long-term assessment on the behavior pattern of a building and its occupants. Typically, detailed assessments of energy and IEQ are associated with longer monitoring periods and additional spot measurements. Often a formal commissioning is arranged in order to check the compliance of building accomplishment as well as the operation of building services. The monitoring approaches are distinguished due to their duration and purpose:

- Spot measurements: used to validate unique IEQ and energy related physical parameters (daylight factors as indicators of the necessity of artificial lighting), mostly in combination with qualitative inquiries of occupants to get feedback about specific physical building performance indicators. The measurement timing depends on the specific issue, but should by synchronized with conduction of questionnaires.

- Short-them (temporary) monitoring lasts at least two years. While the first year of operation is characterized by the adjustment of the building operation and, therefore, may have limited significance for long term energy and IEQ assessment, the second year is able to deliver sound results.

- Long-term (continuous) monitoring is proceeded for a longer time span. The aim and scope differ from the short-term monitoring. Currently, it is only performed for scientific reasons, within pilot or demonstration projects or for checking indicators for funding reasons. Recent technologies like smart meters, smart home applications and building management systems facilitate the implementation of continuous monitoring. A complementary verification of indoor climate introduces new perspectives for the planning of the monitoring system.

\subsubsection{Measurement instruments}

A wide range of products is available, a further detailed description of instruments and equipment to measure physical quantities is out of the scope of this paper. The standard "ISO 7726:1998" is now under revision and the "ISO 7726:2010-03-19: Ergonomics of the thermal environment - Instruments for measuring physical quantities" is also available.

\subsubsection{Position of sensors/ meter points}

The location of sensors and the number of meter points will vary with building types. For example, a school, office or multi-residential building will require measurements at different locations depending on the occupancy density, thermal load profiles, and space uniformity among others. Table 5-4 provides a description of IEQ measurement levels. Aligned with standards (ISO EN 15251 and ASHRAE 55-2010) and experiences from practice, the following principles for monitoring physical indicators should be considered:

- All indicators concerning indoor climate should be verified within the occupied areas;

- A monitoring only focused on IEQ does not need measurement points in non-occupied areas, except some target validation points; on the contrary, the energy balance check of non-residential buildings requires data also from sparsely or non-occupied areas to verify the correlation between design parameters (e.g., indoor T) and energy use.

In the case of occupied areas the of temperature sensor position shall be:

- within the expected stay of occupants or

- in the centre of the area or room, but

- at least 1,0 m from walls and especially large windows 
In case of unoccupied areas the location should be aligned with an expected mean condition in the area. Sensors for humidity, $\mathrm{CO}_{2}$ and volatile organic compounds (VOC) might be located in combination with temperature sensors, but since uniformity is often observed other locations in the room might be acceptable. The sensors should be located away from the direct sunlight or, alternatively, shielded from it. The outdoor temperature sensors need to be positioned on-site, away from direct solar irradiation and possible interferences from the building (open windows, exhaust air, other outlets or protected areas). Furthermore, outside temperature monitoring according to the EN 15251 should start approximately one week prior to monitoring of IEQ (ThermCo - guideline, page 2, University of Karlsruhe, 2009). The sensor height for indoor air temperature and velocity in occupied areas depends on the expected user's position (e.g., seated in dining/living rooms, classrooms, offices or standing in corridors, washrooms, kitchen). The measurement heights for temperature and air velocity shall be:

- $0,1 / 0,6 / 1,1 \mathrm{~m}$ above floor in case of seated occupants

- $0,1 / 1,1 / 1,7 \mathrm{~m}$ above floor in case of standing occupants

Humidity sensor shall be positioned at a height of (ideally collocated with temperature sensor):

- 0,6 $\mathrm{m}$ for seated and

- $1,1 \mathrm{~m}$ for standing occupants

Strategies to reduce the number of sensors are mentioned for the different monitoring levels in Table 5-7. However, it needs to be considered that the purpose of the monitoring is to determine factors affecting the measurement positions. The compromise between the detection of malfunction or critical values of parameters and a statistic representative statement is decided by the position of measurement points. It is important to record the information associated with the measurement point measured, the instruments used and their connections. Table 5-5 presents an example of the kind of information that could be recorded and a possible table structure. 
Table 7-4: Levels of monitoring with reference to the EN ISO 7730, EN 15251, ASHRAE 55-2010

\begin{tabular}{|c|c|c|c|c|c|}
\hline \multicolumn{6}{|c|}{ Level 1 - Basic Monitoring } \\
\hline Indicators & Sensors & Range & $\begin{array}{c}\text { Time } \\
\text { resolution }\end{array}$ & Time span & Questionnaires \\
\hline $\begin{array}{l}\text { Indoor air } \\
\text { temperature } \\
\\
\text { Outdoor air } \\
\text { temperature } \\
\text { Global } \\
\text { irradiation }\end{array}$ & $\begin{array}{l}\text { Temperature sensors wireless } \\
\text { (ideally solar powered) with data } \\
\text { radio transmission or internal } \\
\text { datalogger. If monitoring is planned } \\
\text { for long duration, wired is a feasible } \\
\text { option. } \\
\text { Advantages: } \\
\text { - No wiring necessary } \\
\text { - } \quad \text { Installation of data loggers after } \\
\text { completion of user's equipment } \\
\text { and devices (minimization of } \\
\text { interference factors or } \\
\text { unfavorable position) } \\
\text { - Inexpensive monitoring } \\
\quad \text { equipment, possible to equip all } \\
\text { apartments/ offices } \\
\text { - New sensor technology } \\
\text { reduces failures and false } \\
\text { measurement results } \\
\text { Disadvantages: } \\
\text { - No further data on IEQ. }\end{array}$ & $\begin{array}{l}\text { Reduced positions. } \\
\text { Indoor positions only } \\
\text { at one height, either: } \\
\text { - } 0,6 \mathrm{~m} \text { in zones } \\
\text { where occupants } \\
\text { are mainly } \\
\text { seated } \\
\text { - } 1,1 \mathrm{~m} \text { in zones } \\
\text { where occupants } \\
\text { are mainly } \\
\text { standing } \\
\text { Sensors for } \\
\text { temperature in } \\
\text { occupied zone or (if } \\
\text { not known) in the } \\
\text { middle of the room. }\end{array}$ & $\begin{array}{l}\text { Temperature: } \\
\text { Hourly average } \\
\text { Global } \\
\text { irradiation: } \\
\text { Daily amount }\end{array}$ & $\begin{array}{l}\text { Generally } \\
\text { season or } 1 \\
\text { year, after the } \\
1^{\text {st }} \text { year. }\end{array}$ & $\begin{array}{l}\text { General satisfaction survey (an example is } \\
\text { given in the appendix section, Table A1.3). } \\
\text { Conducted in the same year as measurement, } \\
\text { compilation to a significant number of } \\
\text { occupants. The survey must be conducted at } \\
\text { least one year after the building is fully } \\
\text { occupied. }\end{array}$ \\
\hline
\end{tabular}


$M \& V$ protocol for Net ZEB. A technical report of STA

Table 5-4 (continued): Levels of monitoring with reference to the EN ISO 7730, EN 15251, ASHRAE 55-2010

\begin{tabular}{|c|c|c|c|c|c|}
\hline \multicolumn{6}{|c|}{ Level 2 - Advanced Basic Monitoring } \\
\hline Indicators & Sensors & Range & Time resolution & Time span & Questionnaires \\
\hline $\begin{array}{l}\text { Indoor air } \\
\text { temperature } \\
\text { Indoor } \\
\text { humidity } \\
\text { Operative } \\
\text { temperature } \\
\text { Outdoor air } \\
\text { temperature } \\
\text { Global } \\
\text { irradiation }\end{array}$ & $\begin{array}{l}\text { Temperature \& humidity sensors wireless } \\
\text { (ideally solar powered) with data radio } \\
\text { transmission or internal datalogger. If } \\
\text { monitoring is planned for long duration, } \\
\text { wired is a feasible option } \\
\text { Black globe temperature sensor for } \\
\text { operative temperature wired. } \\
\text { Advantages: } \\
\text { - No wiring necessary } \\
\text { - Installation of loggers after completion } \\
\text { of user's equipment and devices } \\
\text { (minimization of interference factors or } \\
\text { unfavorable position) } \\
\text { - Enables temperature and climate } \\
\text { alignment of measured data to } \\
\text { evaluate energy use } \\
\text { Disadvantages: } \\
\text { - The additional operative temperature } \\
\text { sensors cause increased costs and } \\
\text { effort to evaluate; } \\
\text { Unlikely to equip all rooms/ } \\
\text { apartments/ offices } \\
\text { - No further data on IEQ }\end{array}$ & $\begin{array}{l}\text { Reduced positions for } \\
\text { temperature and } \\
\text { humidity. } \\
\text { Zones with expected } \\
\text { critical values for air } \\
\text { velocity. } \\
\text { Indoor positions only at } \\
\text { one height, either } \\
\text { - } 0,6 \text { m in zones } \\
\quad \text { where occupants } \\
\quad \text { are mainly seated } \\
\quad 1,1 \text { m in zones } \\
\quad \text { where occupants } \\
\text { are mainly standing } \\
\text { Sensors for } \\
\text { temperature in } \\
\text { occupied zone or (if not } \\
\text { known) in the middle of } \\
\text { the room }\end{array}$ & $\begin{array}{l}\text { Temperature and } \\
\text { humidity: Hourly } \\
\text { average } \\
\text { Global irradiation: } \\
\text { Daily amount. } \\
\text { Resolution } \\
\text { depends on } \\
\text { indicator and } \\
\text { purpose }\end{array}$ & $\begin{array}{l}\text { Generally } 1 \text { year, } \\
\text { after the } 1^{\text {st }} \text { year. } \\
\text { Time-span depends } \\
\text { on indicator and } \\
\text { purpose }\end{array}$ & $\begin{array}{l}\text { General satisfaction survey. } \\
\text { If it is possible, conduct it } \\
\text { two times a year in different } \\
\text { seasons. }\end{array}$ \\
\hline
\end{tabular}


$M \& V$ protocol for Net ZEB. A technical report of STA

Table 5-4 (continued): Levels of monitoring with reference to the EN ISO 7730, EN 15251, ASHRAE 55-2010

\begin{tabular}{|c|c|c|c|c|c|}
\hline \multicolumn{6}{|c|}{ Level 3 - Detailed Monitoring } \\
\hline Indicators & Sensors & Range & $\begin{array}{c}\text { Time } \\
\text { resolution }\end{array}$ & Time span & Questionnaires \\
\hline $\begin{array}{l}\text { Indoor air } \\
\text { temperature } \\
\text { Indoor } \\
\text { humidity } \\
\text { Operative } \\
\text { temperature } \\
\text { Indoor air } \\
\text { velocity } \\
\mathrm{CO}_{2} \\
\text { concentration } \\
\text { Outdoor } \\
\text { temperature } \\
\text { Outdoor } \\
\text { humidity } \\
\text { Global } \\
\text { irradiation }\end{array}$ & $\begin{array}{l}\text { Temperature and humidity } \\
\text { sensors wireless (e.g., solar } \\
\text { powered), with data radio } \\
\text { transmission or internal } \\
\text { datalogger. If monitoring is } \\
\text { planned for long duration, wired } \\
\text { is a feasible option } \\
\mathrm{CO}_{2} \text { sensor logged to } \\
\text { independent logger or linked to } \\
\text { cable network. It requires } \\
\text { external power supply. } \\
\text { Black globe temperature } \\
\text { sensor for operative } \\
\text { temperature wired } \\
\text { Advantages: } \\
\text { - Feedback for optimization } \\
\quad \text { of building services } \\
\quad \text { possible } \\
\text { Feedback on IEQ possible } \\
\text { Enables additional } \\
\text { evaluation of a broader } \\
\text { range of IEQ indicators } \\
\text { Disadvantages: } \\
\text { - Installation of CO }{ }_{2} \text {-sensor } \\
\text { needs wiring and has to be } \\
\text { done in planning stage } \\
\text { Increased costs and effort } \\
\text { to evaluate } \\
\text { Less units equipped }\end{array}$ & $\begin{array}{l}\text { Positions of } \\
\text { temperature, } \\
\text { humidity and } \mathrm{CO}_{2} \\
\text { sensors according to } \\
\text { standards. } \\
\text { Points with expected } \\
\text { critical values for air } \\
\text { velocity. } \\
\text { Indoor positions only } \\
\text { at three heights: } \\
\text { - } \quad 0,1 / 0,6 / 1,1 \text { m in } \\
\quad \text { zones where } \\
\text { occupants are } \\
\text { mainly seated. } \\
\text { - } 0,1 / 1,1 / 1,7 \text { m in } \\
\text { zones where } \\
\text { occupants are } \\
\text { mainly standing. } \\
\text { Sensors for } \\
\text { temperature and } \\
\text { humidity in occupied } \\
\text { zone or (if not } \\
\text { known) in the middle } \\
\text { of the room }\end{array}$ & $\begin{array}{l}\text { Temperature, } \\
\text { humidity and } \\
\mathrm{CO}_{2} \text { : } \\
30 \text { min average } \\
\text { Air velocity: } 10 \\
\text { sec } \\
\text { Global } \\
\text { irradiation: } \\
\text { Hourly average } \\
\text { Resolution } \\
\text { depends on } \\
\text { indicator and } \\
\text { purpose }\end{array}$ & $\begin{array}{l}\text { Generally } 2 \text { years, air } \\
\text { velocity as spot } \\
\text { measurements } \\
\text { (duration about } 3 \text { min. } \\
-\quad \text { see ASHRAE } \\
\text { standard) } \\
\text { Time-span depends on } \\
\text { indicator and purpose }\end{array}$ & $\begin{array}{l}\text { General satisfaction survey conducted } \\
\text { each year for } 5 \text { years as measurement, } \\
\text { compilation to a significant number of/all } \\
\text { occupants. Spot surveys to a random } \\
\text { sample of occupants (synchronized in } \\
\text { time and unit with detailed monitoring } \\
\text { positions) - at least at the end of second } \\
\text { year. }\end{array}$ \\
\hline
\end{tabular}


Table 5-4 (continued): Levels of monitoring with reference to the EN ISO 7730, EN 15251, ASHRAE 55-2010

\begin{tabular}{|c|c|c|c|c|c|}
\hline \multicolumn{6}{|c|}{ Level 4 - Advanced Detailed Monitoring } \\
\hline Indicators & Sensors & Range & $\begin{array}{c}\text { Time } \\
\text { resolution }\end{array}$ & Time span & Questionnaires \\
\hline $\begin{array}{l}\text { Indoor air } \\
\text { temperature } \\
\text { Indoor humidity } \\
\text { Operative } \\
\text { temperature } \\
\text { Indoor air } \\
\text { velocity } \\
\mathrm{CO}_{2} \\
\text { concentration } \\
\text { Volatile organic } \\
\text { compounds } \\
\text { (VOC) } \\
\text { Daylight factor / } \\
\text { useful daylight } \\
\text { index (UDI) } \\
\text { Mean radiant } \\
\text { temperature } \\
\text { Outdoor air } \\
\text { temperature } \\
\text { Outdoor } \\
\text { humidity } \\
\text { Global and } \\
\text { diffuse solar } \\
\text { radiation } \\
\text { Wind direction } \\
\text { and speed at } 3 \mathrm{~m} \\
\text { and 10m height }\end{array}$ & $\begin{array}{l}\text { Temperature and humidity sensors wireless (e.g., } \\
\text { solar powered), with data radio transmission or } \\
\text { internal datalogger. If monitoring is planned for long } \\
\text { duration, wired is a feasible option } \\
\mathrm{CO}_{2} \text { sensor linked to cable network. It requires } \\
\text { external power supply. } \\
\text { Possible: } \\
\text { Thermographical pictures for surface temperatures. } \\
\text { Daylight sensors. } \\
\text { Portable unit with air temperature, globe temperature, } \\
\text { humidity, air velocity on site for spot measurements. } \\
\text { Weather station on site } \\
\text { Advantages: } \\
\text { - Feedback for optimization of building services } \\
\text { possible } \\
\text { Detailed evaluation of indoor environmental quality } \\
\text { possible } \\
\text { Enables verification of energy balance in } \\
\text { compliance with assessment of IEQ according to } \\
\text { current standards; } \\
\text { Quantitative and qualitative IEQ and socio- } \\
\text { economic assessment } \\
\text { Disadvantages: } \\
\text { - Installation of monitoring equipment requires } \\
\text { detailed monitoring concept }+ \text { good alignment } \\
\text { during planning stage +completion of building } \\
\text { services } \\
\text { Increased costs and effort to evaluate } \\
\text { - Less rooms/ apartments equipped, increased cost }\end{array}$ & $\begin{array}{l}\text { Positions of } \\
\text { temperature, } \\
\text { humidity and } \mathrm{CO}_{2} \\
\text { sensors according } \\
\text { to standards. } \\
\text { Points with } \\
\text { expected critical } \\
\text { values for air } \\
\text { velocity. } \\
\text { Indoor positions } \\
\text { only at three } \\
\text { heights: } \\
\text { - } 0,1 / 0,6 / 1,1 \mathrm{~m} \\
\text { in zones where } \\
\text { occupants are } \\
\text { mainly seated. } \\
\text { 0,1/1,1/ } 1,7 \mathrm{~m} \\
\text { in zones where } \\
\text { occupants are } \\
\text { mainly } \\
\text { standing. } \\
\text { Sensors for } \\
\text { temperature and } \\
\text { humidity in } \\
\text { occupied zone or (if } \\
\text { not known) in the } \\
\text { middle of the room }\end{array}$ & $\begin{array}{l}\text { Temperature, } \\
\text { humidity and } \\
\mathrm{CO}_{2}: 30 \text { min } \\
\text { average, 5- } \\
10 \text { min } \\
\text { during critical } \\
\text { periods. } \\
\text { vOC: } \\
\text { integrated } \\
\text { weekly value. } \\
\text { Air velocity } \\
\text { (accuracy: } \\
0.1 \text { m/s): } 10 \\
\text { Seconds } \\
\text { Resolution } \\
\text { depends on } \\
\text { indicator and } \\
\text { purpose }\end{array}$ & $\begin{array}{l}\text { Generally } 2 \\
\text { years, air } \\
\text { velocity and } \\
\text { daylight } \\
\text { factor as } \\
\text { spot } \\
\text { measureme } \\
\text { nts better to } \\
\text { be done } \\
\text { once and } \\
\text { during an } \\
\text { isotropic } \\
\text { sky. } \\
\text { Time-span } \\
\text { depends on } \\
\text { indicator } \\
\text { and } \\
\text { purpose }\end{array}$ & $\begin{array}{l}\text { General satisfaction survey } \\
\text { conducted each year for } 5 \\
\text { years as measurement, } \\
\text { compilation to a significant } \\
\text { number of/all occupants. } \\
\text { Spot surveys of a random } \\
\text { sample of occupants } \\
\text { (synchronized in time and unit } \\
\text { with detailed monitoring } \\
\text { positions) - several times } \\
\text { during the two years. }\end{array}$ \\
\hline
\end{tabular}


IEA SHC/ECBCS Task 40/Annex 52 - Towards Net Zero Energy solar Buildings

M\&V protocol for Net ZEB. A technical report of STA

Table 5-5. Example for sensor distribution scheme and information

\begin{tabular}{|c|c|c|c|c|c|}
\hline Location & Kind of Measurement & Kind of sensor & Accuracy & Commercial product & Connection \\
\hline Room 1-2 Radiant floor system & Heat flux [Wh] & Heat meter & & & \\
\hline Room 2-3 Radiant floor system & Heat flux [Wh] & Heat meter & & & \\
\hline Room 3-3 Radiant floor system & Heat flux [Wh] & Heat meter & & & \\
\hline Room 1-2 Re-heating unit ventilation & Heat flux [Wh] & Heat meter & & & \\
\hline Room 2-3 Re-heating unit ventilation & Heat flux [Wh] & Heat meter & & & \\
\hline Room 3-3 Re-heating unit ventilation & Heat flux [Wh] & Heat meter & & & \\
\hline Whole building electric network analyzer & Network Analyses & Network analyzer & & & \\
\hline Whole building electric meter & Electric consumption [Wh] & Electric Meter & & & \\
\hline First Floor Electric meter appliances & Electric consumption [Wh] & Electric Meter & & & \\
\hline First Floor Electric meter light & Electric consumption [Wh] & Electric Meter & & & \\
\hline Room 1-1 Electric meter appliances & Electric consumption [Wh] & Electric Meter & & & \\
\hline Room 1-1 Electric meter light & Electric consumption [Wh] & Electric Meter & & & \\
\hline Closest existing weather station & Exterior Air Temperature $\left[{ }^{\circ} \mathrm{C}\right]$ & Temperature sensor & & & \\
\hline Closest existing weather station & Exterior Air Relative Humidity [\%] & $\mathrm{RH}$ sensor & & & \\
\hline Closest existing weather station & Horizontal global radiation [W/m²] & Pyranometer & & & \\
\hline Room 1-1 & Indoor Air Temperature $\left[{ }^{\circ} \mathrm{C}\right]$ & Temperature sensor & & & \\
\hline Room 1-1 & Indoor Air Relative Humidity [\%] & RH sensor & & & \\
\hline Room 1-1 & Indoor Air CO2 concentration [ppm] & CO2 sensor & & & \\
\hline Room 1-1 & Indoor Light [lux] & Luxmeter sensor & & & \\
\hline Room 1-1 & People presence & Presence sensor & & & \\
\hline Room 1-1 & Window opening & Window status sensor & & & \\
\hline Room 1-1 & Inlet air ventilation temperature $\left[{ }^{\circ} \mathrm{C}\right]$ & Temperature sensor & & & \\
\hline
\end{tabular}




\section{Range and distribution of measurement installation}

Any monitoring procedure, independent from the level in Table 5-4, needs an appropriate monitoring plan. The plan needs to show details regarding the different procedure steps ranging from the installation plan and equipment specification, data acquisition, storage to the final evaluation as shown in the previous chapters. The success lies in the first steps: the position and number of measurement points in order to get representative and scientific based values for IEQ.

\subsubsection{Distribution of measurement installation}

A complementary verification of indoor climate introduces new perspectives for the planning of the monitoring system. Therefore, it is essential to specify the purpose of measured parameters since different parameters serve different purposes. For example, the indoor temperature indicates the compliance of actual values with designed input values for energy calculations or simulations and allows a direct comparison between energy demand and use.

One or few critical points (e.g., cold surface temperature of a wall or one exposed room with lower indoor temperatures) will have only a small influence on the overall energy balance, but may affect IEQ significantly possibly causing unsatisfied users, mould or building damage. The definition of the monitoring targets is critical since it influences the selection and target-oriented compilation of measurement points. Two main targets should be distinguished (see Figure 5-8):

- To verify the energy consumption/balance on an aggregated level for a number of apartments/zones/units;

- To assess the correct system operation and IEQ compliance for critical units/zones (e.g., increased consumption, overheating). 


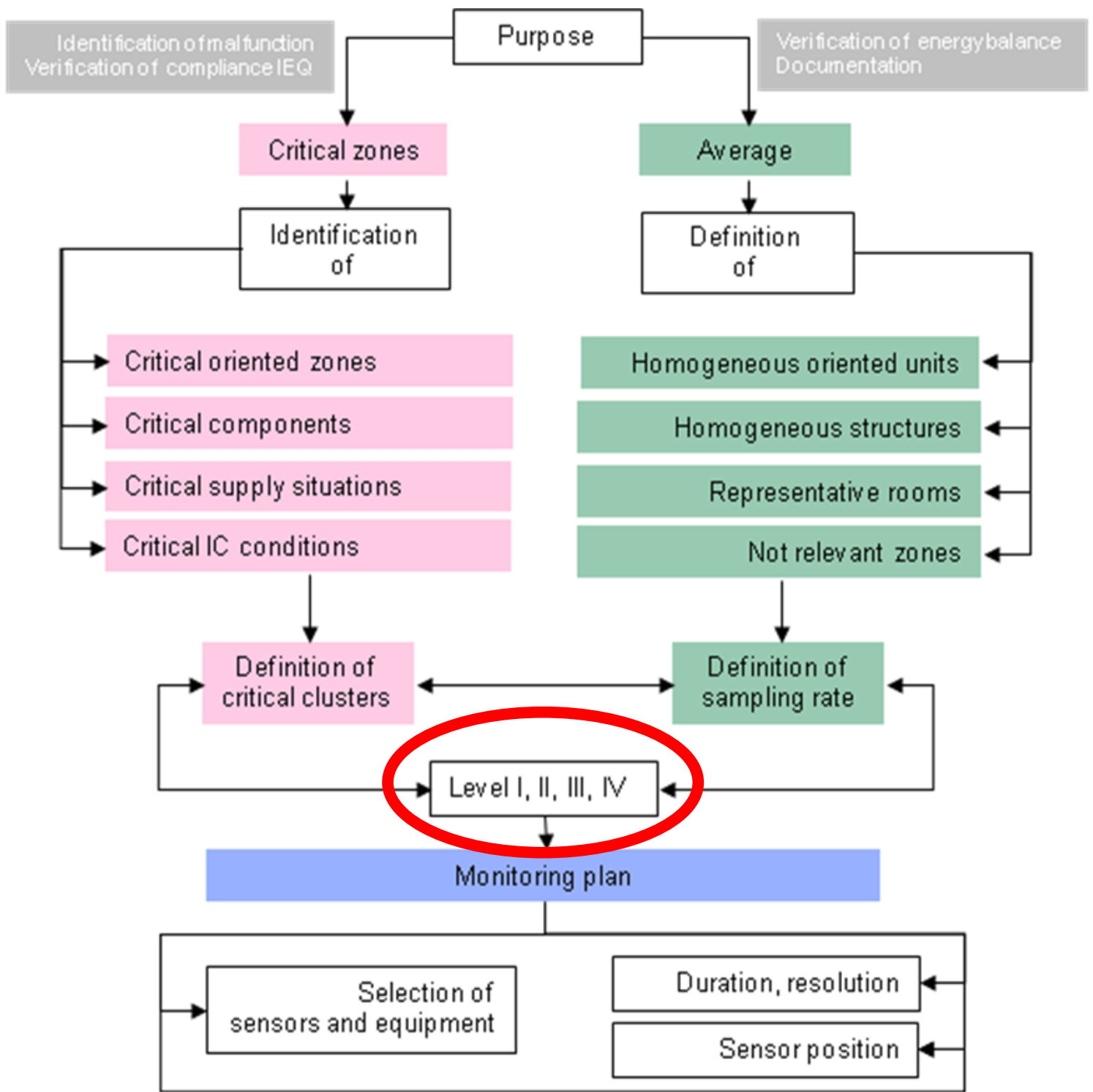

Figure 5-8: Target-oriented distribution of measurement installation associated to the IEQ levels in Table 5-4 (red circle).

In order to reduce the efforts it is crucial to level the monitoring approach. Also, an effective distribution of sensors that should include a mix of areas representing the average condition and critical areas is important.

\subsubsection{Identification of critical zones}

Critical zones are areas that, for a variety of reasons, are prone to the formation of negative conditions. Table 5-6Error! Reference source not found. provides an excerpt of possible critical zones within a building, a building complex or an aggregate of apartments. The list should help identifying risks, but is not intended to be exhaustive. It is necessary to define which critical areas are of interest within the actual conditions of the monitored building. 
Table 5-6: Aspects for specification of critical zones

\begin{tabular}{|c|c|c|}
\hline Specification & Impact/ Risk & Reason \\
\hline \multicolumn{3}{|c|}{ Critical oriented or designed zones } \\
\hline $\begin{array}{l}\text { Units oriented east and } \\
\text { west }\end{array}$ & Overheating & $\begin{array}{l}\text { Flatter angle of sunlight enables deeper } \\
\text { indices of direct sunlight }\end{array}$ \\
\hline $\begin{array}{l}\text { Exposed units (top floor or } \\
\text { projecting building parts) }\end{array}$ & Overheating, cold surfaces & Surface/volume ratio worse than average \\
\hline Occupied attics & Overheating or heat losses & $\begin{array}{l}\text { Less insulation, less thermal mass, roof- } \\
\text { top windows }\end{array}$ \\
\hline $\begin{array}{l}\text { Areas neighboring } \\
\text { unheated zones }\end{array}$ & $\begin{array}{l}\text { Cold surfaces, radiant } \\
\text { temperature asymmetry }\end{array}$ & Less insulation or thermal bridges \\
\hline Glazed areas in general & $\begin{array}{l}\text { Cold surface, radiant } \\
\text { temperature asymmetry }\end{array}$ & $\begin{array}{l}\text { U-value worse than surrounding walls or } \\
\text { components }\end{array}$ \\
\hline $\begin{array}{l}\text { Glazed areas with no } \\
\text { automatic shading systems }\end{array}$ & $\begin{array}{l}\text { Overheating, radiant } \\
\text { temperature asymmetry }\end{array}$ & Direct unshaded sunlight \\
\hline $\begin{array}{l}\text { Exposed room/area with } \\
\text { two or more external walls }\end{array}$ & $\begin{array}{l}\text { Cold surfaces, radiant } \\
\text { temperature asymmetry }\end{array}$ & Higher heat loss \\
\hline Units orientated south & overheating & Sun protection necessary \\
\hline \multicolumn{3}{|l|}{ Critical components } \\
\hline $\begin{array}{l}\text { Vast glazing, especially } \\
\text { without automatic shadings }\end{array}$ & Overheating & \\
\hline Double glazed façades & Overheating & $\begin{array}{l}\text { Direct incidence of sunlight in } \\
\text { combination with inefficient shading and } \\
\text { ventilation }\end{array}$ \\
\hline $\begin{array}{l}\text { Light weight constructions } \\
\text { without thermal mass or } \\
\text { efficient shading systems }\end{array}$ & Overheating & $\begin{array}{l}\text { Direct incidence of sunlight and worse } \\
\text { inertia }\end{array}$ \\
\hline $\begin{array}{l}\text { Less insulated exterior } \\
\text { walls }\end{array}$ & $\begin{array}{l}\text { Radiant temperature } \\
\text { asymmetry }\end{array}$ & Lower surface temperatures \\
\hline High glazed facades & $\begin{array}{l}\text { Cold surface, elevated air } \\
\text { speed }\end{array}$ & \\
\hline \multicolumn{3}{|l|}{ Critical supply situations } \\
\hline $\begin{array}{l}\text { Areas with reduced } \\
\text { delivered airflow }\end{array}$ & $\begin{array}{l}\text { Elevated indoor air pollutant } \\
\text { concentration }\left(\mathrm{CO}_{2} / \mathrm{VOC}\right)\end{array}$ & Lower air change rates \\
\hline $\begin{array}{l}\text { Areas with high intake of } \\
\text { fresh air }\end{array}$ & Air drafts & $\begin{array}{l}\text { Necessary air change rate enabled by } \\
\text { higher air velocity }\end{array}$ \\
\hline High temperature radiators & $\begin{array}{l}\text { Radiant temperature } \\
\text { asymmetry }\end{array}$ & Surface temperatures differences \\
\hline \multicolumn{3}{|l|}{ Critical IEQ conditions } \\
\hline $\begin{array}{l}\text { Rooms with elevated } \\
\text { occupancy }\end{array}$ & $\begin{array}{l}\text { Higher } \mathrm{CO}_{2} \text { concentration } \\
\text { and humidity, overheating }\end{array}$ & Higher internal loads than expected \\
\hline $\begin{array}{l}\text { Rooms with high internal } \\
\text { loads (e.g., IT equipment) }\end{array}$ & Overheating & High internal loads \\
\hline Areas with indoor plants & Mould & $\begin{array}{l}\text { High humidity and thermal bridges or } \\
\text { other surfaces with lower surface } \\
\text { temperatures }\end{array}$ \\
\hline $\begin{array}{l}\text { Rooms/ units with no cross } \\
\text { ventilation }\end{array}$ & $\begin{array}{l}\text { Overheating; higher air } \\
\text { pollutant concentration } \\
\left(\mathrm{CO}_{2} / \mathrm{VOC}\right)\end{array}$ & Inefficient ventilation \\
\hline $\begin{array}{l}\text { Rooms with temporarily } \\
\text { use (special education } \\
\text { classrooms) }\end{array}$ & $\begin{array}{l}\text { Lower / higher indoor } \\
\text { temperatures; higher air } \\
\text { pollutant concentration } \\
\left(\mathrm{CO}_{2} / \mathrm{VOC}\right)\end{array}$ & $\begin{array}{l}\text { Variations from expected use (estimation } \\
\text { of internal loads), lower ventilation rates } \\
\text { due to random use; when used quick } \\
\text { adaptation needed }\end{array}$ \\
\hline $\begin{array}{l}\text { Areas with overhead } \\
\text { glazing (atriums) }\end{array}$ & Overheating & \\
\hline $\begin{array}{l}\text { Inefficient exhaust } \\
\text { ventilation (e.g., low flow) }\end{array}$ & $\begin{array}{l}\text { Increased concentration of } \\
\mathrm{CO}_{2} \text {, humidity and other } \\
\text { pollutant }\end{array}$ & $\begin{array}{l}\text { Inefficient removal of contaminant from } \\
\text { building }\end{array}$ \\
\hline
\end{tabular}




\subsubsection{Identification of homogeneous and representative areas, clusters or units}

Table 5-7 provides an excerpt for specifications of homogeneous areas, clusters or units within a building, a building complex or an aggregate of apartments. The list should help understanding the process of grouping and clustering but is not intended to be exhaustive. It is necessary to adopt the specifications with reference to the actual conditions of the monitored building.

Table 5-7: Aspects for specification of homogeneous and representative areas, clusters or units

\begin{tabular}{|c|c|c|}
\hline Specification & Argumentation & Comment \\
\hline \multicolumn{3}{|l|}{ Similar orientation } \\
\hline $\begin{array}{l}\text { Same cardinal direction or } \\
\text { orientation }\end{array}$ & $\begin{array}{l}\text { Similar incidence of } \\
\text { sunlight }\end{array}$ & $\begin{array}{l}\text { Other conditions must be similar (e.g., } \\
\text { shading systems, glazing percentage) }\end{array}$ \\
\hline \multicolumn{3}{|l|}{ Similar components } \\
\hline Same structural design & $\begin{array}{l}\text { Same characteristics of } \\
\text { building physics }\end{array}$ & $\begin{array}{l}\text { Differences in occupancy may } \\
\text { influence characteristics }\end{array}$ \\
\hline $\begin{array}{l}\text { Same percentage of glazing or } \\
\text { windows }\end{array}$ & $\begin{array}{l}\text { Same conditions for } \\
\text { direct incidence of } \\
\text { sunlight and cooling }\end{array}$ & $\begin{array}{l}\text { Other components (e.g., shading, } \\
\text { ventilation) and orientation must be } \\
\text { also similar }\end{array}$ \\
\hline \multicolumn{3}{|l|}{ Similar supply conditions } \\
\hline $\begin{array}{l}\text { Same supply lines (for heating } \\
\text { and cooling) }\end{array}$ & $\begin{array}{l}\text { Equal supply } \\
\text { temperatures }\end{array}$ & $\begin{array}{l}\text { Individual room or zone control may } \\
\text { influence the situation }\end{array}$ \\
\hline $\begin{array}{l}\text { Same heating / cooling } \\
\text { distribution system }\end{array}$ & $\begin{array}{l}\text { Comparable heating and } \\
\text { cooling situation }\end{array}$ & $\begin{array}{l}\text { Individual room or zone control may } \\
\text { influence the situation }\end{array}$ \\
\hline $\begin{array}{l}\text { Same ventilation system } \\
\text { (dimension and air change rates) }\end{array}$ & $\begin{array}{l}\text { Comparable ventilation } \\
\text { situation }\end{array}$ & $\begin{array}{l}\text { Individual room or zone control may } \\
\text { influence the situation }\end{array}$ \\
\hline \multicolumn{3}{|l|}{ Similar indoor conditions } \\
\hline Similar occupancy of space & Same internal loads & \\
\hline $\begin{array}{l}\text { Continuous use, especially by } \\
\text { same group of people }\end{array}$ & $\begin{array}{l}\text { Comparable behavior } \\
\text { pattern }\end{array}$ & $\begin{array}{l}\text { Adjustment of control systems and } \\
\text { user behavior easier }\end{array}$ \\
\hline $\begin{array}{l}\text { Similar equipment / installation } \\
\text { level }\end{array}$ & Similar internal loads & \\
\hline
\end{tabular}




\subsubsection{Sound survey sample size}

The upcoming need for verification of Net ZEB faces building owners, operators and property managers with the challenge to check the energy balance of an entire residential area, large office buildings or non-residential buildings. The monitoring of a unique building (e.g. demonstration building, smaller administrative or other non-residential building) will be a oneof-kind solution requiring the measurement of all points of interest and the specification in the monitoring plan of the details and installation positions of the software. In general, the need for comprehensive IEQ verification additionally to the energy balance may discourage operators because of the required effort. So there is the need to reduce the monitoring effort without losing necessary information to get scientific based statements.

One option is a stepwise monitoring process for a building over a long period, the other is a reduction in the number of measured units, zones, apartments. The most important aspect to consider is the selection of the number of apartments/units being monitored and of the number of data loggers being installed. The most reliable data will be given by monitoring of all units/apartments, which is possible for energy flows. But the same for comfort measurements would significantly increase the effort. The monitoring of a multi-family building with a larger number of apartments/units may not include all the measurement equipment associated to the levels 3 and 4 (see Table 5-4) in every apartment/unit.

In statistics, it is common to plan the collection and interpretation of data systematically. If, for example, every unit of a building is analyzed a so-called "census" is conducted. However, often a census is not feasible and a certain number of samples is selected in depth analysis with the goal of finding conclusions that can be generalized to the main unit. So the determination of the sample size is a very important issue and needs a structured procedure.

\section{Sample survey procedure:}

A. The first step is the identification of homogeneous and critical zones (see Tables 5-6 and Table 5-7):

- The definition of homogeneous clusters (of e.g. units) within the building

- The determination of homogeneous clusters of buildings within one area

- The separate identification of critical zones within the building(s)

The identification of critical zones and the related monitoring results should be used as further evidence for checking the balance.

B. The second step is the calculation of the number of measured apartments/units within a predefined cluster which is expected to generate representative results. A sample is considered to be representative when the length of the confidence interval does not exceed a predefined value. Before calculating the right sample size number, $n$, the following parameters must be defined ${ }^{9}$ :

- The confidence interval, $I$, is the range in which a searched value, $G$, is expected with the probability of $1-\alpha$ around the calculated mean value, $\hat{G}$.

- The tolerance, $\delta$, is the maximum deviation from the mean value of the measurements; $2^{*} \delta$ is the maximum length of the confidence interval which should be reached after the measurements.

\footnotetext{
${ }^{9}$ Felsenstein K., Nov. 2012: Optimale Stichprobenumfänge für Wohnklimamessungen, Department of Statistics and Probability Theory - TU Vienna
} 
- The measurement error, $\Delta$, of a single measurement or the measuring instrument is given in \%. It is equivalent to the statistical coefficient of variation.

- Uncertainty of the statistical procedure, $\alpha$, represents the percentage of cases in which the measured value is not within the confidence interval; normally here $\alpha=5 \%$.

- The $t$-quantile, $t_{n, 1-\alpha / 2}$, is the 1- $\alpha / 2$-quantile of the $t$-distribution with $n$ degrees of freedom.

- The normal distribution quantile $u_{1-\alpha / 2}$ is the 1- $\alpha / 2$-quantile of the normal distribution; it is taken as approximation for the $t$-quantile; normally here $u_{1-\alpha / 2}=1,96$.

- The number $N$ represents the entire amount of a limited main unit, means the main unit consists of a limited quantity of $N$ (e.g. apartments/units).

The following equation could be used to define the sample size number $n$ of a limited main unit:

$$
\left[\frac{-\mathrm{N} * \delta+\sqrt{N^{2} * \delta^{2}+4 * \Delta^{2} * \mathrm{~N} * u_{1-\alpha / 2}^{2}}}{2 * \Delta * u_{1-\alpha / 2}}\right]^{2}
$$

As example the following Table 5-8 provides an overview of the sample size number, $n$, for different measurement errors regarding an intended tolerance of $\delta=5 \%$.

Table 5-8. Sample size numbers $n$ of different main unit quantities $N$ and 10 to $40 \%$ measurement error.

\begin{tabular}{|c|c|c|c|c|}
\hline $\begin{array}{c}\text { Measurement } \\
\text { error } \Delta\end{array}$ & $\mathrm{N}=25$ & $\mathrm{~N}=50$ & $\mathrm{~N}=100$ & $\mathrm{~N}=300$ \\
\hline 0,1 & 8 & 10 & 12 & 14 \\
\hline 0,15 & 11 & 16 & 21 & 28 \\
\hline 0,2 & 13 & 21 & 30 & 45 \\
\hline 0,25 & 15 & 25 & 38 & 61 \\
\hline 0,3 & 16 & 28 & 44 & 77 \\
\hline 0,35 & 17 & 30 & 49 & 91 \\
\hline 0,4 & 18 & 32 & 53 & 104 \\
\hline
\end{tabular}

C. The third step is the selection process of the sample size number. Within the homogeneous clusters (units, buildings) the selection could be done randomly, like explained below as the "three main types of sampling", according to Figure 5-9 and Figure 5-10. Within the critical zones all apartments/units should be selected (monitored) if the number of the sample does not exceed an maximum size. If the critical zones exceed this size (for example: an entire glazed building façade) this zone should be treated as further "homogeneous cluster". 


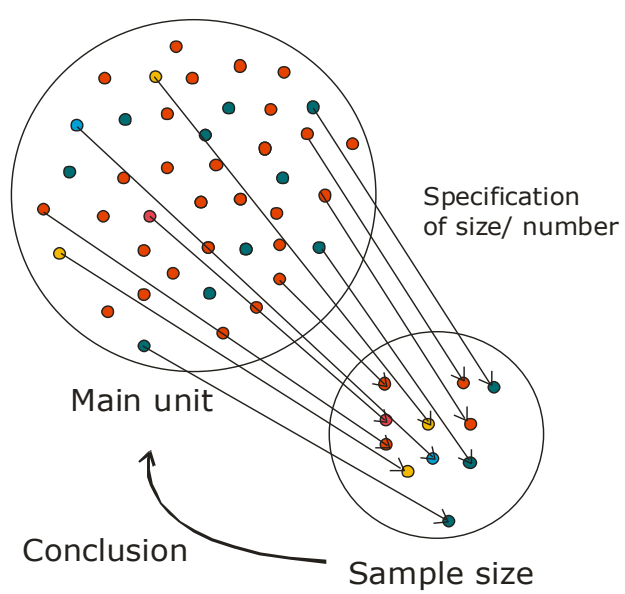

Figure 5-9: Sampling - the analysis of a smaller part (sample size) is used to draw conclusions into the main unit.

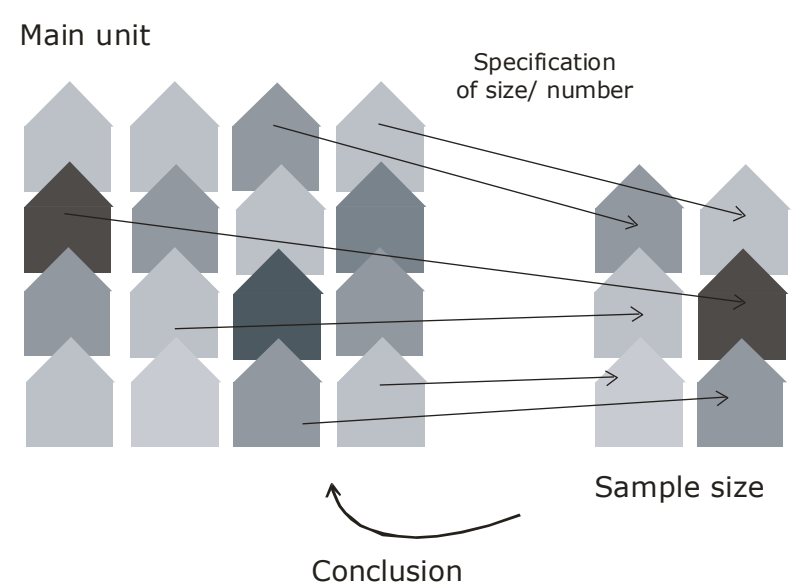

Figure 5-10: The analysis of a smaller number of apartments/units/rooms (sample size) may be used (under specific conditions) to draw conclusions into the apartments/units/rooms of the entire building complex.

Considering some basic principles of statistics it is possible to draw general conclusions from sample observations characterizing the main unit with an associated quantifiable confidence and imprecision. Depending on the sampling strategy, the sample approach can be classified in three main types of samples:

- Random samples: each part of the main unit has a certain chance to be selected as a part of the sample.

- Non-random samples: various types of non-random samples exist, based on judgment, purposive or snowball selection; often there are subjective choices within the selection procedures. This sampling strategy typically does not generate representative results.

- "Cluster sampling" in which some sort of grouping strategy is implemented (e.g., all buildings within one neighborhood are studied, but no other neighborhoods). It is generally cheaper than other options but tends to have a bigger sampling error and more assumptions.

\section{Example of a sample survey procedure:}

The task in this example is to develop a complementary comfort monitoring plan in order to check the balance of a residential area with 100 apartments in 5 building blocks of 20 apartments each; two buildings in the front and three in the back row (Figure 5-11). The apartments are oriented toward south, east and west, while staircases and the arcades to the north. The last floors of 3 buildings are built as lightweight constructions (see Figure 5-12 bright orange apartments). 


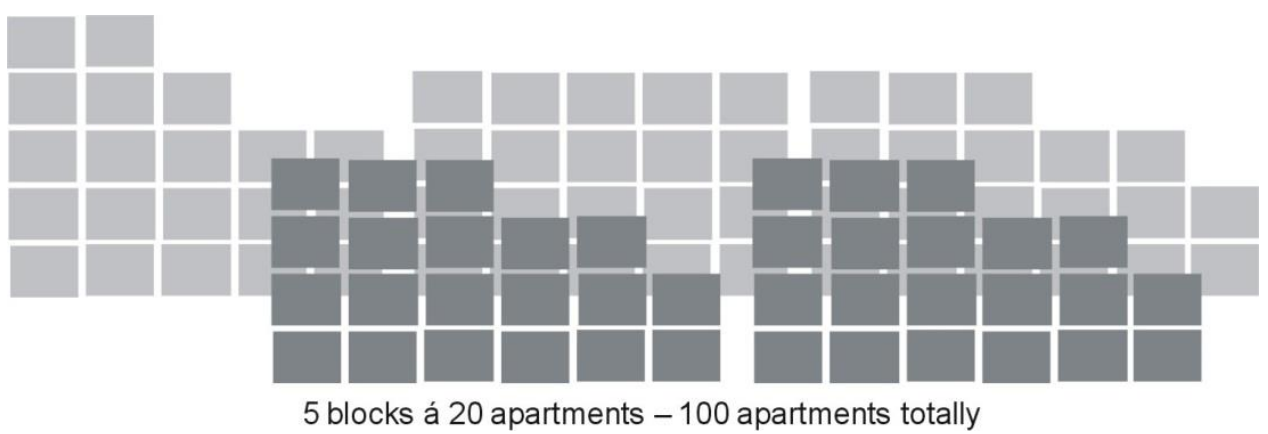

Figure 5-11: Example of a residential area with five building blocks of 20 apartments each.

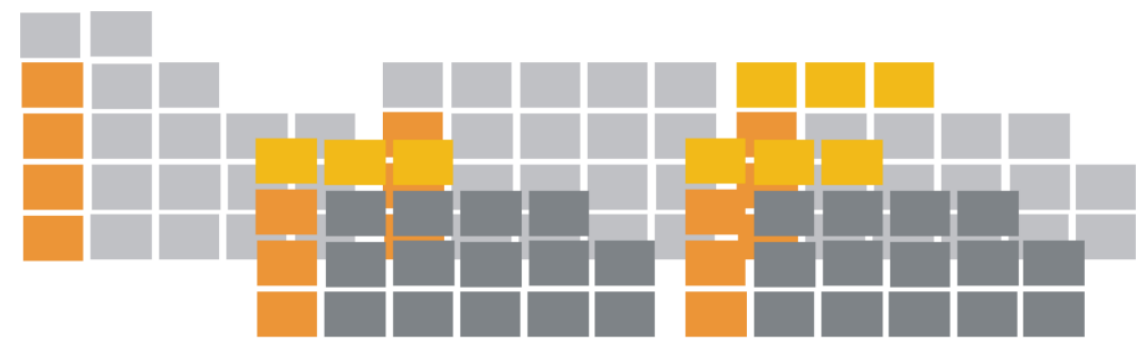

Homogeneous groups

Figure 5-12: The orange marked apartments have one dominating homogeneous specification: the orientation (dark orange on the left side) and structure type (light orange on top floor as lightweight construction).

In order to obtain statistically representative measurements (for example temperature, relative humidity and $\mathrm{CO}_{2}$-concentration in every single apartment/unit), the first step is to define homogeneous clusters and critical zones. Although there are different specifications by the orientation of the apartments/units, all of them are seen as one homogeneous cluster, except those with the lightweight constructions, situated in the top floor; these are defined as one critical zone.

Second step is the calculation of the sample size number of the homogeneous cluster:

$$
\mathrm{n}=\left[\frac{-91 * 0,05+\sqrt{91^{2} * 0,05^{2}+4 * 0,1^{2} * 91 * 1,96^{2}}}{2 * 0,1 * 1,96}\right]^{2}=12
$$

Where:

$\mathrm{N}=100-9=91$

$\delta=5 \%$

$\Delta=10 \%$

Therefore, the sample size of the measured apartments/units within the homogeneous cluster should be 12. The third and final step is to make a random choice out of all apartments in the homogeneous cluster (Figure 5-13, green-colored apartments/units), plus non-randomly chosen three apartments/units from the critical zone (Figure 5-13, red-colored apartments/units). Therefore, for this example 15 apartments/units are measured to get a comprehensive overview on the comfort situation of the whole residential area. 


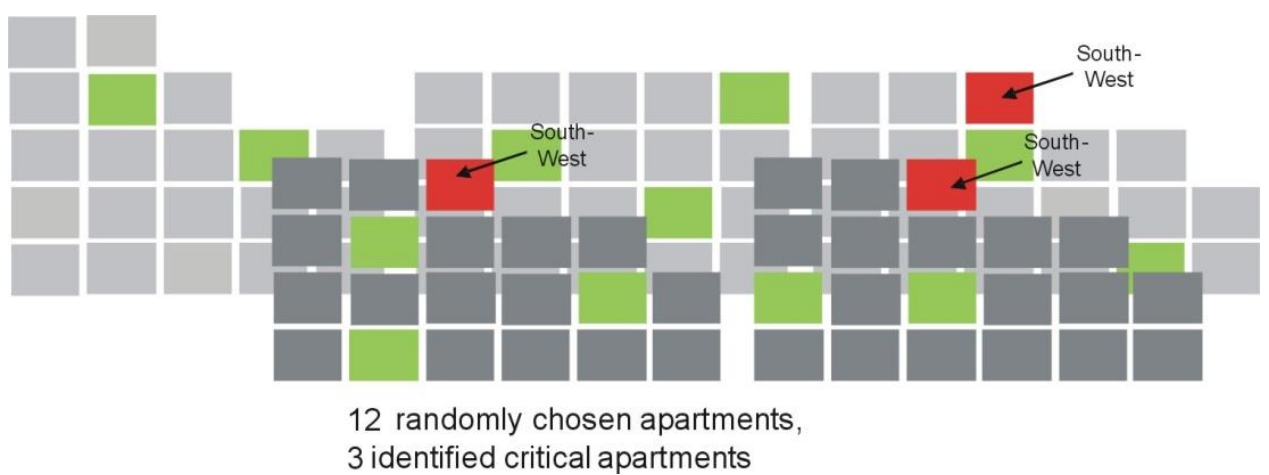

Figure 5-13: The green marked apartments are selected randomly, the red ones identified to be necessary for measuring the critical zone.

\subsubsection{Interpretation of results}

The most critical part is the interpretation of the results. Since external weather conditions, internal loads and user behaviour vary spatially and temporally, IEQ and the required energy supply to maintain the adequate indoor conditions will vary accordingly. Therefore, long-term assessment will show a more representative picture and complementary comfort monitoring when conducted in parallel of energy measurement in order to check the yearly balance. Typically, the first year of operation is needed for the users to adjust to the new building services; The "IBK"-monitoring project in Austria (Wagner et al., 2010) demonstrated that the first year of measurements, that included close cooperation with in-house technicians and occupants, has a great potential for system optimization. In many cases the second year of measurement brought better results than the first year in terms of actual energy consumption assessment.

Occupancy pattern and weather conditions (in combination) provide varying base conditions and experts in the field of IEQ and assessment (Olesen, 2010) suggest that a small percentage of measured values (3-5\%) are permitted to be outside the range. Applying that approach to residential buildings it could also be considered that $3-5 \%$ of the utilization hours per day can be permitted to be out of range. However, due to a more intense usage, the acceptable variation should not be summed up monthly or yearly, since that would possibly lead to an increased stress on the occupants over a short time span; for example, overheating occurs predominantly in summertime during the daytime - a higher percentage of allowed hours of overheating leads to doubling the days with overheating. The interpretation of the measured comfort indicators in order to complement the energy balance check should consider that range. A critical view is necessary to assess the outcomes resulting from the random sample data and from the critical zones. Big variations have to be scrutinized due to the different solution set alternatives. Additionally, a differentiated view on the observation regarding measured comfort conditions is necessary since the symptoms, reasons and influence on the energy balance vary. Finally, the complementary assessment of comfort criteria together with energy balance check is both a verification of the building performance and a chance to optimize building operation. The installation of sensors in the selected spaces is conditional to agreement with the inhabitants, especially for the residential sector.

\subsubsection{Post Occupancy Evaluation (POE) questionnaires}

The IEQ should also be evaluated with subjective assessments that rely on occupant survey via questionnaires based on scientific methods. A review of post-occupancy evaluation (POE) studies can be found in (Gossauer and Wagner, 2007; Mlecnik et al., 2012). When properly used, occupant surveys are an effective method of assessing the acceptability of the 
indoor environment. Additionally, they can provide feedback during the commissioning of HVAC systems or passive strategies to quickly identify failure causes and address complaints as well as to correlate building energy consumption with the corresponding comfort conditions. At the same time, a critical evaluation of the questionnaire results should be conducted since several biases exist.

Two types of POE questionnaires (sometimes coupled with interviews) can be distinguished. They can be used as a separate tool, but usually they are accompanied with measurements and/ or site visits. Spot surveys are short questionnaires with the objective to receive feedback from the occupant right at the moment when the survey is answered. General satisfaction surveys have the objective of tracking the general evaluation of the indoor environment by the occupant.

\subsubsection{Spot surveys}

In a spot survey the occupants are asked how they feel right now. It is also recommended to combine this with a spot measurement of the physical environment (see Figure 5-14). The survey can also be done frequently using online questionnaire via internet or intranet repeated each month or in different seasons with the same individuals. It is recommended to administer the survey several times in the day (e.g., morning and afternoon in the case of offices or working places, avoiding lunch pauses or after the entry time). The survey has the objective to record current impressions and should be short (1-5 minutes). A selection of spot survey questions is presented in Table A1.1. Net ZEB usually are built with passive strategies and/or environmental controls that could be managed by the user. Therefore, spot surveys are important to record which environmental controls have been activated by the users. Some example of questions is reported in Figure 5-15, but that should be adapted to the building features.

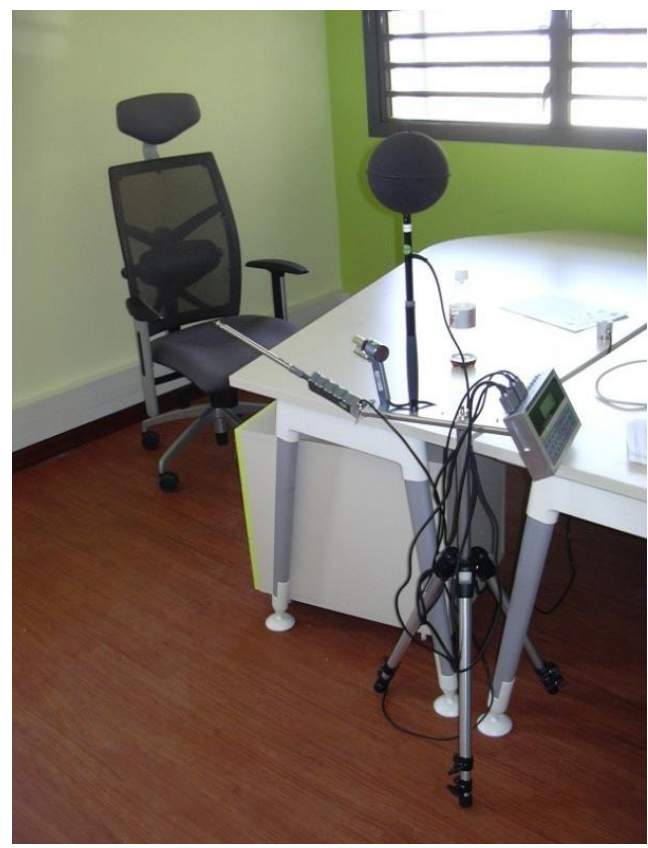

Figure 5-14: Example of portable unit used for the spot measurements and the assessment of thermal comfort in the Enerpos Building. Indoor air temperature, indoor humidity, black globe temperature, illuminance and air velocity are measured every minute ( 10 seconds for air velocity) and stored every 15 minutes. Source : University of Reunion. 


\begin{tabular}{ll}
\hline Environmental controls & Internal door open / closed \\
& External door open / closed \\
& General heating on/off \\
& Local heater on/off \\
& Window open / closed \\
& Blinds/curtains open / closed \\
& General lighting on/off \\
& Local lighting on/off \\
& Local fan on /off \\
\hline
\end{tabular}

Figure 5-15. Example of questions about environmental controls.

Additional questions about how the environmental conditions affect productivity or health can be asked depending of the survey objective. Contextual information is needed to make further analysis and to relate the interviewed person to the building. Examples of the questions used to characterize contextual circumstances are presented in Annex 1, Table A1.2.

\subsubsection{General satisfaction surveys}

A second form of environmental survey is an overall questionnaire that includes several background questions with the purpose of evaluating occupant satisfaction with respect to the environment. The basic premise of this survey method is that occupants can recall instances or periods of discomfort and provide a general evaluation of their indoor environment. However, attention should be paid to the accuracy of occupant recollection to periods and instances far in the past. This survey type does not relate to a specific moment in time but based on a seasonal evaluation. Since the survey results encompass a larger time-frame, the questionnaires can be administer every six months or repeated in different seasons (heating, cooling and intermediate). An example of that kind of surveys is the BUS (Building Use Studies) methodology surveys (Baird, 2009; Baird, 2010). Also, some extended questionnaires are required for renovated buildings (AEE INTEC, 2010) or for special or broader studies (Cannata and Pörnbacher, 2011). Questionnaires need to be adapted in the case that there will be the intention to record feedback from transient users of a building, rather than only from the permanent staff or occupants. Examples of questions used in general satisfaction surveys are presented in Annex 1, Table A1.3 for work spaces. Note that there might be a need to adapt such questionnaires for residential buildings. For example, for the evaluation of zero energy housing the importance of checking the perceived quality of installed building services was noted, as well as the presence of suitable end-user information (Mlecnik et al., 2012). 


\section{Data post-processing and standard reporting}

After the energy and IEQ data are collected, they need to be processed in order to verify the satisfaction of the Net ZEB criteria as well as to characterize the indoor conditions, identify trends and in general draw conclusions. The following sections will describe possible postprocessing and data visualization. The findings from the data analysis and the associated figures/tables can then be included in a standard report summarizing the outcomes (see subchapter 3.1.3). The report can be divided considering the different monitoring parameters and aspects.

\subsection{Energy}

The analysis will assist in the verification of the elevated building performance in terms of energy consumption and environmental conditions. Additionally, the analysis and data visualization may highlight dependencies and important factors to be considered.

\subsubsection{Whole building energy balance}

In order to check the energy balance and verify that the building is performing as Net ZEB, the desired definition (subchapter 4.3.1) and boundaries (subchapter 3.1.1) must be chosen. Subsequently, the balance check can be performed. One possibility is to use the Net ZEB evaluation tool (available for free download at http://task40.iea-shc.org/net-zeb) that assist in the calculation of the balance and the operating costs associated with different selected definitions and load match indexes for electricity and thermal energy.

Figure 6-1 presents an example of the tool outputs. Balance results are reported for each definition, identified by the frame cell color, in the upper part of the section. The definitions are summarized in Figure 6-1. Figure 6-2 presents the balance graph results with the weighted demand on the $x$-axis and the weighted supply on the $y$-axis. If the weighted supply equals the weighted demand, the point falls on the diagonal and the balance is zero. If the balance is positive, the point falls above the diagonal, while if the balance is negative the point falls below the diagonal. The graphs on the right indicate the load match indexes for electricity and thermal energy. Monthly values of load and generation (as presented in the example) or of delivered and exported energy can be plotted. Average electricity and thermal load match are reported in the cells above the respective graphs. In the lowest part of the section, identified by the framed cell color, operating costs for each definition (and the associated included elements) are reported. 


\begin{tabular}{|c|c|c|c|c|c|}
\hline \multicolumn{6}{|c|}{$\begin{array}{l}\text { A Net Zero Energy Building is the "building system" delimited by set physical boundaries, connected to any energy infrastructure, which balance between its } \\
\text { weighted energy loads and supplies is zero. }\end{array}$} \\
\hline & & Net ZEB limited & Net ZEB primary & Net ZEB strategic & Net ZEB carbon \\
\hline $\begin{array}{l}\text { Building } \\
\text { system } \\
\text { boundary }\end{array}$ & Balance boundary & $\begin{array}{l}\text { HEATING } \\
\text { DHW } \\
\text { COOLING } \\
\text { VENTILATION } \\
\text { AUXILARIES } \\
\text { BUILT-IILLGHTING (only non } \\
\text { residential buildings) }\end{array}$ & $\begin{array}{l}\text { HEATING } \\
\text { DHW } \\
\text { COOLING } \\
\text { VENTILATION } \\
\text { AUXILIARIES } \\
\text { BUILT-IN LIGHTING } \\
\text { PLUG LOADS }\end{array}$ & $\begin{array}{l}\text { HEATING } \\
\text { DHW } \\
\text { COOLING } \\
\text { VENTILATION } \\
\text { AUXILIARIES } \\
\text { BUILT-IN LIGHTING } \\
\text { PLUG LOADS }\end{array}$ & $\begin{array}{l}\text { HEATING } \\
\text { DHW } \\
\text { COOLING } \\
\text { VENTILATION } \\
\text { AUXILIARIES } \\
\text { BUILT-IN LIGHTING } \\
\text { PLUG LOADS }\end{array}$ \\
\hline \multirow{3}{*}{$\begin{array}{l}\text { Weighting } \\
\text { system }\end{array}$} & Metric & PRIMARY ENERGY & PRIMARY ENERGY & Whichever metric desired & CARBON EMISSION \\
\hline & Symmetry & SYMMETRIC & SYMMETRIC & SYMMETRIC Or ASYMMETRIC & SYMMETRIC Or ASYMMETRIC \\
\hline & $\begin{array}{l}\text { Time dependent } \\
\text { accounting }\end{array}$ & STATIC OR QUASI-STATIC & STATIC OR QUASISTATIC & STATIC OR QUASISTATIC & STATIC OR QUASI-STATIC \\
\hline \multirow[t]{2}{*}{$\begin{array}{l}\text { Net ZEB } \\
\text { balance }\end{array}$} & Energy efficiency & $\begin{array}{l}\text { NATIONAL/LOCAL ENERGY } \\
\text { EFFICIENCY REQUIREMENTS } \\
\text { ARE FULFILLED }\end{array}$ & $\begin{array}{l}\text { NATIONAL/LOCAL ENERGY } \\
\text { EFFICIENCY REQUIREMENTS } \\
\text { ARE FULFILLED }\end{array}$ & $\begin{array}{l}\text { ANY NATIONAL/LOCAL ENERGY } \\
\text { EFFICIENCY REQUIREMENTS } \\
\text { HAS TO BE FULFILLED } \\
\end{array}$ & $\begin{array}{l}\text { ANY NATIONAL/LOCAL ENERGY } \\
\text { EFFICIENCY REQUIREMENTS } \\
\text { HAS TO BE FULFILLED }\end{array}$ \\
\hline & Energy supply & $\begin{array}{l}\text { ON SITE GENERATION DRIVEN } \\
\text { BY ON/OFF SITE SOURCES }\end{array}$ & $\begin{array}{l}\text { ON SITE GENERATION DRIVEN } \\
\text { BY ON/OFF SITE SOURCES }\end{array}$ & $\begin{array}{l}\text { ON/OFF SITE GENERATION } \\
\text { DRIVEN BY ON/OFF SITE } \\
\text { SOURCES }\end{array}$ & $\begin{array}{l}\text { ON SITE GENERATION DRIVEN } \\
\text { BY ON/OFF SITE SOURCES }\end{array}$ \\
\hline
\end{tabular}

Figure 6-1. Overview of the four definitions considered.

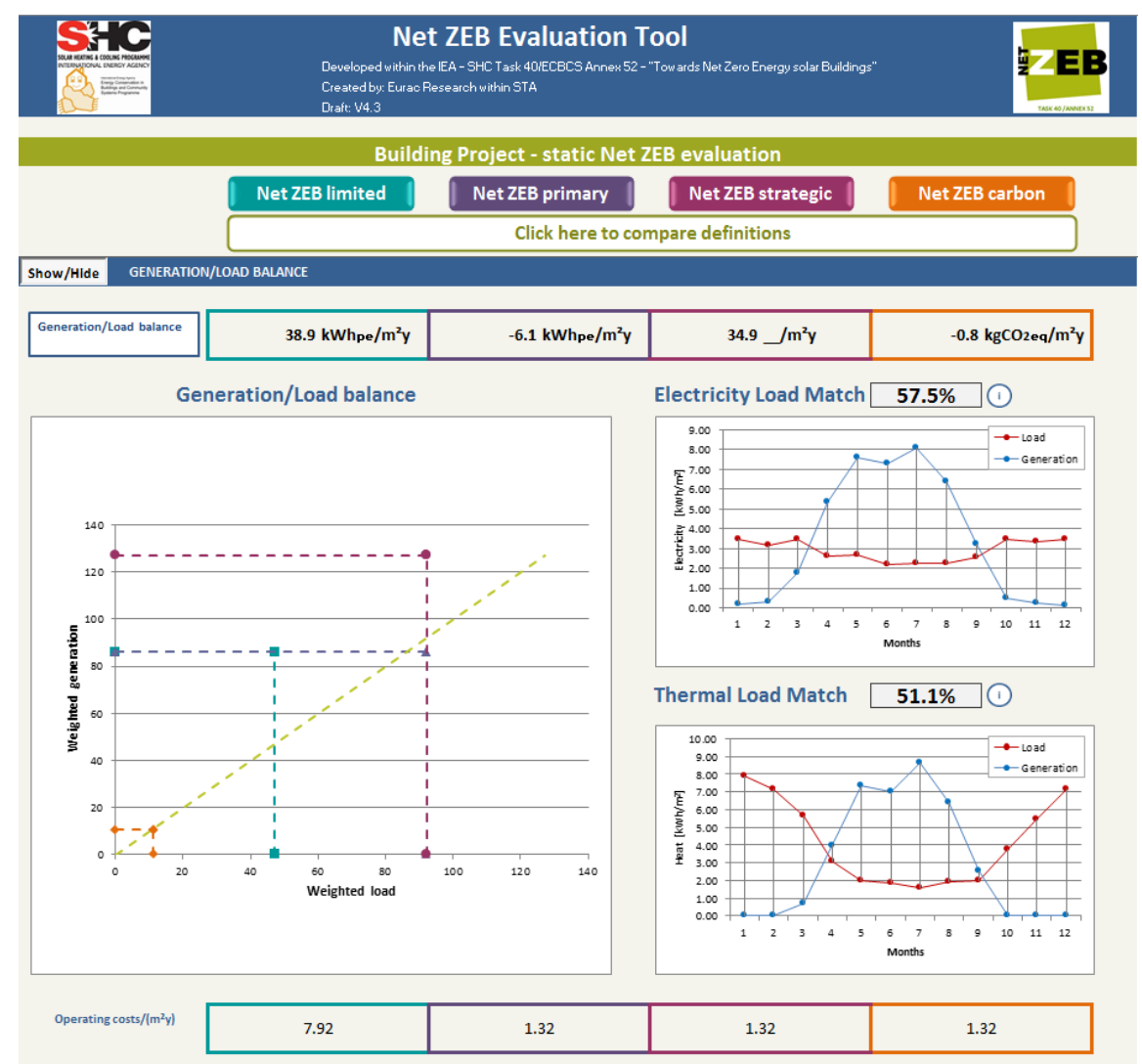

Figure 6-2: Net ZEB evaluation tool outputs presentation.

\subsubsection{Thermal energy consumption}

This section should include a description of the HVAC and DHW systems ranging from generation to the terminal units and control strategy as well as an introduction to the energy consumptions. Subsequently, it should include information to characterize and generalize 
the consumption, also taking into account the external weather and the indoor temperature conditions during the period of interest as exemplified in Table 6-1 and Figure 6-3.

Table 6-1: Example of measured and normalized heating energy consumption expressed in .

\begin{tabular}{|c|c|c|c|c|}
\hline \multirow[t]{2}{*}{ Month } & $\begin{array}{l}\text { Monthly energy } \\
\text { per } \mathrm{m}^{2}\end{array}$ & $\begin{array}{l}\text { Normalized to } \\
\text { external climate }\end{array}$ & $\begin{array}{l}\text { Normalized to external and } \\
\text { internal climate }\end{array}$ & $\begin{array}{l}\text { PHPP } \\
\text { calculation }\end{array}$ \\
\hline & \multicolumn{4}{|c|}{$\left(\mathrm{kWh} / \mathrm{m}^{2} \mathrm{month}\right)$} \\
\hline October & 0,0 & 0,0 & 0,0 & \\
\hline November & 1,0 & 1,1 & 0,9 & \\
\hline December & 3,2 & 3,8 & 3,2 & \\
\hline January & 3,2 & 3,9 & 3,2 & \\
\hline February & 2,9 & 3,4 & 2,8 & \\
\hline March & 0,02 & 0,02 & 0,02 & \\
\hline April & 0,0 & 0,0 & 0,0 & \\
\hline Winter ${ }^{1}$ & 10,3 & 12,3 & 10,1 & 14 \\
\hline
\end{tabular}

${ }^{1}$ This figure refers to the Northern hemisphere. In the Southern hemisphere it would be summer. Note: $\mathrm{m}^{2}$ refers to the treated floor area (TFA)

Different possible figures can be created to show the energy consumption profile and the dependencies with external variables (e.g., Heating Degree Days (HDD) and solar radiation) as shown in Figure 6-2. The figures and tables should facilitate the associated discussion that should elucidate patterns and help the reader focus the attention on the important aspects.

Monthly thermal energy consumption for heating and domestic hot water

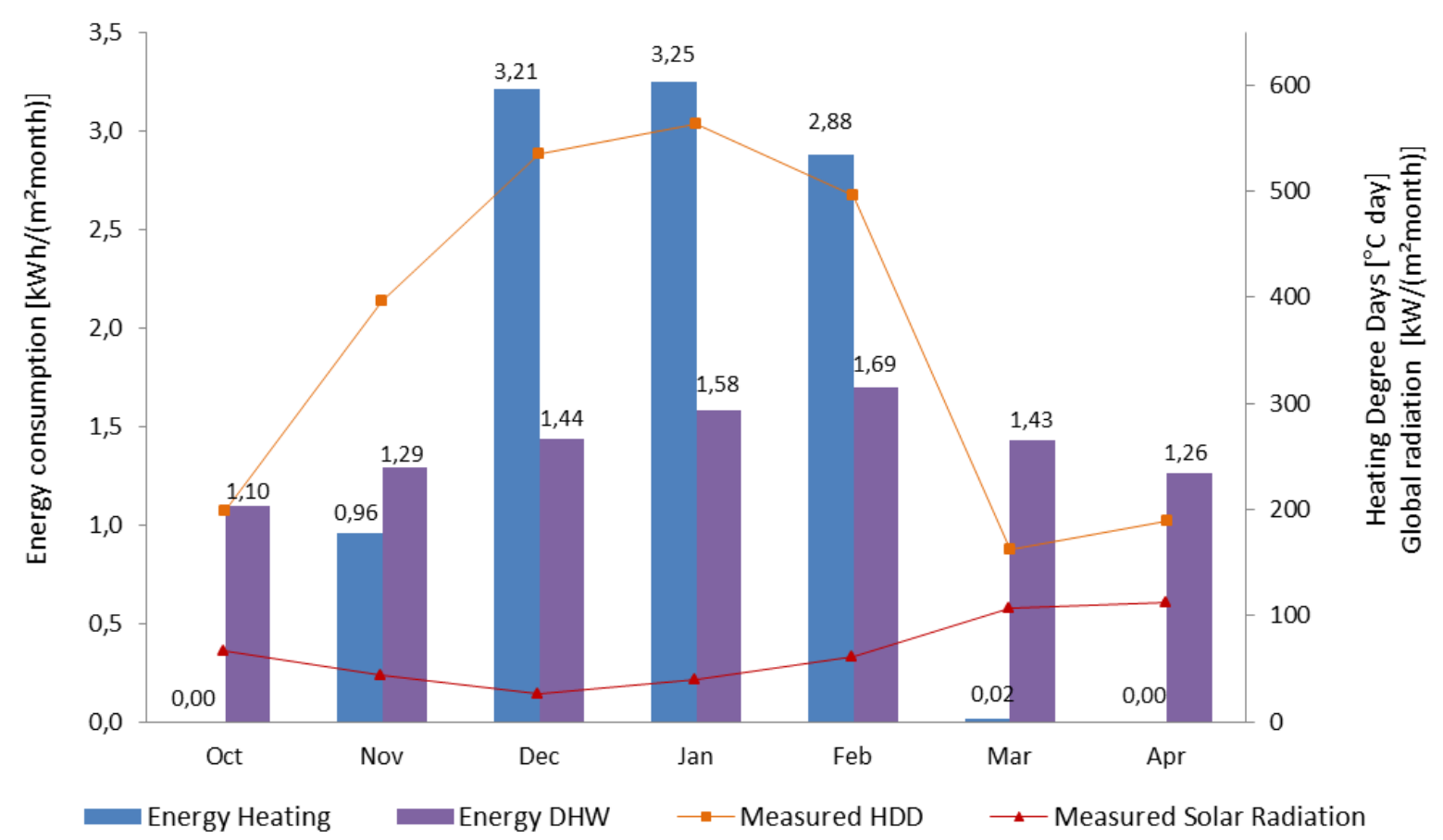

Figure 6-3: Measured monthly energy consumption for heating and DHW. The measured monthly solar radiation and the heating degree days are also shown. 


\subsubsection{Electric energy consumption}

This section should include an introduction to electric energy consumptions and production systems. The energy consumption systems could include heating and DHW (if electric) cooling, ventilation and lighting system as well as the main appliances present. If energy production is present it should also be described. After this descriptive phase, the monitored consumptions can be presented and various possible data visualization options exist. In Figures 6-4a and 6-4b examples with different levels of resolutions are presented.

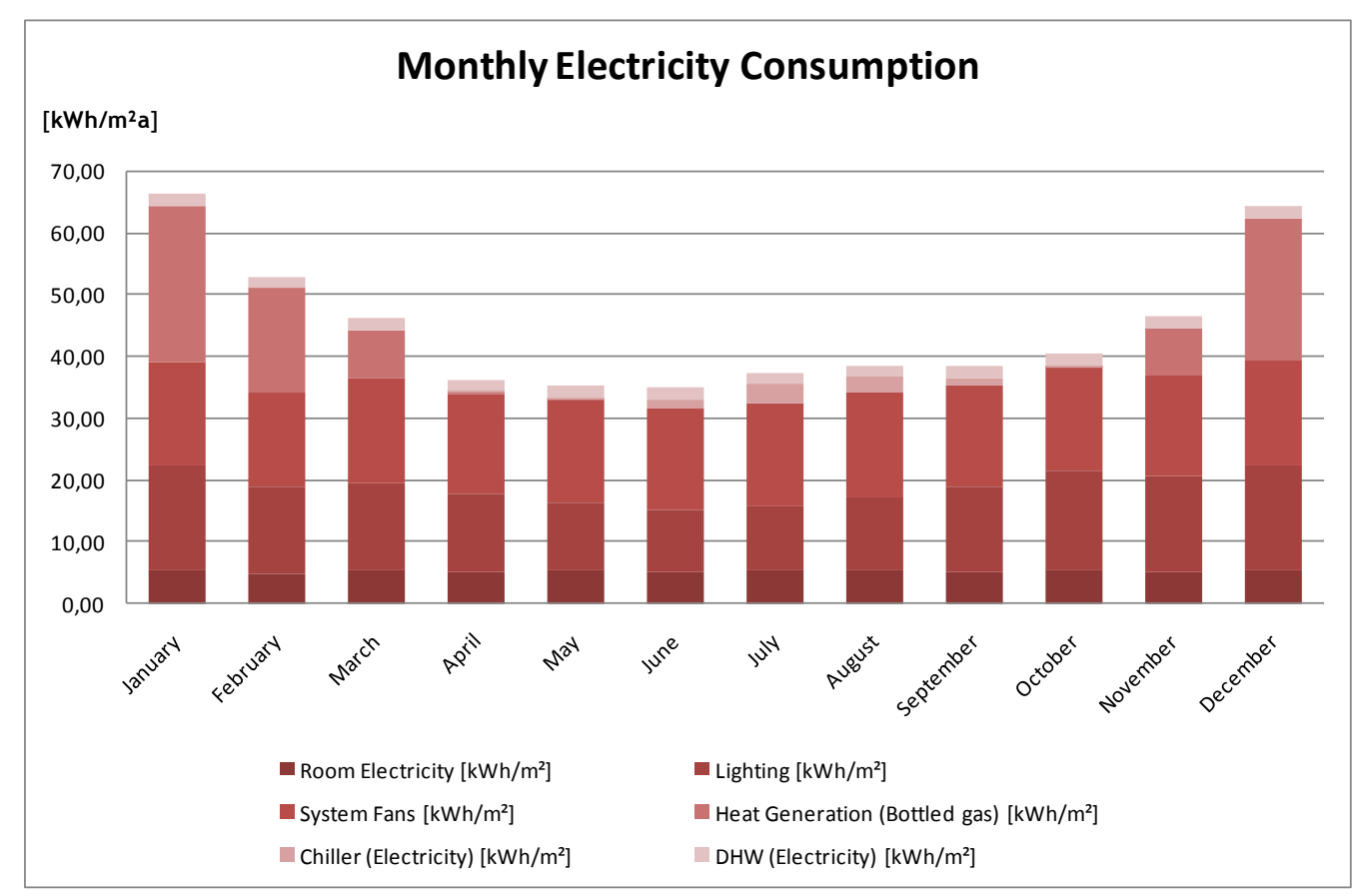

Figure 6-4a: Monthly electric energy consumptions for different uses as well as total consumption.

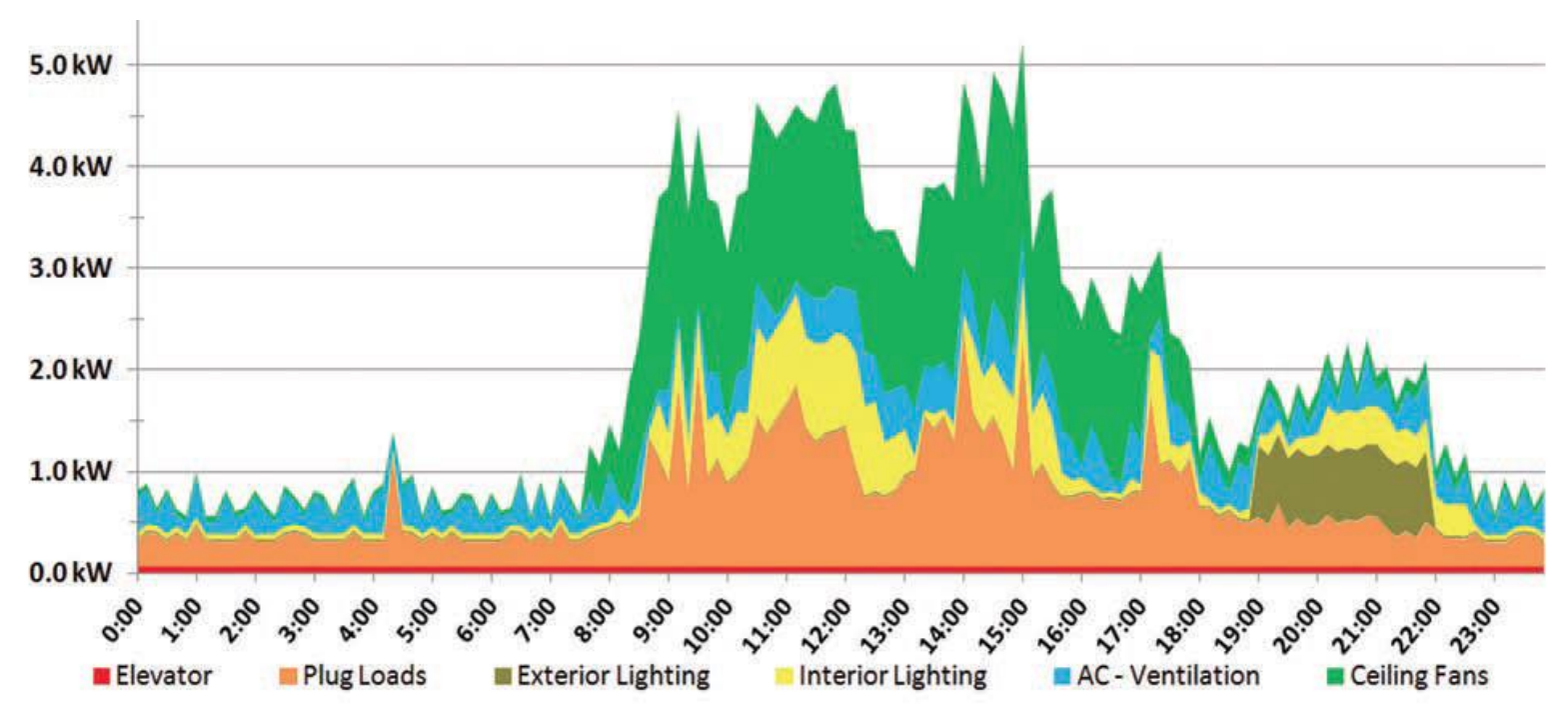

Figure 6-4b: Load curve and daily electric energy consumptions for different end uses for one day, the hottest day of the year, ENERPOS (Lenoir et al., 2012b). The 10 min time step allows to have clear indications about how the building operates and the possible improvements in terms of energy savings. One can note the very low peak power for a $680 \mathrm{~m}^{2}$ Net Floor Area building. 


\subsubsection{Primary energy consumption}

If the reference metric is the primary energy consumption instead of the site energy consumption, the primary energy factors need to be factored in to convert the energy uses to a common metric (see subchapter 4.3.1).

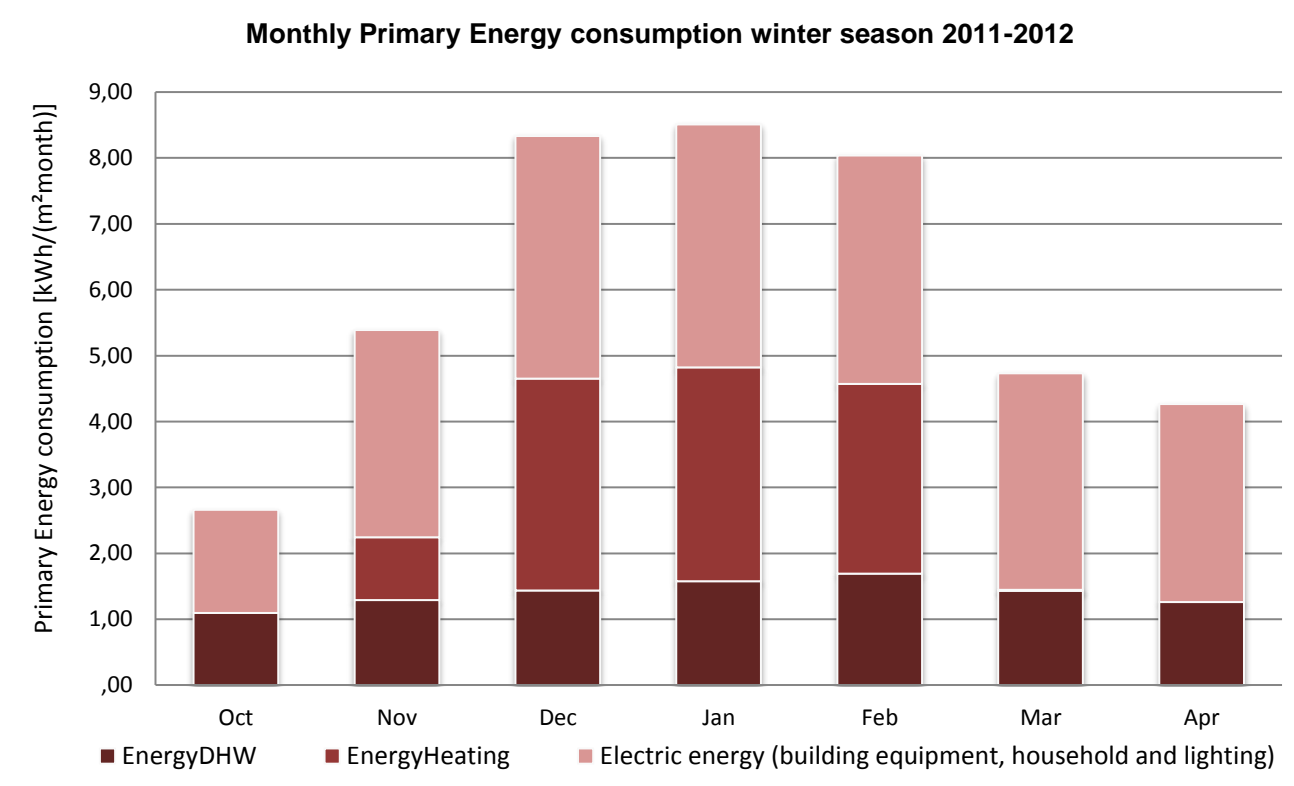

Figure 6-5. Representation of monthly primary energy consumption with primary energy factor taken from DIN V 4701-10/GEMIS 4.14.

\subsubsection{Sub-metered energy measurements}

For the different subsystems present in the building additional analyses and associated data visualization exist. The analysis will depend on the specific systems, variables and interest and must be decided by the building monitoring expert. One additional objective could be to verify the correct operation of a specific system and its functioning schedule.

\subsection{Indoor Environmental Quality}

Different factors and parameters influence occupant comfort (e.g., temperature, relative humidity, air speed, luminosity, carbon dioxide concentration). Depending on which parameters are considered important and measured, different analyses and data visualization are possible. The following subchapters and figures present a few examples. Several considerations need to be made in order to select the most appropriate approach for assessing comfort. One of the most important aspects to consider is the reliance on mechanical cooling system (less dependency from outdoor climate) versus the reliance on the adaptive capabilities of occupants (for buildings without mechanical cooling).

\subsubsection{Analysis of ambient temperature and relative humidity}

A graph similar to the one in Figure 6-6 is useful to visualize and identify possible spatial and/or temporal issues with the measurements. 


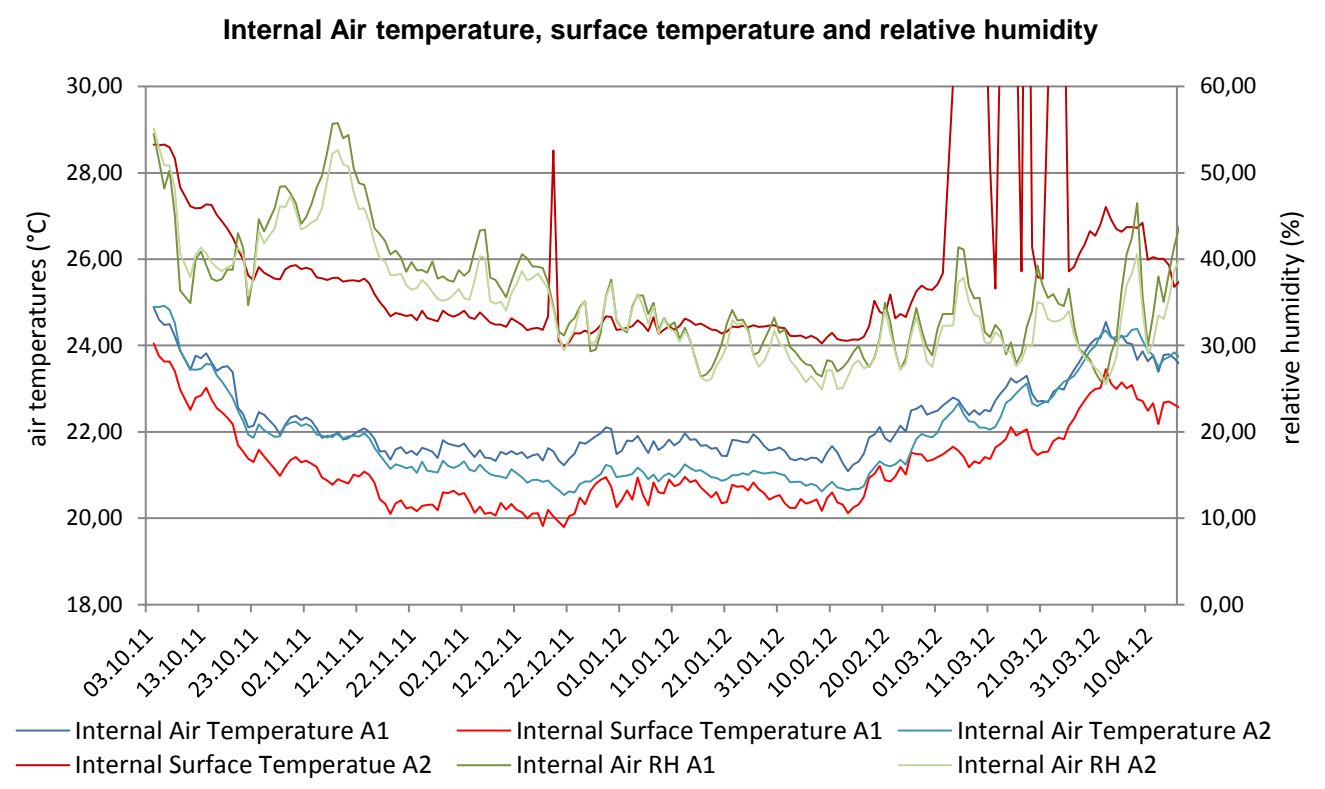

Figure 6-6: Temperature, surface temperature and relative humidity measured in ambient 1 (living room) and ambient 2 (child's bedroom) over a month.

\subsubsection{Thermal comfort analysis during winter with Fanger model, EN ISO 7730}

Figure 6-7 presents the correlation between predicted mean vote (PMV) and percentage people dissatisfied (PPD). Several parameters need to be measured or assumed to be able to estimate comfort conditions. The objective is to obtain PPD lower than $10 \%$, which approximately corresponds to PMV between -0.5 and 0.5 . PMV depends on the operative temperature (influenced by air temperature and mean radiant temperature), clothing level, metabolic rate, air humidity and air speed; the PMV steady-state model is based on an empirical equation typically solved by a computer solver.

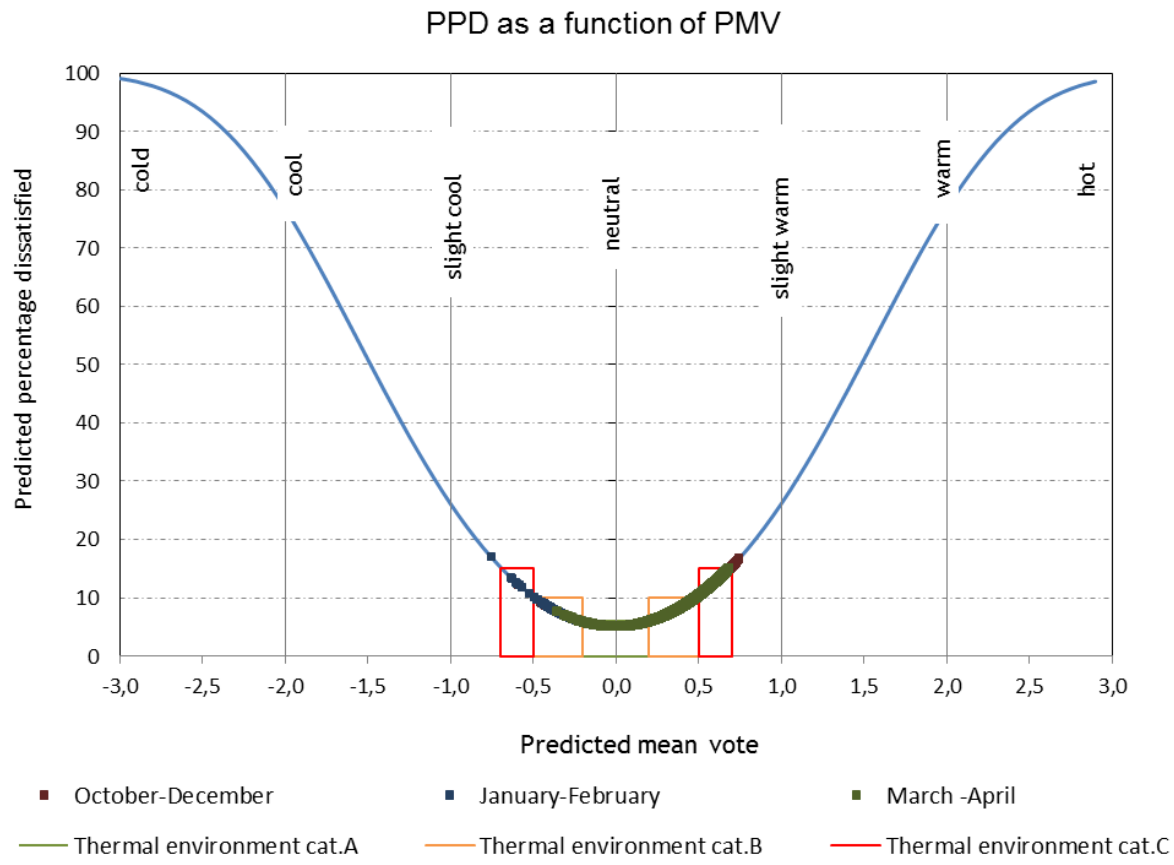

Figure 6-7: Comfort diagram ISO 7730 


\subsubsection{Thermal comfort analysis with psychometric chart and ASHRAE comfort zones}

Another methodology to assess comfort is using ASHARE comfort zones and associated psychometric chart as presented in Figure 6-8. The red (summer) and blue (winter) boxes represent the 0.5 PMV boundaries as a function of operative temperature and humidity ratio for common conditions for clothing level and metabolic rate. This chart identifies comfort zones for winter and summer and, by comparing where the temperature and $\mathrm{RH}$ measured points fall on the chart. Then, it is possible to verify the presence of adequate comfort conditions during the year.

Psychrometric chart with Ashrae comfort zones_ambient 1

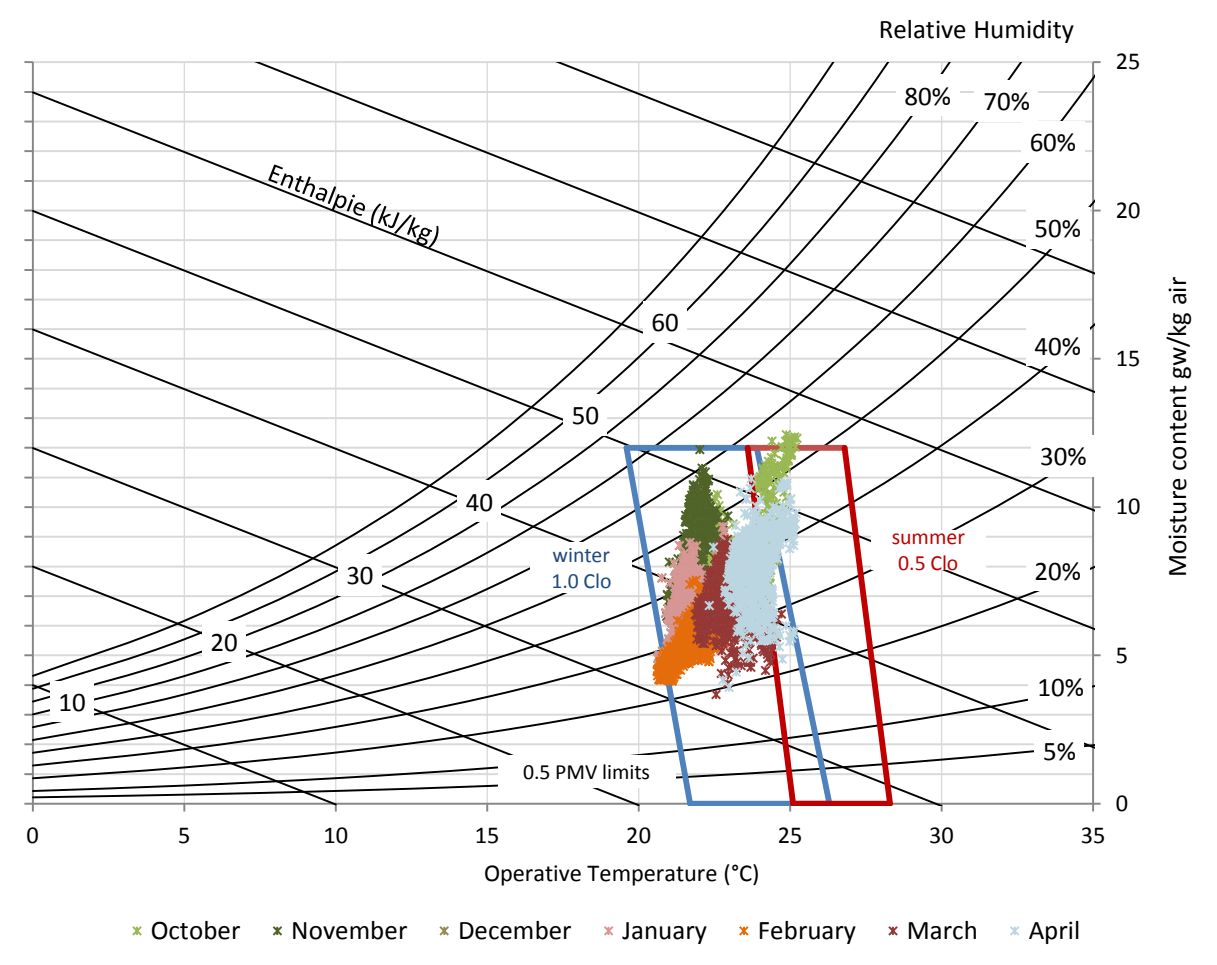

Figure 6-8: Ambient air temperature and humidity for different winter months with ASHRAE comfort zones for summer and wintertime.

\subsubsection{Thermal comfort analysis in hot climate/summer or tropical regions with the Givoni comfort zones}

The Givoni comfort zones have been first introduced by Baruch Givoni in 1971 in his first book "Man, Climate, Architecture" but has been updated more recently in 1998 (Givoni, 1998). To use this approach the four main parameters that influences thermal comfort(air temperature, mean radiant temperature, relative humidity and air velocity) need to be gathered and can be plotted on the psychometric chart Givoni has proposed for tropical/hot regions with comfort zones depending on air velocity. These comfort zones apply for a metabolic rate of 1.2 (tertiary activity) and a summer clothing (0.5 Clo). Regarding the thermal comfort assessment, the output is the percentage of discomfort (e.g., percentage of points outside the comfort zones for the different air velocities).

Figure 6-9 gives an example of the results for a classroom during the hot season (from October to April) in the Enerpos building, Reunion island, Southern hemisphere (Lenoir et al., 2012a). One can note that the percentage of discomfort is $10 \%$ for this example. 


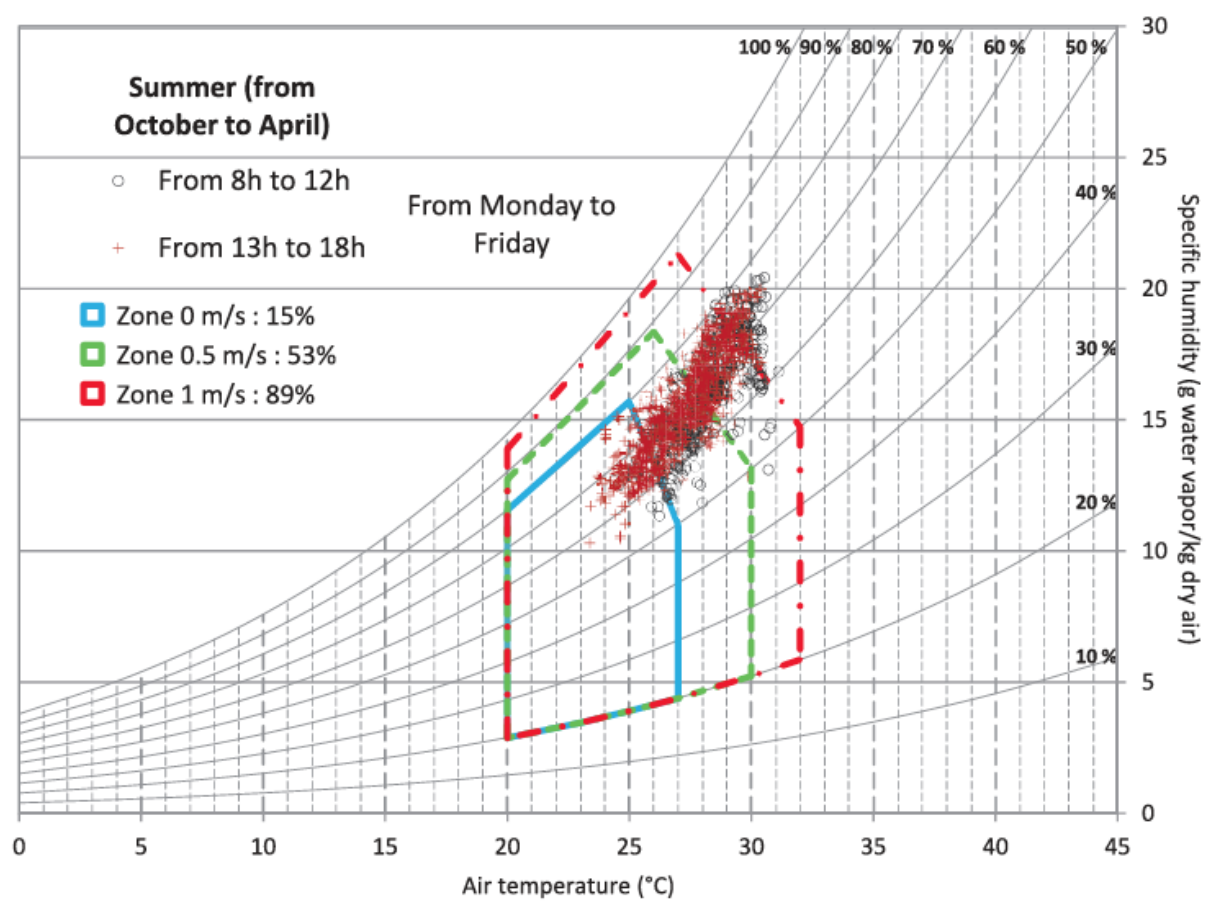

Figure 6-9. Givoni comfort zones on the psychometric chart for a classroom of the ENERPOS building (Reunion Island, France)

\subsubsection{Comfort evaluation in compliance with standard EN 15251:2008}

One of the most used models to assess comfort is the adaptive comfort model based on the adaptive principle. This principle indicates that if a change leading to discomfort occurs, people will tend to act to restore their comfort (e.g., reduce their clothing, increase air movement). As a consequence, people tend to adapt to external conditions and their comfort zone is therefore modified. This adaptive comfort model can be applied to naturally cooled buildings with operable windows and no mechanical cooling system. Standard EN 15251 focuses on overall comfort in buildings with an adaptive approach (i.e. including a behavioral component). The standard defines acceptable indoor operative temperatures according to the adaptive approach as displayed in Figure 6- (for the three building categories). They depend on a running mean outdoor temperature defined by the Equation 3 below. This temperature is calculated by exponentially weighting the daily mean external air temperatures of the day of interest and of a few previous days. It is also possible to use the second equation that is a simplification of the first one and that considers the running mean temperature of the previous day.

$\Theta_{r m}=(1-\alpha)\left[\Theta_{e d-1}+\alpha \Theta_{e d-2}+\alpha^{2} \Theta_{e d-3}+\ldots\right]$

$\Theta_{r m}=(1-\alpha) \Theta_{e d-1}+\alpha \Theta_{r m-1}$

where

$\Theta_{\mathrm{rm}}=$ the running mean temperature for the day.

$\alpha=a$ constant between 0 and 1 , recommended to use 0.8 .

$\Theta_{\text {ed- }-1}=$ the daily mean external temperature for the previous day.

$\Theta_{\text {ed-2 }}=$ the daily mean external temperature for the day before the previous.

$\Theta_{\mathrm{rm}-1}=$ the running mean temperature for the previous day 
Figure 6-10 illustrates the ISO 15251 diagram with comfort zones for different categories during the summer months. Category $I$ is the highest level of comfort and is suggested for spaces occupied by sensitive or fragile people. Category II is the normal level of comfort and should be used as target for typical new constructions and renovations. Category III provides an acceptable level of comfort and could be used for existing buildings. The Category IV is outside the Category III limit.

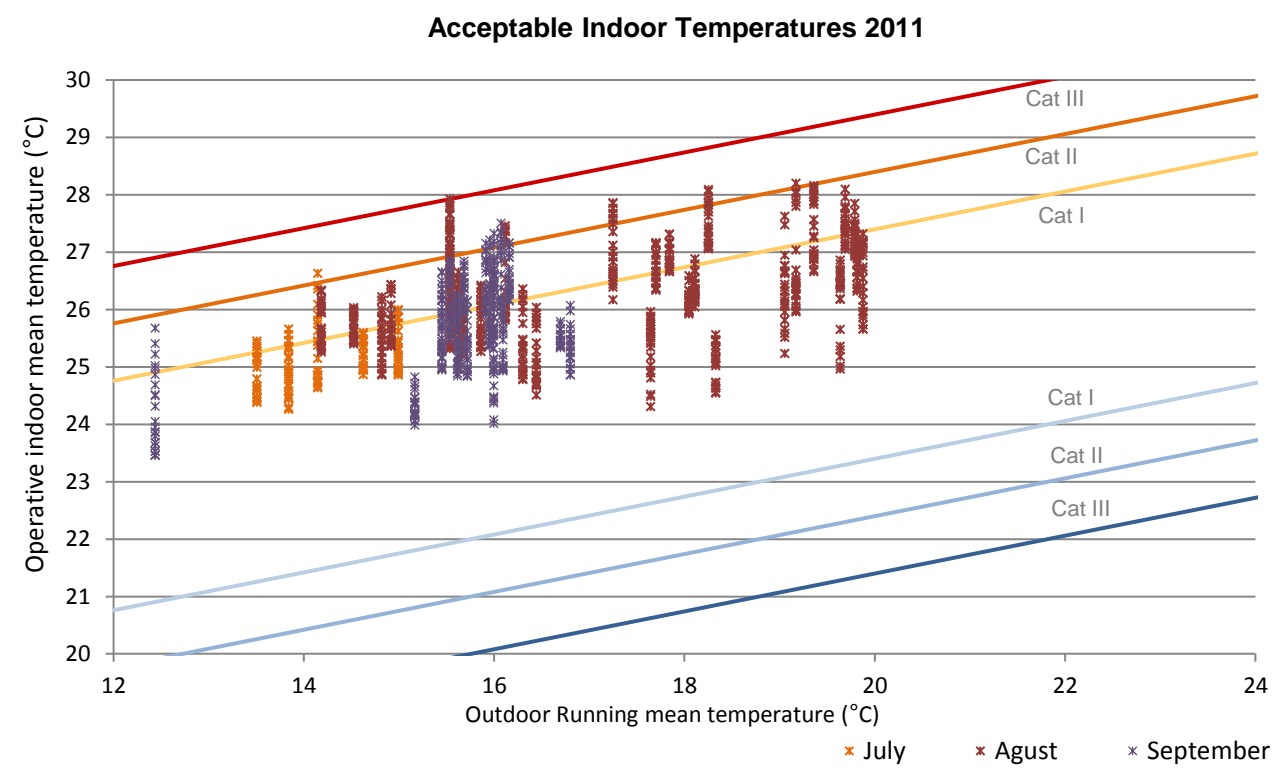

Figure 6-10. Acceptable indoor operative temperature according to EN 15251 in summer (red lines) and winter (blue lines)

For occupants engaged in near sedentary physical activity the operative temperature can be approximately calculated with the following formula from ISO 7730:

$t_{o}=\frac{\left(t_{a}+t_{r}\right)}{2}$

$t_{0}=$ operative temperature

$t_{a}=$ air temperature

$t_{r}=$ mean radiant temperature

If the mean radiant temperature is not measured, the surface temperature can be used as an approximation to calculate the operative temperature. In this case the operative temperature is assumed as the mean value of the air temperature and the surface temperature.

Long term comfort indexes can be illustrated using category distribution. For instance, the calculated number or \% of occupied hours (those during which the building is occupied) when the parameter under study (e.g., PMV, operative temperature, air temperature, $\mathrm{CO}_{2}$ concentration above outdoor, ventilation level, illumination, acoustic) is within the different categories can be shown. Figure 6-11 (Olesen et al., 2011) shows the thermal performance of two rooms in an office building. It illustrates the percentage of time according to the four categories (corresponding to different temperature ranges) suggested by the standard summer period. 

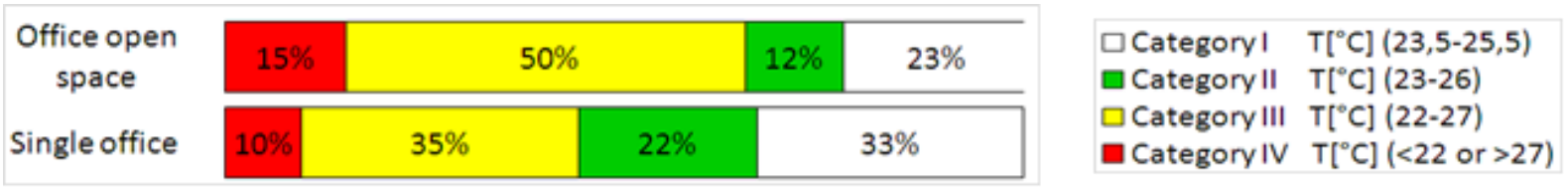

Figure 6-11. Indoor Thermal Quality expressed in percentage of time for four categories of the two analyzed rooms (Olesen et al., 2011).

\subsubsection{Analysis of $\mathrm{CO}_{2}$ measurements}

Carbon dioxide $\left(\mathrm{CO}_{2}\right)$ concentrations are monitored because, since $\mathrm{CO}_{2}$ is the main component present in exhaled air, it is a good indicator of inadequate ventilation and/or elevated occupancy.

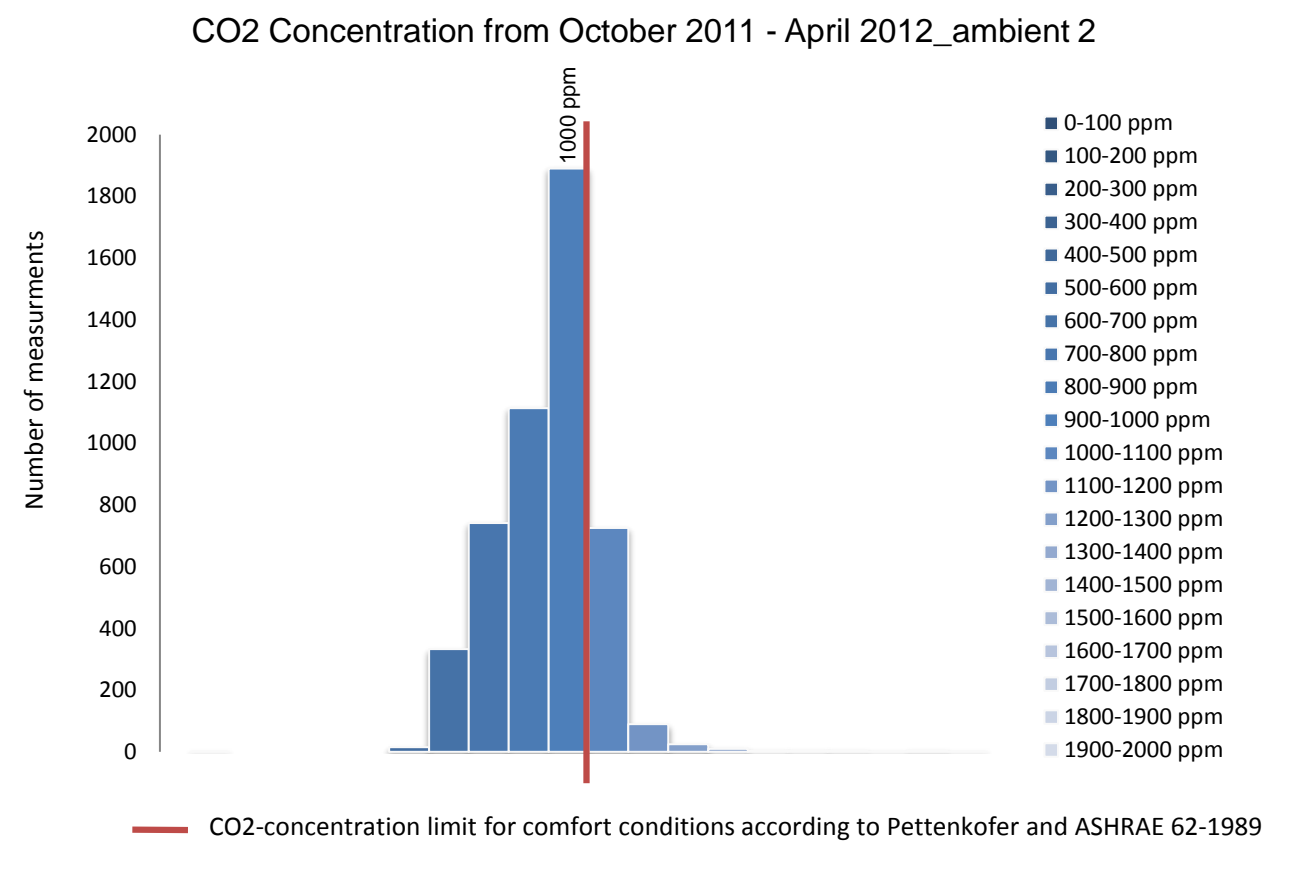

Figure 6-12: $\mathrm{CO}_{2}$ measurement distribution with 100ppm steps in a room. The red bar indicated the $1,000 \mathrm{ppm}$ threshold which is often considered the indicator for adequate conditions.

\subsubsection{Post Occupancy Evaluation results}

There are different approaches to analyze and visualize data from surveys to understand occupant satisfaction with the indoor environment. Additionally to IEQ evaluation, the questionnaires could also assess the activities and possible control strategies implemented by the occupants that could potentially influences energy and IEQ data.

\section{a) Example results of a spot survey: Case study of the Enerpos building (Lenoir et al., 2012a)}

To assess thermal comfort in the building, a specific survey was carried out during three summer seasons. About 2100 questionnaires were answered by the students and their teachers during 125 lectures. The survey was carried out mainly in December, February, March and April which corresponds to summer in the South Hemisphere (university holidays are in January). The survey included questions about the thermal sensation, thermal judgment but also air movement and humidity judgments and preferences (see Table A1.1). The students were asked to fill in the survey when arriving and leaving the classrooms after $1-4 \mathrm{~h}$ of lecture. Only the results at the end of the lectures are taken into account as it was 
shown that the answers when arriving in the room are much too dependent on the previous activity which can be different for all students. The level of a physical activity is expressed by the Metabolic Equivalent Task coefficient (MET). 1 MET is considered as the resting metabolic rate. During the surveys the activity is assumed to be $1.2 \mathrm{MET}$ which corresponds to a seated office activity.

Figure 6-13 illustrates the survey results for the student thermal sensations. The survey asked about their thermal sensation on a 7-point scale similar to the PMV scale: from 'cold' $(-2)$ to 'extremely warm' $(+4)$. The graph shows that only $16 \%$ of the values are above 0.5 which corresponds to predicted percentage of dissatisfied lower than $10 \%$. This figure demonstrates that in some cases with elevated air speed, people do not complain about the thermal comfort even with black globe temperature around $30.5^{\circ} \mathrm{C}$, which is a significant result. In other cases, the students start having comfort issue at lower temperatures (i.e., $\left.28.5^{\circ} \mathrm{C}\right)$. It is demonstrated that air-conditioning could be avoided until this temperature level, if other strategies are implemented.

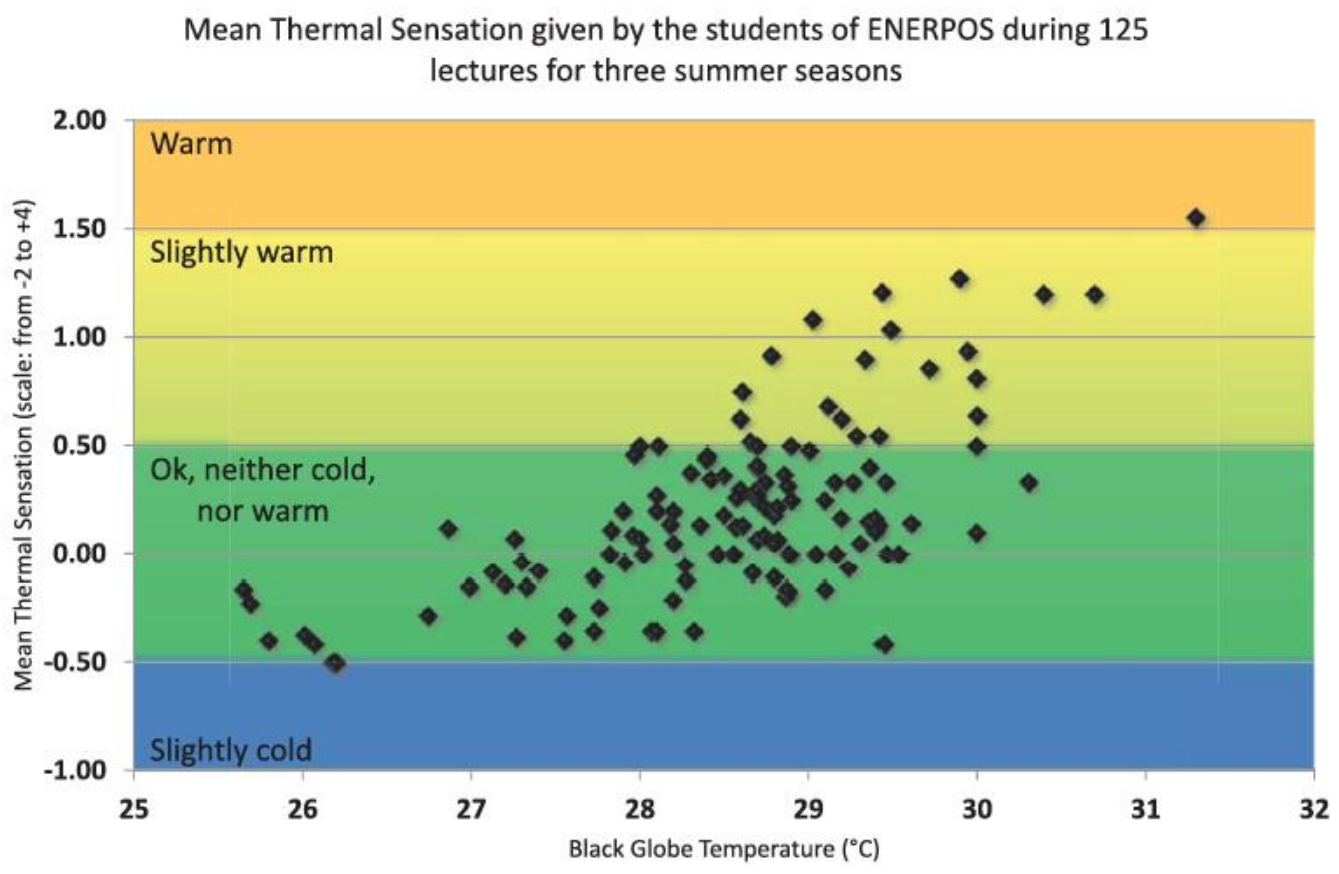

Figure 6-13: Mean thermal sensation functions of the black globe temperature (averaged over the last hour of exposure). 


\section{b) Example results of a general satisfaction survey}

Figure 6-14 shows an example of temperature satisfaction assessment. Similar graphs could be created for satisfaction with other variables (humidity, draft, luminosity) and system (e.g., ventilation, heating, cooling). It is recommended to assess the winter and summer conditions separately. For each question, the results can be presented numerically, too. In that case, it is common to report the mean value together with the standard deviation.
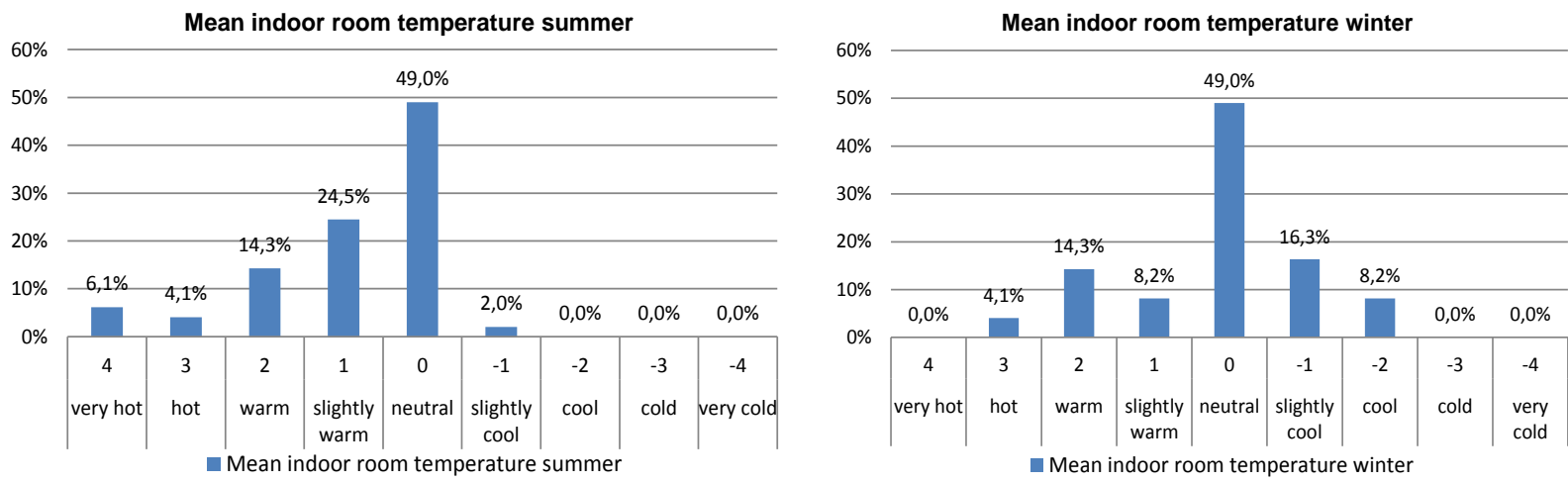

Figure 6-14. Satisfaction survey results to indoor temperatures in winter and summer for the Enerpos example.

Figure 6-15 presents questionnaire results with respect to user behavior and specifically to user control on the window opening. The frequency that windows are open is an important parameter for interpreting energy and IEQ data.
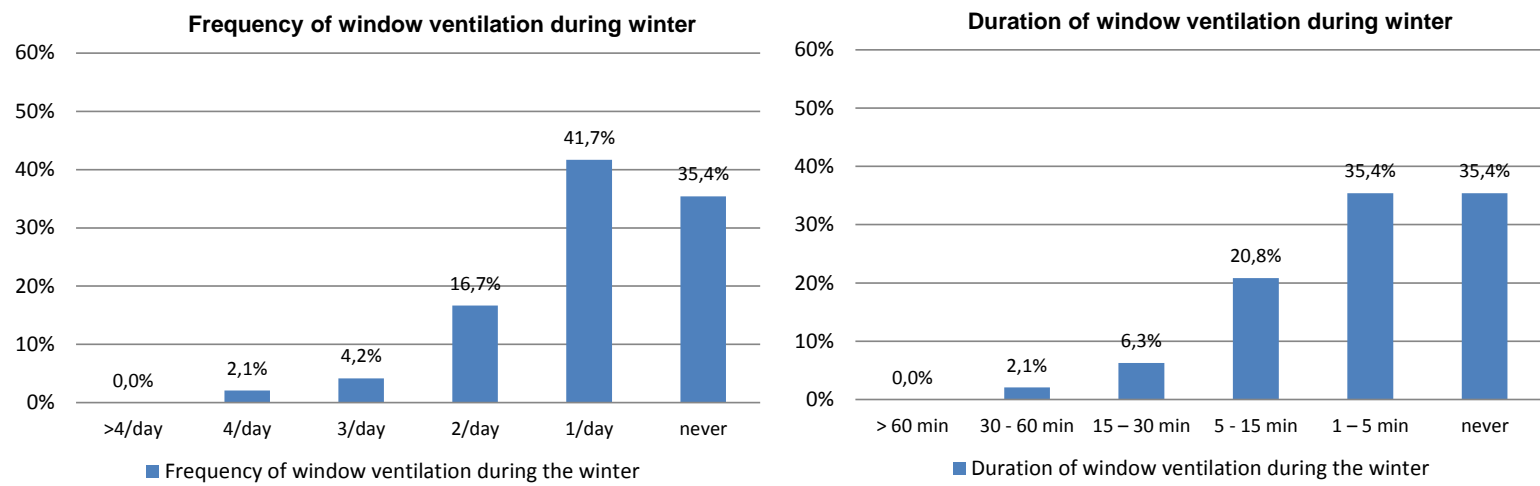

Figure 6-15. Frequency and duration of window opening during winter.

Figures 6-16 and 6-17 show results from a POE survey conducted in the Enerpos Building (Lenoir et al., 2012a). The BUS (building use studies) methodology was used for this survey (Baird 2009), basically a three-page questionnaire for staff and a one-page shorter version for students. The aspects investigated included building design, space, building image, cleanliness, availability of meeting rooms, storage capacity, size of the offices, furniture, noise, thermal comfort according to the seasons, productivity, health, control of heating, air conditioning, ventilation, lighting and round trip journey from home to work. The vast majority of responses are on a 7-point scale, typically ranging from unsatisfactory to satisfactory or comfortable to uncomfortable. Ten members of the staff and 127 students completed the questionnaires during 2 weeks in April. To obtain a global view of the entire building, care was taken to include students from all classrooms of the building.

Figure 6-16 indicates the mean scores for the main general variables for both staff and students. The green squares indicate scores that are better than the mid-point of the scale 
and the relevant benchmark (based on the scores for the previous 50 buildings surveyed), while an orange circle indicates a score that is not significantly different.

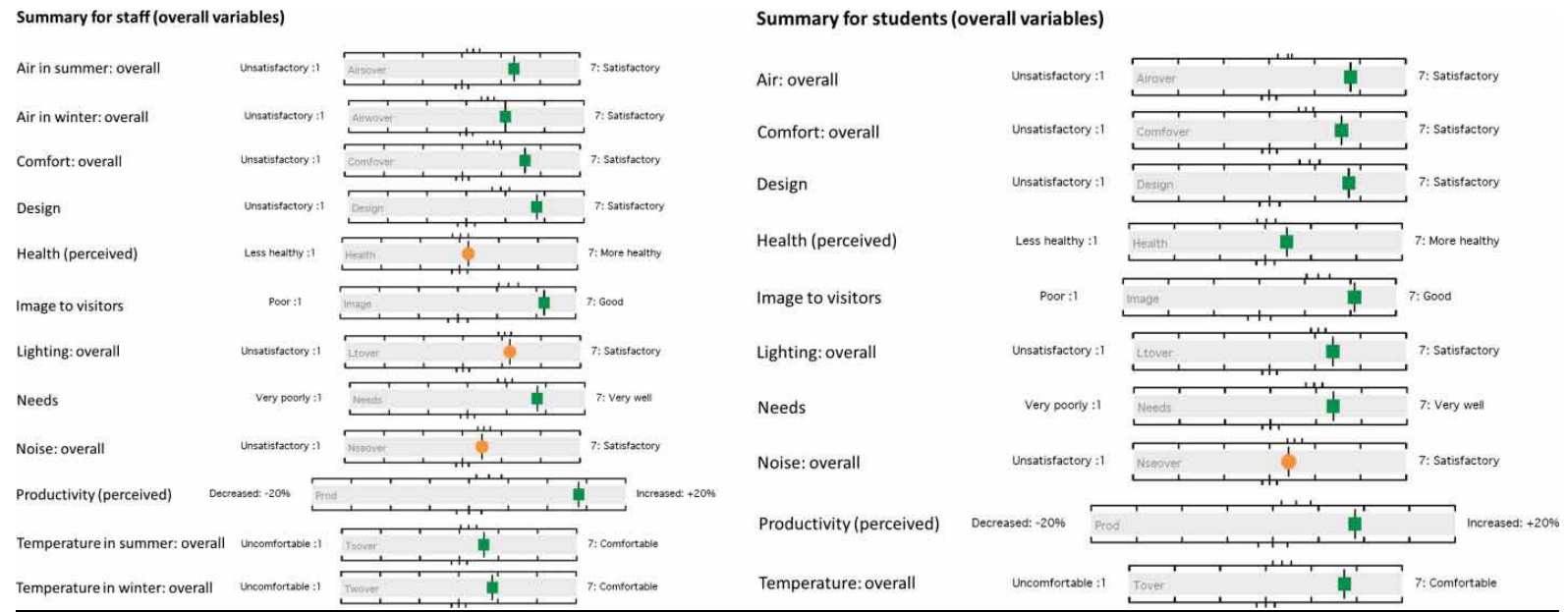

Figure 6-16: Example of POE results for the Enerpos Building. Overall variables for staff (left) and students (right)

Figure 6-17 gives the temperature perception of the students. An average student score of 5.7 (out of a scale of 7) places the ENERPOS building at the 94th percentile of the BUS benchmark.
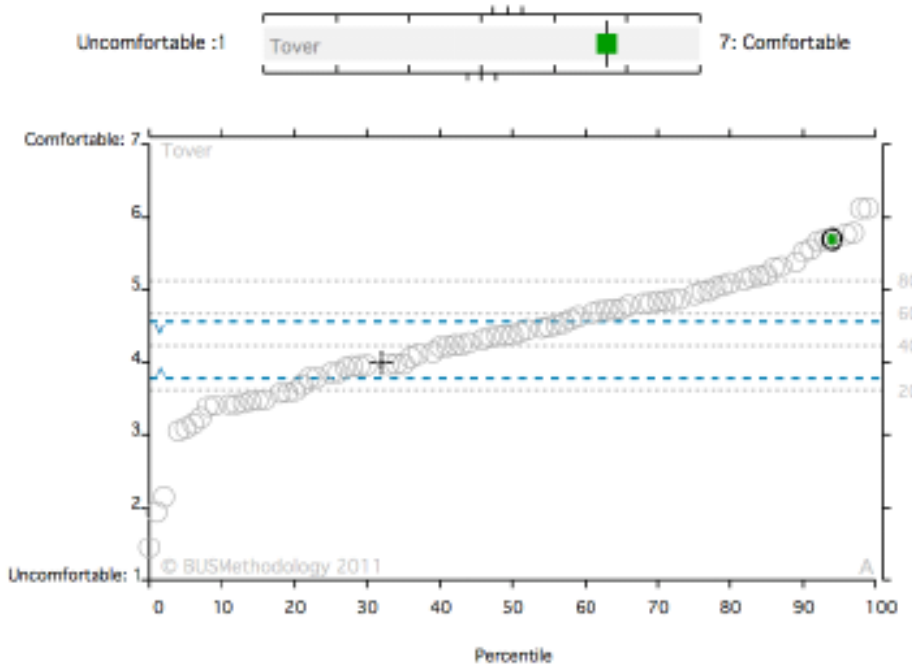

Figure 6-17. Temperature perception of the students in the ENERPOS building and comparison with the BUS benchmark (Lenoir et al., 2012a) 


\section{Conclusion}

The adoption of ambitious energy performance targets in buildings and the need of substantiate claims of energy efficiency through measured data, requires the development of standard measurement and verification procedures. This Measurement and Verification $(\mathrm{M} \& \mathrm{~V})$ protocol for Net ZEBs defines the activities to be conducted for the assessment of the balance relevant to the applied Net ZEB definition and the IEQ. Three phases have been identified: planning, installation and operation of a monitoring system, including sixteen different steps to be conducted. The following steps are particularly relevant for the assessment of Net ZEB:

a) Collection of building data

b) Definition of monitoring boundaries

c) Selection of metrics and relevant data required

d) Selection of data frequency and duration of measurements

e) Identification of suitable sensors and data acquisition system

f) Final planning of the monitoring equipment and installation

g) Definition and implementation of data post-processing (e.g., performance indicators)

h) Definition of a standard reporting

Within this context, for the planning phase a standard diagram was developed (step a, subchapter 4.2) with the goal of illustrating the building, its relevant systems and the metrics of interest. The monitoring boundaries (step b) depend on the physical and balance boundaries set in the Net ZEB definition. As the core element of a definition is the weighted balance often between exported and delivered energy, the focus is on the interface between the building and the grids. The metrics (step c) useful to check the balance refer to the flow entering and exiting the building boundaries, so these metrics should be included in the monitoring. This monitoring strategy is usually referred to as whole building monitoring. The alternative would be to measure individual flow for the different systems and therefore apply the isolation-approach. The accuracy, frequency and the duration of the measurements (step d) depend, among other factors, on the additional analysis desired (e.g., improvement of system performance, IEQ assessment). Depending on the information needed and the associated requirements and acceptable cost, sensors and data acquisition system can be identified (step e). For instance, for load match index quantification, sub-metering is necessary; therefore, monthly load and generation for the different systems must also be monitored, while for only checking the balance yearly data are often necessary.

After the planning phase, the actual monitoring (installation phase) can occur via spot, short or long measurements (step f). It is recommended to monitor for at least two years to correct possible malfunctioning and obtain a clearer picture of the situation.

After the data is acquired, during the operation phase, the post processing is used to investigate the fulfillment of the balance as well as additional conditions and possible relationships among variables (step g). The Net ZEB evaluation tool can be used to assist when checking the balance. To compare the measured consumption with the design values the alignment procedure is suggested to take into consideration indoor and outdoor conditions different than assumed. Particular emphasis should be paid to the IEQ assessment to ensure the energy performance are not achieve at the expense of a reduction 
IEA SHC/ECBCS Task 40/Annex 52 - Towards Net Zero Energy solar Buildings

$M \& V$ protocol for Net ZEB. A technical report of STA

of indoor comfort conditions. different monitoring levels and strategies to identify the relevant areas to be monitored are suggested, including POE surveys Finally, a standard report, including data analysis and data visualization, must be prepared and disseminated (step h). 


\section{Glossary}

\begin{tabular}{|c|c|}
\hline ASHRAE & $\begin{array}{l}\text { American Society for Heating, Refrigeration and Air-conditioning } \\
\text { Engineers }\end{array}$ \\
\hline BUS & Building Use Studies \\
\hline DAS & Data Acquisition System \\
\hline DHW & Domestic Hot Water \\
\hline ECM & Energy Conservation Measure \\
\hline EPBD & Energy Performance Building Directive \\
\hline EN & European Standard \\
\hline EVO & Efficiency Valuation Organization \\
\hline HDD & Heating Degree Days \\
\hline HVAC & Heating Ventilation and Air-Conditioning \\
\hline $\mathrm{IAQ}$ & Indoor Air Quality \\
\hline IEA & International Energy Agency \\
\hline IEQ & Indoor Environmental Quality \\
\hline IPMVP & International Performance Measurement and Verification Protocol \\
\hline ISO & International Organisation for Standards \\
\hline LEED & Leadership in Energy and Environmental Design \\
\hline MET & Metabolic Equivalent Task \\
\hline$M \& V$ & Measurement and Verification \\
\hline NIST & National Institute of Standards and Technology \\
\hline NREL & National Renewable Energy Laboratory \\
\hline PHPP & Passive House Planning Package \\
\hline PMV & Predicted Mean Vote \\
\hline POE & Post Occupancy Evaluation \\
\hline PPD & Percentage People Dissatisfied \\
\hline PV & Photovoltaic \\
\hline RES & Renewable Energy Source \\
\hline VOC & Volatile Organic Compounds \\
\hline ZEB & Zero Energy Building \\
\hline
\end{tabular}




\section{References}

AEE INTEC, Questionnaire Occupants of Renovated Residential Buildings, (2010)

ASHRAE, ANSI/ASHRAE Standard 55-2010: "Thermal Environmental Conditions for Human Occupancy"; ASHRAE, Atlanta USA 2010

ASHRAE, ANSI/ASHRAE Standard 189-2011: "Standard for the Design of High-Performance Green Building"; ASHRAE, Atlanta USA 2011

ASHRAE, ASHRAE GUIDELINE 14-2002 Measurement of energy and Demand Savings.

Australian Government, Energy Efficiency Opportunities Section, Energy and Environment Division. (2008). Energy savings measurement guide: how to estimate, measure, evaluate and track energy efficiency opportunities. Department of Resource, Energy, and Tourism / WorleyParsons Service Pty Ltd .

Barley, D., Deru, M., Pless, S., \& Torcellini, P. (2005). Procedure for Measuring and Reporting Commercial Building Energy Performance. Retrieved January 24, 2011, from http://www.osti.gov/bridge: http://www.nrel.gov/docs/fy06osti/38601.pdf

Baird, G. (2009) Incorporating User Performance Criteria into Building Sustainability Rating Tools (BSRTs) for buildings in operation, Sustainability, 2009, ISSN 2071-1050

Baird, G. (2010). Sustainable buildings in practice: what the users think. Abingdon, UK: Routeledge.

Botsaris, P., N., and Tsanakas, J., A., (2010) Infrared thermography as an estimator technique of a photovoltaic module performance via operating temperature measurements, 10th ECNDT, Moscow 2010

Cannata, G., Pörnbacher, H. (2011) Enerbuild: Survey on existing buildings for final user, Institute of Social Research and Opinion Polling

Corgnati S., Gameiro da Silva M., et al. (2011): "Indoor Climate Quality Assessment. REHVA Guidebook No. 14"; Federation of European Heating, Ventilation and Air Conditioning Associations; www.rehva.eu

EPBD (Energy Performance of Buildings Directive) 2010/31/EU of the European Parliament and of the Council on the, June 2010. http://www.energy.eu/directives/2010-31-EU.pdf

EN 15251:2008: “ Indoor environmental input parameters for design and assessment of energy performance of buildings addressing indoor air quality, thermal environment, lighting and acoustics"; International Organization for Standardisation, Geneva 2008

EN ISO 7730:2005: "Ergonomics of the thermal environment - Analytical determination and interpretation of thermal comfort using calculation of the PMV and PPD indices and local thermal comfort criteria"; International Organization for Standardisation, Geneva 2005

ENERGY SYSTEMS LABORATORY (1992). BUILDING ENERGY MONITORING WORKBOOK.

EVO Efficiency Valuation Organization (2012). International Performance Measurement and Verification Protocol - Concepts and Options for Determining Energy and Water Savings Volume 1. January 2012 da www.evo-world.org.

Givoni, B. 1998. Climate considerations in building and urban design, Baruch Givoni, John Wiley and Sons. ISBN 0-471-29177-3.

Gossauer, E and Wagner, A. (2007) Post-occupancy Evaluation and Thermal Comfort: State of the Art and New Approaches, Advances in Building Energy Research, Volume 1, Pages 151-175. 2007

Haberl, J. C. (1990). The design of Field Experiments and Demonstrations. Field Monitoring Workshop. Gothernburg : IEA Proceedings.

IEA, "SHC Task 40/ECBCS Annex 52, Towards Net Zero Energy Solar Buildings, IEA SHC Task 40 and ECBCS Annex 52, http://task40.iea-shc.org/". 
Jensen. S.Ø. (2013).Guideline on documentation of the performance of built low energy buildings. Danish Technological Insitute.

Lenoir, A., Thellier, F., Garde, F. (2011).Towards Net Zero Energy Buildings. Part II : Experimental feedback. ASHRAE Transactions Vol. 117 Part 1, LV-11-C056

Lenoir, A. Baird G., Garde F. (2012a). Post-occupancy evaluation and experimental feedback of a net zero-energy building in a tropical climate. Architectural Science Review Journal. July 2012. ISSN 0003-8628 print/ISSN 1758-9622 online.

Lenoir, A. and Garde, F. (2012b). Tropical NZEB“. High Performing Building Journal. Article downloadable at www.hpbmagazine.org (July 2012 issue).

Marszal, A. J., Bourrelle, J. S. et al. (2010). Net Zero Energy Buildings - Calculation Methodologies versus National Building Codes. Euro Sun 2010 International scientific conference on solar heating, cooling and buildings. Graz, Austria.

MacDonald, J. M. (1989). Investigation of Metered Data Analysis Methods for Commercial and Related Buildings. Oak Ridge Natioanl Laboratory Report No. ORNL/CON-279.

Mlecnik E., Schuetze T., Janssen S. J. T., de Vries G., Visscher H., and van Hal A. (2012), End-user experiences in nearly zero-energy houses, Energy and Buildings, 49, 471-478

Mills, E. and P. Matthew (2009). Monitoring-Based Commissioning: Benchmarking Analysis of 24 UC/CSU/IOU Projects - Lawrence Berkeley National Laboratory Report 1972 E.

Misuriello, H. P. (1987). A Uniform Procedure for the Development and Dissemination of Monitoring Protocols. Atlanta: ASHRAE Transactions 93 (1).

National Institute of Standards and Technology. http://www.nist.gov/el/netzeroenergygoal.cfm abgerufen

Nexant, Inc. (2008). M\&V Guidelines:Measurement and Verification for Federal Energy Projects.

Olesen B. W. (2010). Information paper on EN 15251. Indoor environmental input parameters for design and assessment of energy performance of buildings addressing indoor air quality, thermal environment, lighting and acoustics. Paper P114.15-02-2010 published within CENSE (EIE /07/069/SI2.466698); European Commission, 2010. www.iee-cense.eu; Download 20.07.2011

Olesen B. W., Corganti, S. P., Raimondo, D. (2011). Evaluation methods for long term indoor environmental quality. Proceedings of Indoor Air 2011, Austin, TX, USA.

Salom,J., Widén, J., Candanedo, J., Sartori, I., Voss, K., Marszal, A. (2011) Understanding net zero energy buildings: evaluation of load matching and grid interaction indicators, Proceedings of Building Simulation 2011:12th Conference of International Building Performance Simulation Association, Sydney, 14-16 November

Sartori, I., Napolitano, A., Voss K., Net zero energy buildings: A consistent definition framework, Energy and Buildings, Volume 48, May 2012, Pages 220-232.

Sartori Igor, et al. (2009): "Comfort and Energy Recommendations for Net Zero Energy Buildings"; Internal Report A1-7. Further integration in Report A1-14.

University of Karlsruhe (2009): "Guideline for field experiments on thermal comfort in the context of EN 15251 adaptive comfort model"; European Project ThermCo Thermal Comfort in Buildings with Low-Energy Cooling. Contract No. EIE/07/026/SI2.466692; Karlsruhe 2009.

U.S. Department of Energy, Office of Energy Efficiency and Renewable Energy. (2003). Performance Metrics Research Project.

http://www1.eere.energy.gov/buildings/commercial_initiative/performance_metrics.html

U.S.Department of Energy, Office of Energy Efficiency and Renewable Energy. (2000). Measurement and Verification Guidelines for Federal Energy Management Projects. Abgerufen am January 2011 von http://www1.eere.energy.gov/femp/pdfs/mv_guidelines.pdf

Wagner, W, et al.(2010):,IBK-Guideline. Results of Monitoring Building of Tomorrow Demonstration Projects"; Editor AEE INTEC, Gleisdorf 2010; www.nachhaltigwirtschaften.at/hdz_pdf/messprojekt_leitfaden.pdf 
IEA SHC/ECBCS Task 40/Annex 52 - Towards Net Zero Energy solar Buildings

$M \& V$ protocol for Net ZEB. A technical report of STA

Wagner, W, et al.(2009):,,Results of monitoring Building of Tomorrow demonstration projects. Housing complex Dreherstrasse-Wien"; Gleisdorf 2009;

www.hausderzukunft.at/publikationen/view.html/id893 


\section{Annex 1}

Table A1.1: Examples of questions for IEQ spot surveys.

\begin{tabular}{|c|c|c|c|c|c|}
\hline 1) & $\begin{array}{l}\text { What is your general } \\
\text { thermal sensation at } \\
\text { this moment? }\end{array}$ & $\begin{array}{l}\text { Hot }(+3) \\
\text { Warm }(+2) \\
\text { Slightly warm }(+1) \\
\text { Neutral }(0) \\
\text { Slightly cool }(-1) \\
\text { Cool }(-2) \\
\text { Cold }(-3)\end{array}$ & 2) & $\begin{array}{l}\text { You would prefer to } \\
\text { be ... }\end{array}$ & $\begin{array}{l}\text { Much warmer } \\
\text { A bit warmer } \\
\text { No change } \\
\text { A bit cooler } \\
\text { Much cooler }\end{array}$ \\
\hline 3) & $\begin{array}{l}\text { Clothing at this } \\
\text { moment (that can be } \\
\text { adapted or simplified } \\
\text { depending on the } \\
\text { study) }\end{array}$ & $\begin{array}{l}\text { Short sleeve shirt/blouse } \\
\text { Long-Sleeve shirt } \\
\text { T-shirt } \\
\text { Long-Sleeve Sweatshirt } \\
\text { Sweater } \\
\text { Jacket } \\
\text { Knee-length skirt } \\
\text { Ankle-length skirt } \\
\text { Dress } \\
\text { Shorts } \\
\text { Athletic sweatpants } \\
\text { Trousers } \\
\text { Undershirt } \\
\text { Long Underwear Bottoms } \\
\text { Long Sleeve coveralls } \\
\text { Overalls } \\
\text { Slip } \\
\text { Nylons } \\
\text { Socks } \\
\text { Boots } \\
\text { Shoes } \\
\text { Sandals }\end{array}$ & 4) & $\begin{array}{l}\text { Activity level (select } \\
\text { from a list and adapt } \\
\text { if necessary) }\end{array}$ & $\begin{array}{l}\text { Sitting (passive work) } \\
\text { Sitting (active work) } \\
\text { Standing relaxed } \\
\text { Standing light activity } \\
\text { Standing medium activity }\end{array}$ \\
\hline 5) & $\begin{array}{l}\text { How do you find the } \\
\text { air movement? }\end{array}$ & $\begin{array}{l}\text { Very stagnant } \\
\text { Stagnant } \\
\text { Slightly too stagnant } \\
\text { Just right } \\
\text { Slightly too drafty } \\
\text { Drafty } \\
\text { Very drafty }\end{array}$ & 6) & $\begin{array}{l}\text { What would you } \\
\text { prefer to have? }\end{array}$ & $\begin{array}{l}\text { Much more air movement } \\
\text { A little more air movement } \\
\text { No change } \\
\text { A little less air movement } \\
\text { Much less air movement }\end{array}$ \\
\hline 7) & $\begin{array}{l}\text { How do you find the } \\
\text { air humidity? }\end{array}$ & $\begin{array}{l}\text { Very humid } \\
\text { Humid } \\
\text { Slightly humid } \\
\text { Neither humid nor dry } \\
\text { Slightly dry } \\
\text { Dry } \\
\text { Very Dry }\end{array}$ & 8) & $\begin{array}{l}\text { What would you } \\
\text { prefer to have? }\end{array}$ & $\begin{array}{l}\text { Much drier } \\
\text { A little drier } \\
\text { No change } \\
\text { A little more humid } \\
\text { Much more humid }\end{array}$ \\
\hline 9) & $\begin{array}{l}\text { How do you find the } \\
\text { lighting level? }\end{array}$ & $\begin{array}{l}\text { Very bright } \\
\text { Bright } \\
\text { Slightly bright } \\
\text { Neither bright nor dim } \\
\text { Slightly dim } \\
\text { Dim } \\
\text { Very Dim }\end{array}$ & 10) & $\begin{array}{l}\text { What would you } \\
\text { prefer to have? }\end{array}$ & $\begin{array}{l}\text { Much dimmer } \\
\text { A little dimmer } \\
\text { No change } \\
\text { A little brighter } \\
\text { Much more brighter }\end{array}$ \\
\hline 11) & $\begin{array}{l}\text { How do you find the } \\
\text { noise level? }\end{array}$ & $\begin{array}{l}\text { Very noisy } \\
\text { Noisy } \\
\text { Slightly noisy } \\
\text { Neither noisy nor quiet } \\
\text { Slightly quiet } \\
\text { Quiet } \\
\text { Very quiet }\end{array}$ & 12) & $\begin{array}{l}\text { What would you } \\
\text { prefer to have? }\end{array}$ & $\begin{array}{l}\text { Much quieter } \\
\text { A little quieter } \\
\text { No change } \\
\text { A little nosier } \\
\text { Much nosier }\end{array}$ \\
\hline
\end{tabular}


Table A1.2: Examples of contextual information questions in IEQ surveys

\begin{tabular}{|c|c|c|c|c|c|}
\hline 1) & $\begin{array}{l}\text { Fraction of working time } \\
\text { that you are seated } \\
\text { (office work, } \\
\text { meetings,...) }\end{array}$ & $\begin{array}{l}<20 \% \\
20-39 \% \\
40-59 \% \\
60-79 \% \\
>=80 \%\end{array}$ & 2) & $\begin{array}{l}\text { What is your } \\
\text { gender? }\end{array}$ & $\begin{array}{l}\text { Female } \\
\text { Male }\end{array}$ \\
\hline 3) & $\begin{array}{l}\text { Would you describe the } \\
\text { work you do? }\end{array}$ & $\begin{array}{l}\text { Administrative support } \\
\text { Technical } \\
\text { Professional } \\
\text { Managerial/supervisory } \\
\text { Other, please specify... }\end{array}$ & 4) & $\begin{array}{l}\text { What is your } \\
\text { age? }\end{array}$ & $\begin{array}{l}<=30 \\
31-40 \\
41-50 \\
51-60 \\
>=61\end{array}$ \\
\hline 5) & $\begin{array}{l}\text { How many years have } \\
\text { you worked in this } \\
\text { building? }\end{array}$ & $\begin{array}{l}\text { Less than } 1 \text { year, but at least one } \\
\text { winter month and one summer } \\
\text { month } \\
\text { Less than } 1 \text { year and no summer } \\
\text { month, but at least one winter } \\
\text { month } \\
\text { Less than } 1 \text { year and no winter } \\
\text { month, but at least one summer } \\
\text { month Less than } 1 \text { year and no } \\
\text { winter month and no summer month } \\
1-2 \text { years } \\
3-5 \text { years } \\
\text { More than } 5 \text { years } \\
\text { I don't work in this building (a) }\end{array}$ & 6) & $\begin{array}{l}\text { How long } \\
\text { have you } \\
\text { been working } \\
\text { at your } \\
\text { present } \\
\text { workspace? }\end{array}$ & $\begin{array}{l}\text { Less than } 3 \text { months } \\
4-6 \text { months } \\
7-12 \text { months } \\
1-2 \text { years } \\
3-5 \text { years } \\
\text { More than } 5 \text { years }\end{array}$ \\
\hline 7) & $\begin{array}{l}\text { In a typical week, how } \\
\text { many hours do you } \\
\text { spend in your } \\
\text { workspace? }\end{array}$ & $\begin{array}{l}10 \text { or less } \\
11-30 \\
\text { More than } 30\end{array}$ & 8) & $\begin{array}{l}\text { Distance to } \\
\text { closest } \\
\text { window }\end{array}$ & $\begin{array}{l}<3 \text { meter } \\
3-5 \text { meter } \\
5-9 \\
>9 \text { meter }\end{array}$ \\
\hline 9) & $\begin{array}{l}\text { Which of the following } \\
\text { best describes your } \\
\text { personal workspace }\end{array}$ & $\begin{array}{l}\text { Enclosed office ,private } \\
\text { Enclosed office, shared with other } \\
\text { people } \\
\text { Cubicles with high partitions walls } \\
\text { (about } 1,5 \text { or more meter high) } \\
\text { Cubicles with low partitions walls } \\
\text { (lower than } 1,5 \text { meter high) } \\
\text { Workspace in open office with no } \\
\text { partitions (just desks) } \\
\text { Other, specify.... }\end{array}$ & 10) & $\begin{array}{l}\text { How many } \\
\text { people, } \\
\text { including } \\
\text { yourself, } \\
\text { normally } \\
\text { share the } \\
\text { workspace } \\
\text { (enclosed } \\
\text { office, } \\
\text { cubicle or } \\
\text { open office) } \\
\text { where you } \\
\text { work? }\end{array}$ & $\begin{array}{l}1 \\
2 \\
3 \\
4 \\
5 \\
6 \\
7 \\
8 \\
9 \\
10-14 \\
15-19 \\
>20\end{array}$ \\
\hline
\end{tabular}


Table A1.3: Examples of questions for a IEQ general satisfaction survey

\begin{tabular}{|c|c|c|c|c|c|}
\hline 1) & $\begin{array}{l}\text { In the summer, it is regularly too } \\
\text { warm in my workspace }\end{array}$ & $\begin{array}{l}\text { Completely } \\
\text { agree } \\
7 \\
6 \\
5 \\
4 \\
3 \\
2 \\
1 \\
\text { Completely } \\
\text { disagree }\end{array}$ & 2) & $\begin{array}{l}\text { In the summer, it is regularly too } \\
\text { cold in my workspace }\end{array}$ & $\begin{array}{l}\text { Completely agree } \\
7 \\
6 \\
5 \\
4 \\
3 \\
2 \\
1 \\
\text { Completely disagree }\end{array}$ \\
\hline 3) & $\begin{array}{l}\text { In the summer....(check all that } \\
\text { apply) }\end{array}$ & $\begin{array}{l}\text { My hands } \\
\text { are too cold } \\
\text { My feet are } \\
\text { too cold } \\
\text { Other, } \\
\text { specify .... }\end{array}$ & 4) & $\begin{array}{l}\text { In the winter, it is regularly too warm } \\
\text { in my workspace }\end{array}$ & $\begin{array}{l}\text { Completely agree } \\
7 \\
6 \\
5 \\
4 \\
3 \\
2 \\
1 \\
\text { Completely disagree }\end{array}$ \\
\hline 5) & $\begin{array}{l}\text { In the winter, it is regularly too } \\
\text { cold in my workspace }\end{array}$ & $\begin{array}{l}\text { Completely } \\
\text { agree } \\
7 \\
6 \\
5 \\
4 \\
3 \\
2 \\
1 \\
\text { Completely } \\
\text { disagree }\end{array}$ & 6) & In the winter....(check all that apply) & $\begin{array}{l}\text { My hands are too cold } \\
\text { My feet are too cold } \\
\text { Other, specify .... }\end{array}$ \\
\hline 7) & $\begin{array}{l}\text { Draft regularly bothers me in my } \\
\text { workspace }\end{array}$ & $\begin{array}{l}\text { Completely } \\
\text { agree } \\
7 \\
6 \\
5 \\
4 \\
3 \\
2 \\
1 \\
\text { Completely } \\
\text { disagree }\end{array}$ & 8) & $\begin{array}{l}\text { The following characteristics of my } \\
\text { workspace generate discomfort } \\
\text { (check all that apply) }\end{array}$ & $\begin{array}{l}\text { Hot/cold floor surfaces } \\
\text { Hot/cold ceiling surfaces } \\
\text { Hot/cold wall surfaces } \\
\text { Hot/cold window surfaces } \\
\text { Drafts from windows } \\
\text { Drafts from vents } \\
\text { Drafts falling from the } \\
\text { ceiling } \\
\text { My area is hotter than } \\
\text { other area } \\
\text { My area is colder than } \\
\text { other areas } \\
\text { Heating/cooling system } \\
\text { does not respond quickly } \\
\text { enough to the thermostat } \\
\text { Other, specify .... }\end{array}$ \\
\hline 9) & $\begin{array}{l}\text { Overall, how satisfied are you } \\
\text { with the temperature in your } \\
\text { workspace? }\end{array}$ & $\begin{array}{l}\text { Very } \\
\text { dissatisfied } \\
7 \\
6 \\
5 \\
4 \\
3 \\
2 \\
1 \\
\text { Very } \\
\text { satisfied }\end{array}$ & 10) & $\begin{array}{l}\text { Please describe any other issues } \\
\text { related to being too hot or too cold } \\
\text { in your workspace. }\end{array}$ & \\
\hline 11) & $\begin{array}{l}\text { Temperature during the day in } \\
\text { winter }\end{array}$ & $\begin{array}{l}\text { Stable } \\
7 \\
6 \\
5 \\
4 \\
3 \\
2 \\
1 \\
\text { Changes } \\
\text { during the } \\
\text { day }\end{array}$ & 12) & $\begin{array}{l}\text { Temperature during the day in } \\
\text { summer }\end{array}$ & $\begin{array}{l}\text { Stable } \\
7 \\
6 \\
5 \\
4 \\
3 \\
2 \\
1 \\
\text { Changes during the day }\end{array}$ \\
\hline 13) & $\begin{array}{l}\text { The air is regularly dry in my } \\
\text { workspace }\end{array}$ & $\begin{array}{l}\text { Completely } \\
\text { agree } \\
7 \\
6\end{array}$ & 14) & $\begin{array}{l}\text { The air is regularly stuffy or smelly } \\
\text { in my workspace }\end{array}$ & $\begin{array}{l}\text { Completely agree } \\
7 \\
6 \\
5\end{array}$ \\
\hline
\end{tabular}




\begin{tabular}{|c|c|c|c|c|c|}
\hline & & $\begin{array}{l}5 \\
4 \\
3 \\
2 \\
1 \\
\text { Completely } \\
\text { disagree }\end{array}$ & & & $\begin{array}{l}4 \\
3 \\
2 \\
1 \\
\text { Completely disagree }\end{array}$ \\
\hline 15) & $\begin{array}{l}\text { Overall, how satisfied are you } \\
\text { with the air quality in your } \\
\text { workspace (i.e. stuffy/ stale air, } \\
\text { cleanliness, odors)? }\end{array}$ & $\begin{array}{l}\text { Very } \\
\text { dissatisfied } \\
7 \\
6 \\
5 \\
4 \\
3 \\
2 \\
1 \\
\text { Very } \\
\text { satisfied }\end{array}$ & 16) & $\begin{array}{l}\text { Please describe any other issues } \\
\text { related to the air quality in your } \\
\text { workspace that are important to } \\
\text { you. }\end{array}$ & $\mathrm{n} / \mathrm{a}$ \\
\hline 17) & $\begin{array}{l}\text { If lighting is switched on, it is } \\
\text { generally too dark on my working } \\
\text { place }\end{array}$ & $\begin{array}{l}\text { Completely } \\
\text { agree } \\
7 \\
6 \\
5 \\
4 \\
3 \\
2 \\
1 \\
\text { Completely } \\
\text { disagree }\end{array}$ & 18) & $\begin{array}{l}\text { There is generally insufficient } \\
\text { daylight in my workspace }\end{array}$ & $\begin{array}{l}\text { Completely agree } \\
7 \\
6 \\
5 \\
4 \\
3 \\
2 \\
1 \\
\text { Completely disagree }\end{array}$ \\
\hline 19) & $\begin{array}{l}\text { Overall, how satisfied are you } \\
\text { with the amount of light in your } \\
\text { workspace? }\end{array}$ & $\begin{array}{l}\text { Very } \\
\text { dissatisfied } \\
7 \\
6 \\
5 \\
4 \\
3 \\
2 \\
1 \\
\text { Very } \\
\text { satisfied }\end{array}$ & 20) & $\begin{array}{l}\text { Overall, how satisfied are you with } \\
\text { the visual comfort of the lighting } \\
\text { (e.g., glare, reflections, contrast)? }\end{array}$ & $\begin{array}{l}\text { Very dissatisfied } \\
7 \\
6 \\
5 \\
4 \\
3 \\
2 \\
1 \\
\text { Very satisfied }\end{array}$ \\
\hline 21) & $\begin{array}{l}\text { Overall, how satisfied are you } \\
\text { with the light in your workspace } \\
\text { (i.e. amount of light and visual } \\
\text { comfort)? }\end{array}$ & $\begin{array}{l}\text { Very } \\
\text { dissatisfied } \\
7 \\
6 \\
5 \\
4 \\
3 \\
2 \\
1 \\
\text { Very } \\
\text { satisfied }\end{array}$ & 22) & $\begin{array}{l}\text { Please describe any other issues } \\
\text { related to light that are important to } \\
\text { you: }\end{array}$ & $\mathrm{n} / \mathrm{a}$ \\
\hline 23) & $\begin{array}{l}\text { How satisfied are you with the } \\
\text { noise level in your workspace? }\end{array}$ & $\begin{array}{l}\text { Very } \\
\text { dissatisfied } \\
7 \\
6 \\
5 \\
4 \\
3 \\
2 \\
1 \\
\text { Very } \\
\text { satisfied }\end{array}$ & 24) & $\begin{array}{l}\text { How satisfied are you with the } \\
\text { sound privacy in your workspace } \\
\text { (ability to have conversations } \\
\text { without your neighbours } \\
\text { overhearing and vice versa)? }\end{array}$ & $\begin{array}{l}\text { Very dissatisfied } \\
7 \\
6 \\
5 \\
4 \\
3 \\
2 \\
1 \\
\text { Very satisfied }\end{array}$ \\
\hline 25) & $\begin{array}{l}\text { Overall, how satisfied are you } \\
\text { with the acoustic comfort in your } \\
\text { workspace, i.e. noise level and } \\
\text { sound privacy? }\end{array}$ & $\begin{array}{l}\text { Very } \\
\text { dissatisfied } \\
7 \\
6 \\
5 \\
4 \\
3 \\
2 \\
1 \\
\text { Very } \\
\text { satisfied } \\
\end{array}$ & 26) & $\begin{array}{l}\text { Please describe any other issues } \\
\text { related to acoustics that are } \\
\text { important to you: }\end{array}$ & $\mathrm{n} / \mathrm{a}$ \\
\hline 27) & $\begin{array}{l}\text { I can ventilate my workspace by } \\
\text { opening the windows }\end{array}$ & $\begin{array}{l}\text { Completely } \\
\text { agree }\end{array}$ & 28) & $\begin{array}{l}\text { I can control sufficiently the artificial } \\
\text { light in my workspace }\end{array}$ & $\begin{array}{l}\text { Completely agree } \\
7\end{array}$ \\
\hline
\end{tabular}




\begin{tabular}{|c|c|c|c|c|c|}
\hline & & $\begin{array}{l}7 \\
6 \\
5 \\
4 \\
3 \\
2 \\
1 \\
\text { Completely } \\
\text { disagree }\end{array}$ & & & $\begin{array}{l}6 \\
5 \\
4 \\
3 \\
2 \\
1 \\
\text { Completely disagree }\end{array}$ \\
\hline 29) & $\begin{array}{l}\text { I can control sufficiently the } \\
\text { shading from the sun in my } \\
\text { workspace }\end{array}$ & $\begin{array}{l}\text { Completely } \\
\text { agree } \\
7 \\
6 \\
5 \\
4 \\
3 \\
2 \\
1 \\
\text { Completely } \\
\text { disagree }\end{array}$ & 30) & $\begin{array}{l}\text { I can control sufficiently the heating } \\
\text { in my workspace }\end{array}$ & $\begin{array}{l}\text { Completely agree } \\
7 \\
6 \\
5 \\
4 \\
3 \\
2 \\
1 \\
\text { Completely disagree }\end{array}$ \\
\hline 31) & $\begin{array}{l}\text { I can control sufficiently the } \\
\text { cooling in my workspace }\end{array}$ & $\begin{array}{l}\text { n/a (no } \\
\text { cooling) } \\
\text { Completely } \\
\text { agree } \\
7 \\
6 \\
5 \\
4 \\
3 \\
2 \\
1 \\
\text { Completely } \\
\text { disagree }\end{array}$ & 32) & $\begin{array}{l}\text { I can adapt sufficiently my clothing } \\
\text { in case of summery temperatures }\end{array}$ & $\begin{array}{l}\text { Completely agree } \\
7 \\
6 \\
5 \\
4 \\
3 \\
2 \\
1 \\
\text { Completely disagree }\end{array}$ \\
\hline 33) & $\begin{array}{l}\text { When I would propose an } \\
\text { adaptation of the temperature in } \\
\text { the building to the building } \\
\text { manager, my request would be } \\
\text { taken serious }\end{array}$ & $\begin{array}{l}\text { Completely } \\
\text { agree } \\
7 \\
6 \\
5 \\
4 \\
3 \\
2 \\
1 \\
\text { Completely } \\
\text { disagree }\end{array}$ & 34) & $\begin{array}{l}\text { Overall, I can control sufficiently the } \\
\text { environmental conditions in my } \\
\text { workspace (i.e. air, light, noise and } \\
\text { temperature) }\end{array}$ & $\begin{array}{l}\text { Completely agree } \\
7 \\
6 \\
5 \\
4 \\
3 \\
2 \\
1 \\
\text { Completely disagree }\end{array}$ \\
\hline 35) & $\begin{array}{l}\text { Please, tick if it is important for } \\
\text { you to control the following } \\
\text { environment parameters }\end{array}$ & $\begin{array}{l}\text { Heating } \\
\text { Cooling } \\
\text { Ventilation } \\
\text { Artificial } \\
\text { Lighting } \\
\text { Day lighting } \\
\text { Noise }\end{array}$ & 36) & $\begin{array}{l}\text { Please describe any other issues } \\
\text { related to control that are important } \\
\text { to you: }\end{array}$ & $\mathrm{n} / \mathrm{a}$ \\
\hline
\end{tabular}

